\title{
4 Sachkommentar
}

Dieser Kommentar ist als fortlaufender Kommentar angelegt, wobei Abschnitte, welche durch die inschriftliche Darstellung als zusammengehörend gekennzeichnet sind, ${ }^{1}$ auch zusammen bearbeitet werden. Er liefert in erster Linie Sacherklärungen $\mathrm{zu}$ den in der Inschrift erwähnten Handlungen und versucht, die vielfältigen Zusammenhänge innerhalb der Inschrift zu klären. Da er punktuell zu einzelnen Stellen herangezogen werden kann, lassen sich Wiederholungen nicht vermeiden.

AB I-5 Das Fragment beginnt mit der relatio des Senatsbeschlusses, der die Finanzierung der Spiele regelt; sie wird wie üblich mit einem quod eingeleitet. ${ }^{2}$ Die in $\mathrm{AB} 2$ folgende Beschlussformel bestätigt diese Ergänzung. Das bedeutet, dass vor den erhaltenen Zeilen des Fragments noch folgende Elemente aufgeführt waren: die Konsuln, in deren Amtszeit der Senatsbeschluss fiel, das Datum, der Versammlungsort und die Zeugen. ${ }^{3}$ Die weiteren in der Inschrift überlieferten Senatsbeschlüsse enthalten diese Angaben zum Teil und benötigen dafür zwei bis drei Zeilen. ${ }^{4}$ Wir haben also mit mindestens diesen Angaben vor den erhaltenen Fragmenten zu rechnen. Moretti folgt der Ergänzung Cavallaros und ergänzt mit Recht als Konsuln die des Jahres i 8 v. Chr.: P. Lentulus und Cn. Lentulus.5 Diese Datierung ergibt sich einerseits aus der Erwähnung der ludi pro salute Caesaris ( $\mathrm{AB} 4$ ), die im Jahr 20 stattfanden, andererseits aus dem folgenden Senatsbeschluss (AB 6ff.) unter den Konsuln C. Silanus und C. Furnius aus dem Jahr I7 v. Chr. Eine erneute Erwähnung von Konsuln deutet darauf hin, dass der Senatsbeschluss von AB 6 nicht aus demselben Jahr stammen kann wie der von $A B$ I. ${ }^{6}$ Demnach müsste der in $A B$ I vorgetragene Senatsbeschluss zwischen den Jahren 20 und I7 v. Chr. erfolgt sein. Für das Jahr I 8 v. Chr. spricht die Tatsache, dass die Organi-

I Das wichtigste gliedernde Gestaltungsmittel der Inschrift ist das Herausrücken von Anfangszeilen eines neuen Abschnitts an den linken Rand.

2 Davon ging schon Mommsen I 876 bei der Erstpublikation in CIL VI 877a (=32324) aus, obwohl er den Senatsbeschluss anders datierte.

3 O’Brien Moore, RE Suppl. V (I935) Sp. 800-8 I 2 s. v. senatus consultum.

4 AB 6-10; Z. 50-63.

5 Moretti (1982-I984) 366f.; Cavallaro (1979) 74ff.; zu den Konsuln: Degrassi (1952) 4.

6 Vgl. Z. soff., wo für das senatus consultum die eponymen Konsuln gar nicht erwähnt sind, weil klar ist, dass alle Edikte, Dekrete etc. aus dem Jahr I7 v. Chr. stammen. Die Konsuln wurden schon in Z. 29 und 37 bei der Datierung verschiedener Beschlüsse der Quindecimviri nicht mehr namentlich genannt, sondern nur mit iisdem consulibus klargestellt, dass der betreffende Akt in demselben Jahr stattfand. Für alle weiteren Datumsangaben ist vollständig auf die Angabe des Jahres verzichtet worden. 
sation wohl nicht mehrere Jahre vor den ludi saeculares begann. Außerdem verzeichnet das senatus consultum in Z. 53 Augustus und Agrippa aufgrund ihrer tribunicia potestas als Initianten der ludi saeculares. ${ }^{7} \mathrm{Im}$ Planungsjahr i 8 v. Chr. waren Augustus und Agrippa nicht Konsuln, sie waren somit nur durch die tribunizische Gewalt in der Lage, die Säkularspiele zu veranlassen. Schon eine einjährige Vorbereitungszeit für die Spiele wäre ungewöhnlich lang. Auch für die Vorbereitung der severischen Säkularfeier im Jahr 204 n. Chr. ist ein Antrag der Quindecimviri an den Senat belegt, der im Jahr zuvor eingebracht wurde. ${ }^{8}$ Deswegen wurde der Senatsbeschluss zur Finanzierung der augusteischen ludi saeculares ebenfalls ein Jahr vor den Spielen datiert. Allerdings ist nicht ganz eindeutig zu klären, wie die Namensangabe der beiden Lentuli fomuliert war. Moretti entscheidet sich aufgrund des vorhandenen Freiraums für eine Wiederholung des cognomen. ${ }^{9}$

Beim lucar der Säkularspiele handelt es sich um den Etat der Feier, über den das Kollegium der Quindecimviri verfügt. Das Wort hat eine eindeutig religiöse Konnotation. ${ }^{\circ}{ }^{\circ}$ Es geht aus dem Text nicht eindeutig hervor, aus welcher Quelle das Geld stammt. Der Text macht aber klar, dass der hier aufgeführte Senatsbeschluss nicht der erste Beschluss - wohl aber der erste Senatsbeschluss - bezüglich der künftigen Säkularspiele ist. Hinsichtlich des Datums muss schon vorher ein Dekret ergangen sein, welches den Zeitpunkt der Spiele festgelegt hat. ${ }^{\text {I }}$

$\mathrm{AB} 2$ Diese Zeile enthält die einleitende Beschlussformel mit einer Begründung für die Vorgehensweise. Sie ist wie auch die folgenden drei eingerückt, weil sie alle zum Senatsbeschluss gehören. Moretti hat entsprechend den Überlegungen zu der vorangehenden Zeile hier als Zeitpunkt für die künftigen Spiele sequenti anno eingesetzt. Demnach wurde das Datum

7 Ferrary (200I) I 23 f. weist darauf hin, dass die Erwähnung der tribunicia potestas an dieser Stelle eher der Tatsache zu verdanken sei, dass sie von Augustus selbst als wichtiger Pfeiler seiner Macht gesehen wurde. Für eine solche eher propagandistische Erwähnung der tribunicia potestas spreche die Tatsache, dass sie ohne Nummerierung erfolge. Das Amt aufgrund dessen Augustus und Agrippa die ludi saeculares durchführen konnten, war nach Ferrary nicht die tribunicia potestas, sondern ihre Zugehörigkeit zum Kollegium der Quindecimviri. Die besondere Gestaltung der Edikte der Quindecimviri in der augusteischen Inschrift unterstützt diese Aussage. Vgl. den Sachkommentar zu Z. 24-28.

8 Act. Sev. 5 f.

9 Die verschiedenen überlieferten Varianten für diese Angabe diskutieren: Badian (1980/8 I) IoI; Cavallaro (I984) I 52, Anm. i 2.

I0 Fest. p. I06 Lindsay: Lucar appellatur aes, quod ex lucis captatur.

I I Vgl. AB 2. Da zum Zeitpunkt der augusteischen Säkularspiele Vollmond war, muss die Planung des Datums schon längere Zeit vorher begonnen haben. Vgl. Dessau (I9Io) $360 \mathrm{ff}$. 
der künftigen Säkularspiele vor allen anderen Modalitäten beschlossen und stand zum Zeitpunkt des Senatsbeschlusses im Jahre I 8 v. Chr. schon fest. Die Ergänzung gewinnt an Überzeugungskraft, wenn man sich klarmacht, wie minutiös das Datum in den bestehenden Festkalender, in astronomische Konstellationen und in eine neu begründete Reihe von angeblichen Säkularfeiern eingepasst wurde. ${ }^{{ }^{2}}$ Weil man in den libri antiqui keinen Präzedenzfall für die Finanzierung solcher Spiele gefunden hat, will man nach dem Beispiel der ludi pro salute Caesaris vorgehen. Die Erwähnung der libri antiqui zeigt das große Bemühen der Organisatoren, die neu eingerichteten Säkularspiele in möglichst vielen Belangen an bestehende Traditionen anknüpfen zu lassen, und wenn solche Traditionen nicht existierten, auf keinen Fall willkürlich etwas Neues zu beschließen, sondern bestehende analoge Beispiele heranzuziehen. ${ }^{13} \mathrm{Um}$ welche libri antiqui es sich handelt, ist nur zu vermuten. Infrage kommen entweder die Aufzeichnungen der Priesterschaft der Quindecimviri oder Aufzeichnungen über Aktivitäten des Senats, wie sie in den libri sententiarum vorlagen. Jedes Priesterkollegium verfügte über ein Archiv, das die vielfältigen Aktivitäten des Kollegiums und präzise Anweisungen zur Ausübung des Priesteramts dokumentierte. ${ }^{14}$ Diese Unterlagen wurden commentarii oder libri genannt, sie enthielten Kultanweisungen, carmina, Gebete und andere Ritualtexte, Dekrete, Antworten des Kollegiums auf Anfragen, Mitgliederlisten und Fasten. ${ }^{\text {Is }} \mathrm{Da}$ es sich hier aber nicht um eine kultische Bestimmung handelt, sondern um die Finanzierung der ludi saeculares, die von einem politischen Gremium in einem Senatsbeschluss geregelt wurde, sollte man eher davon ausgehen, dass es sich bei den libri antiqui, an welche der Senatsbeschluss anknüpfen möchte, um Aufzeichnungen früherer ähnlicher Senatsbeschlüsse handelt. ${ }^{16}$

$\mathrm{AB} 3$ Die neue Textergänzung hat inhaltliche Vorteile, weil die Organisation der Spiele in den Händen der Quindecimviri lag und nicht bei einem Magistrat; es handelte sich um priesterlich organisierte Spiele. ${ }^{17}$ Der wei-

I 2 Zur Einpassung in den bestehenden Festkalender vgl. Kap. A.I 2, S. $277 \mathrm{f}$.

I 3 Scheid (I 990a) 728 f.: Für Scheid ist dieses Bemühen um Vorbilder selbst in Fragen der Finanzierung der ludi saeculares ein Beleg dafür, dass ein willkürliches Vorgehen nicht möglich war, geschweige denn in kultischen Fragen.

I 4 Die Existenz dieser Bücher belegen zahlreiche literarische und epigrafische Quellen; u. a. auch die hier behandelte Inschrift, deren Gebetstexte sich auf Aufzeichnungen berufen. Vgl. Z. 92, I05, I 17, I 2 I, I36, I4I. Eine Sammlung der literarischen Quellen bei Wissowa (I9I2) 4 ff. und $65 \mathrm{ff}$.

Is Sini (1983) is ff.

I6 Scheid (I990a) 729, Anm. 79; anders Moretti (1982-1984) 366, der an Aufzeichnungen des Kollegiums der Quindecimviri denkt.

I7 Vgl. Kommentar zur Textkonstitution $\mathrm{AB}_{3}$, S. 4 If. Die Organisation der kultischen vorbereitenden Handlungen (Verteilung von suffimenta und die acceptio frugum) lag 
tere Text besagt, dass für die Verpachtung der Säkularspiele dieselbe Summe beschlossen werden solle, die für die ludi pro salute Caesaris beschlossen war. Es ist anzunehmen, dass hier dieselbe Höhe des Betrags übernommen werden sollte und nicht, dass eine eventuell verbliebene Restsumme der ludi pro salute Caesaris weiterverwendet werden soll. ${ }^{8}$ Durch diesen Senatsbeschluss sollte für alle deutlich gemacht werden, dass die ludi saeculares eine nicht an die Person von Augustus gebundene öffentliche Feier sind und demnach aus öffentlichen Geldern finanziert werden, wie es in AB ${ }_{4}$ f. als zweiter Teil des Senatsbeschlusses dargestellt ist: Danach befehlen die Konsuln den Prätoren, die der Staatskasse vorstehen, dafür zu sorgen, dass das Geld für die Spiele ausgezahlt werde. Schon für das Jahr 27 v. Chr. erwähnt Cassius Dio die Schwierigkeit, Staatskasse und Privatvermögen des Augustus auseinanderzuhalten. ${ }^{19}$ Auch bei der Finanzierung der Säkularspiele scheint ein bereits zehn Jahre zuvor gewähltes Prinzip zur Anwendung gekommen zu sein: Je nachdem, ob Augustus seine Freigebigkeit oder das Fortbestehen republikanischer Gepflogenheiten unterstreichen wollte, wurde entweder aus dem Privatvermögen oder aus der Staatskasse finanziert. Dies war außerdem ein Mittel, die Staatsausgaben - wenn nötig - niedrig zu halten oder die eigene Person in den Hintergrund zu rücken, indem er seine Freigebigkeit

in den Händen der Quindecemviri und wurde von diesen durch entsprechende Edikte und Dekrete geregelt, ebenso die Organisation der Opfer und aller weiterer rituellen Handlungen während der drei Feiertage und an den folgenden Tagen. Die Aufstellung einer marmornen und bronzenen Inschrift zum Gedenken an die Säkularspiele wurde allerdings durch einen Senatsbeschluss den Prätoren übertragen, ebenso war die Aufhebung der Sanktionen gegen die von der lex de maritandis ordinibus Betroffenen Thema eines Senatsbeschlusses, wobei die Aufhebung eines Gesetzes eindeutig in den Kompetenzbereich des Senats fällt, die Aufstellung einer Inschrift aber auch als priesterlicher Entscheid denkbar wäre. Der Bereich von priesterlicher und magistraler Kompetenz lässt sich demnach nicht eindeutig bestimmen.

I 8 Diese beiden Alternativen schlug Cavallaro (I984) I53 vor; ihr war allerdings Fragment B noch nicht bekannt. Cavallaro diskutiert ausführlich die Frage, welche Verbindung zwischen ludi saeculares und ludi pro salute Caesaris des Jahres $20 \mathrm{v}$. Chr. bestanden haben könnte. Sie kommt zu der These, dass wahrscheinlich beide Spiele vom Kollegium der Quindecimviri ausgerichtet wurden. Nach der Integration von Fragment B kann diese These nicht mehr aufrechterhalten werden. Jedoch hat Cavallaro zu Recht behauptet ( $5 \circ$ und i $58 \mathrm{ff}$.), dass der Finanzierungsbeschluss der $l u d i$ saeculares eine Schlüsselstelle hinsichtlich der undurchsichtigen Finanzierungsmanöver unter Augustus darstellt: Denn obwohl Augustus in den Res Gestae (22, 2) bezüglich der ludi saeculares den Ausdruck ludos feci verwendet, was so viel bedeutet, dass er als Financier der Spiele zu gelten hat, wird in diesem Senatsbeschluss ausdrücklich auf ein anderes Finanzierungsprozedere hingewiesen. Das bedeutet nach Cavallaro (1984) I 59f., dass eine strikte Trennung der Staatsfinanzen und des Privatvermögens des Augustus nicht mehr möglich war.

I9 Cass. Dio 53, 22, $3 \mathrm{f}$. 
kaschierte. Im Fall der ludi saeculares scheint Letzteres von Bedeutung gewesen zu sein: Sie sollten als ein Fest der gesamten Bürgerschaft und nicht als von Augustus initiiert gelten. Dem entspricht die Anlage der Feier, an der ungeheuer viele Menschen beteiligt waren. Die massenhafte Beteiligung war von Anfang an vorgesehen und gehört zum Wesen der ludi saeculares. Es handelt sich nicht um die Feier einer Gruppe von Menschen, sondern um eine Feier der res publica als Ganzes. Zum Ausdruck kommt dies in den Gebeten, aber auch in den komplizierten organisatorischen Maßnahmen, die nötig waren, um die geplante Teilnahme aller Bürger zu sichern. Der Finanzierungsmodus der Spiele aus der Staatskasse entspricht diesem Grundgedanken des Festes.

$\mathrm{AB}{ }_{4}$ f. Da das Priesterkollegium, welches die ludi pro salute Caesaris ausgerichtet hat, nicht mehr mit Sicherheit rekonstruierbar ist, und eine entsprechende Ergänzung nicht viel zum Verständnis der Zeilen beiträgt, muss diese Frage offen bleiben. ${ }^{20}$ Einzig interessant ist, dass die Berufung auf bereits praktizierte Finanzierungen für die Veranstalter der ludi saeculares so wichtig war, dass in dem betreffenden Senatsbeschluss darauf hingewiesen werden musste. Die hier erwähnte Regelung, dass die Prätoren auf Geheiß der Konsuln Geld aus dem Staatsschatz auszahlen sollen, findet sich ebenfalls für die Finanzierung der Inschriften, welche zur Erinnerung an die Säkularfeier aufgestellt werden sollten. ${ }^{21}$

AB 6-IO In AB 6 beginnt ein neuer Senatsbeschluss, der mit der üblichen praescriptio beginnt. Diese enthält in der Regel die Nennung der Verhandlungsleiter (meistens die Konsuln), das Datum, den Versammlungsort und die unter scribendo adfuerunt aufgeführten Zeugen. ${ }^{22}$ Diese Ordnung ist hier nicht eingehalten. Als Verhandlungsleiter finden wir die Konsuln des Jahres I7 v. Chr., C. Silanus und C. Furnius, als Tagesdatum den I7. Februar. ${ }^{23}$ Es fehlt an dieser Stelle die Angabe des Versammlungsortes, welchen wir erst in AB 8 mit in curia IJVLIA finden. ${ }^{24}$ Dort folgt dann auch die Aufzählung der Zeugen, ungewöhnlich mit Patronym und der Angabe ihrer tribus. ${ }^{25}$ Die übliche Anzahl der Zeugen liegt bei mindestens zwei, nach oben scheint die Zahl im Prinzipat auf fünf beschränkt zu

20 Vgl. Kommentar zur Textkonstitution AB 4, S. 42, Anm. 7.

2 I Z. 63.

22 Darunter ist nach Coudry (I 994) 72 nicht nur die stumme Anwesenheit zu verstehen, sondern eine helfende Tätigkeit, die darin bestand, dass die aufgeführten Männer an der Redaktion eines senatus consultum maßgeblich beteiligt waren.

23 Degrassi (1952) 4 .

24 Vgl. Kolb (I995) 357 zur Nutzung und Fertigstellung der curia Iulia.

25 Z. 5 I erwähnt die Zeugen ohne diese Angaben. 
sein. ${ }^{26}$ In diesem Senatsbeschluss sind in $A B 8$ zwei und in AB 9 drei Namen lesbar, aber aufgrund des verbleibenden Raums waren sicher mehr erwähnt, das heißt die Zahl von fünf wurde überschritten. ${ }^{27}$ Bei den erwähnten Zeugen des Senatsbeschlusses handelt es sich durchwegs um Mitglieder angesehener Familien der augusteischen Zeit, deren genaue Identität nur in zwei Fällen zu bestimmen ist. ${ }^{28} \mathrm{Zwischen} \mathrm{diesen} \mathrm{Angaben}$ findet sich ein ungewöhnlicher Einschub, der aus anderen Senatsbeschlüssen nicht bekannt ist: VT QVAE OPVS $\mid[\cdot 9 \cdot$ sac]RIFICIVM SAECVLARES LOCARENTVR IN EA VERBA QVAE INFRA SCRIPTA SVNT. In der sonst üblichen Redaktion eines Senatsbeschlusses wird das Thema mit quod eingeleitet, weswegen es sich hier noch nicht um das Thema des Senatsbeschlusses handeln kann. ${ }^{29}$ Wegen des schlechten Textzustands ist nicht auszumachen, wo ein solches quod noch folgt, am ehesten nach AB 9, wo die Aufzählung der Zeugen abgeschlossen ist. Der mit $u t$ eingeleitete Einschub gibt an, dass dieser Senatsbeschluss erlassen wurde, damit Verpachtungen für die Opfer der Säkularspiele nach bestimmten weiter unten erwähnten Bestimmungen vorgenommen werden können. Vermutlich enthielt der nun folgende, nicht mehr lesbare Senatsbeschluss diese Bestimmungen.

Es ist anzunehmen, dass zwischen den Fragmenten $\mathrm{AB}$ und $\mathrm{C}$ nur sehr wenige Zeilen fehlen. ${ }^{30}$

26 Mommsen RStR III, Ioos f.; dem widerspricht auch der Senatsbeschluss von Larinum (AE 1978, Nr. I45) nicht, der als Zeugen fünf Senatoren und zwei Quästoren angibt; Moretti (I982-1984) 367 erwähnt dieses senatus consultum als Beleg dafür, dass mehr als fünf Zeugen möglich sind.

27 Moretti (1982-1984) 367 geht von vier oder fünf Namen nur in AB 9 aus.

28 Vgl. Moretti (1982-1984) 368: M. Iunius Silanus, Konsul des Jahres 25 v. Chr., wird hier als einzige Quelle mit der tribus Sabatina erwähnt. Cn. Cornelius Lentulus (cos. I 8 v. Chr.) ist von dem gleichnamigen Konsul des Jahres I4 v. Chr. zu unterscheiden, weil dieser zur Unterscheidung stets das cognomen angur führte. Der dritte Zeuge, dessen cognomen auf JRINVS endet, ist mit Sicherheit nicht der Konsul des Jahres 39 v. Chr., L. Marcius Censorinus, da dieser als älterer Konsular vor den beiden vorangehenden genannt werden müsste. Die Identität dieses JRINVS bleibt somit unbekannt. C. Asinius Pollio ist ein sonst nicht bekanntes Mitglied der Familie des gleichnamigen Historikers und Politikers, der Konsul im Jahre 40 v. Chr. war. Es kann sich nicht um den Konsul des Jahres $40 \mathrm{v}$. Chr. handeln, weil dieser ebenfalls eine höhere Seniorität als die vorangehenden Zeugen dieser Liste hatte. L. Vinicius ist ebenfalls nicht mit endgültiger Sicherheit zu identifizieren, da die bekannten Mitglieder dieser Familie L. Vinicius (cos. suff. 33 v. Chr.) und L. Vinicius L. f. (der Sohn des cos. suff. 33 v. Chr., I6-I 5 v. Chr. tresvir monetalis) entweder zu alt oder zu jung waren, um im Jahre I7 v. Chr. die hier erwähnte Funktion zu erfüllen.

29 Vgl. Z. 52 und 59.

30 Moretti (r982-I984) 364 und 370. Vgl. Kommentar zur Textkonstitution Ci, S. 44 f. 
C I-4 Der Textzustand macht es unmöglich, genaue Angaben über die Fortsetzung des Senatsbeschlusses zu machen. Der in AB 6 begonnene Senatsbeschluss, der offenbar dazu diente, die Verpachtung der Opfer zu regeln, wird wahrscheinlich in Fragment $C$ fortgesetzt, in dem es wie in dem Senatsbeschluss von $\mathrm{AB}$ I-5 auch um die Bewilligung von Geldern geht. Der Beschluss ist in dem Bereich, der das amtliche Prozedere regelt, gleich formuliert wie der vorangehende, wodurch einige Ergänzungen möglich sind. Aufgrund des verbleibenden Raums muss aber davon ausgegangen werden, dass dazwischen noch Angaben darüber gemacht waren, wem und für welche $Z$ wecke das Geld von den Prätoren zuzuteilen war. ${ }^{3 \mathrm{I}}$

C 5-8 In diesen Zeilen wird eine Handlung von Augustus beschrieben, die er zusammen mit dem Kollegium der Quindecimviri durchführt. ${ }^{32}$ Diese müsste am Anfang von $\mathrm{C}$ s wie üblich mit Datum und Ortsangabe eingeleitet sein. Daran schließt in etwas mehr als zwei Zeilen von C s bis C 8 eine Aufzählung des Kollegiums der Quindecimviri an. ${ }^{33}$ Es ist nicht anzunehmen, dass diese Liste mit den beiden anderen Listen der Inschrift ( $\mathrm{s}$ off. und I66ff.) identisch ist. Einerseits fehlt Agrippa, der zu diesem Zeitpunkt, der zwischen dem i7. Februar und dem 25. März des Jahres I7 v. Chr. liegen muss, offenbar abwesend war. ${ }^{34}$ Andererseits können in dieser Liste nicht alle aus den Zeilen I66-I68 bekannten 2 I Quindecimviri genannt sein, weil der vorhandene Raum nicht ausreicht. ${ }^{35}$ Aber dass auch hier die von Hoffman Lewis aufgedeckte hierarchische Ordnung eingehalten wurde, legt schon die Tatsache nahe, dass in Fragment C C. Norbanus Flaccus und M. Cocceius Nerva direkt aufeinander folgen wie in Z. I5 I. ${ }^{36}$ Hoffman Lewis vermutete aufgrund des Alters und der Laufbahn der Quindecimviri, dass die Listen der Inschrift die Mitglieder in der Reihenfolge ihres Eintritts in das Kollegium erwähnen. ${ }^{37}$ Dieses

3 I Moretti (1982-1984) 370 nimmt an, dass es hier um die locatio der Spiele gehe, warnt aber gleichzeitig vor zu optimistischen Ergänzungen.

32 Eine Art Anwesenheitsliste mit adfuerunt eingeleitet wie in Z. I 50 ff. liegt hier nicht vor, weil nur Augustus als Subjekt genannt wird und die anderen Quindecimviri soziativ an Augustus angeschlossen sind.

33 In Z. I66ff. wird für die Aufzählung des gesamten Kollegiums mit 2 I Namen etwas mehr als zwei Zeilen Raum beansprucht, in Z. I soff. für die Aufzählung von I 9 Mitgliedern des Kollegiums ebenfalls etwas mehr als zwei Zeilen. Diese Uneinheitlichkeit rührt von der unterschiedlichen Art der Namensnennung her. Die meisten werden mit praenomen und cognomen genannt, andere mit praenomen und nomen gentile. AB 8 (bzw. AB 6) geben als letztes vorher genanntes Datum den I7. Februar an, Z. 37 enthält als nächstes genanntes Datum den 25 . März I7 v. Chr.

35 Vgl. Kommentar zur Textkonstitution zu diesen Zeilen, S. $45 \mathrm{ff}$.

36 Hoffman Lewis (1952) 289-294; die hierarchische Ordnung hat Hoffman Lewis durch einen Vergleich der Listen der Quindecimviri und durch prosopografische Untersuchungen feststellen können.

37 Hoffman Lewis (1952) $289 \mathrm{f}$. 
Vorgehen ist auch für Priester aus den Priesterschaften der Salier und Pontifices belegt. ${ }^{3}$ Die von Hoffman Lewis vorgeschlagene Reihenfolge wird durch diese neue Liste von Fragment C, welches ihr noch nicht bekannt war, bestätigt.

C 9-I4 Es ist vorstellbar, dass der Abschnitt C 5-8 ein Verb enthielt, das den folgenden Text einleitete und seine Funktion erläuterte. ${ }^{39}$ Solange dieses Verb unbekannt ist, bleibt auch die Funktion dieses Abschnitts unklar. Aus dem Text selbst lassen sich aber doch einige nähere Bestimmungen gewinnen: Die Verben in der I. Pers. Pl. (C I 2) sprechen dafür, hierin eine gemeinsam abgegebene Erklärung des Kollegiums der Quindecimviri zu sehen. Der Wortlaut trägt außerdem die Merkmale eines religiösen Textes. Darauf weisen die Aufzählung verschiedener Götter und die altertümliche Sprache hin. Zunächst zu der Aufzählung der Götter: Es werden nicht die Götter der Säkularfeier genannt, sondern es scheint sich um eine Aufzählung verschiedener Götter zu handeln. Einige von ihnen wie Apollo und Iuppiter spielten auch an der Säkularfeier eine Rolle. In diesem Text stehen sie aber in einer Reihe von Göttern, die wahrscheinlich den gesamten römischen Götterkreis umfasste, ohne dass alle Götter namentlich aufgezählt wurden. Namentlich erscheinen am Anfang die palatinischen Gottheiten Apollo, Latona und Diana, anschließend vielleicht eine Reihe von Kriegs- und Siegesgottheiten, von denen Hercules und Iuppiter Stator noch lesbar sind..$^{\circ}$ Es ist gut vorstellbar, dass auch die kapitolinische Trias in diese Reihe aufgenommen war, daraus lassen sich aber keine Begründungen für mögliche Ergänzungen ableiten. Es scheint sich um eine namentliche Aufzählung von wichtigen Göttern der augusteischen Zeit zu handeln, die mit einer alle anderen Götter umfassenden Formel abgeschlossen wurde: ce]TEROSQVE DEOS DEASQVE INMORTALIS OMN[es]. Offenbar wurden all diese Götter um etwas gebeten, was in Zusammenhang mit der Säkularfeier stand. Da wir durch keinen ähnlichen Text zum Beispiel aus dem severischen commentarium zusätzliche Informationen gewinnen können, muss die Funktion dieser Zeilen ungeklärt bleiben, einzig ihr religiöser Bezug kann erkannt werden..$^{1 \mathrm{I}}$

38 Taylor (1942) 385-4I 2.

39 Moretti (1982-1984) 375 f. hält dieses Textstück für die editio der ludi saeculares, ohne durch einen Paralleltext die Merkmale eines solchen Textes näher bestimmen zu können.

40 Moretti (I982-1984) 375; er hat in diese Reihe Mars ergänzt, weil dieser mit Hercules das Epitheton victor führt.

4 I Act. Sev. IoI-I Io erwähnt die lustratio des Tarentum vor der Feier und Act. Sev. I $8-$ I 36 das sacrum hostiae praecidaneae. Diese Handlungen fanden aber unmittelbar vor Beginn der severischen Säkularfeier statt nach der Verteilung der suffimenta und 
Nach der Götteraufzählung sprechen die Quindecimviri von sich in der I. Person Plural als Ausführende (egimus, aximus). Die Zeilen C I 3 und I 4 legen die Vermutung nahe, dass es sich um eine an die vorher genannten Götter gerichtete Bitte handelt zum Wohl des römischen Volkes. Der Gebetcharakter dieser Zeilen wird durch die archaisierende Sprache des bene verruncent unterstrichen, eine Wendung die bei Livius von Scipio in einem Gebetstext gebraucht wird. ${ }^{42}$

$\mathrm{C}_{\mathbf{I} \text { 5-I7 }}$ Der Beginn eines neuen Abschnitts ist aus dem fragmentarischen Text nicht mit Sicherheit zu erkennen. Meine Lesart audientiam, ein Wort, das zweimal in der Inschrift mit umgebendem vacat erscheint, hat wahrscheinlich einen funktionellen Charakter und kennzeichnet den nun folgenden Text der Inschrift. Da der Text nach C is auf rituelle Bestimmungen der ludi saeculares eingeht, muss man vermuten, dass ein so in der Inschrift hervorgehobenes Wort wie audientiam auch im rituellen Kontext verstanden werden muss. Es könnte sein, dass es sich hier um das audientiam handelt, dass bei öffentlichen Ausrufen von einem Herold verwendet wurde, indem er mit facite audientiam die Aufmerksamkeit des Publikums suchte. ${ }^{43}$ Auch für die Säkularspiele des Jahres I7 v. Chr. ist das Auftreten von Herolden (praecones) vor den Spielen überliefert. ${ }^{44}$ Auf einer augusteischen und einer domitianischen Münze aus Anlass der Säkularspiele ist eine Figur abgebildet, die einen solchen praeco darstellt (siehe Anhang, Abb. I, 5 und 7). ${ }^{45}$ Dabei handelt es sich um einen

der acceptio frugum. Der Text von C 9-I4 schildert bei Annahme eines chronologischen Aufbaus der Inschrift eine Handlung, die vor dem I7. Februar I7 v. Chr. stattgefunden haben muss.

42 Liv. 29, 27, 2-3; Scipio wird kurz vor der Abfahrt nach Afrika ein Gebetstext in den Mund gelegt, der neben der Wendung bene verruncent auch eine Anrede an die Gesamtheit aller Götter und Göttinnen enthält: Divi divaeque qui maria terrasque colitis, vos precor quaesoque, uti quae in meo imperio gesta sunt, geruntur, postque gerentur, ea mibi populo plebique Romanae sociis nominique Latino qui populi Romani quique meam sectam imperium auspiciumque terra mari amnibusque sequuntur bene verruncent, eaque vos omnia bene iuvetis, bonis auctibus auxitis.

43 Solche Heroldausrufe sind überliefert bei Plaut. Poen. I I; Rhet. Her. 4, 55, 67; Liv. 43, I6, 8 .

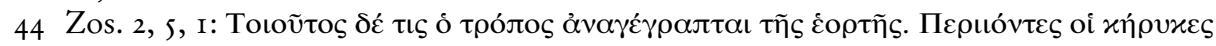

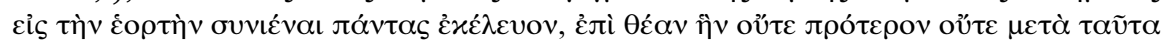

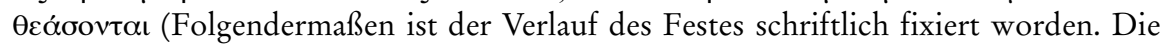
Herolde gingen umher und forderten alle auf, zum Fest zu kommen, zu einer Schau, wie sie sie weder vorher gesehen haben noch nachher sehen werden).

45 Als praeco wurde die abgebildete Person von Mommsen (I89I) 246 (590), Anm. I interpretiert, ebenso von Dressel (I89I) 3 I 4. Scheid (I998b) 22 f. stellt die Diskussion dar, die darüber geführt wurde, ob es sich bei der abgebildeten Person um einen praeco oder einen ludio handelt, wie sie im severischen commentarium (Act. Sev. 248) erwähnt sind. Scheid plädiert dafür, diese Frage offen zu lassen und die abgebildete Figur von ihrer Funktion her zu beurteilen. Ein praeco hatte nach Suet. Claud. 2 I die 
Mann, der eine tunica und einen Helm trägt. In der rechten Hand hält er einen caduceus, den Heroldsstab, in der linken einen Schild. ${ }^{6}$ Die zweite domitianische Münze (Anhang, Abb. 7) zeigt dieselbe Figur neben einem großen cippus, dessen Inschrift ebenso lautet wie die Umschrift der anderen domitianischen Münze. Zwischen der Figur und dem cippus steht ein großer Ständer, ein Leuchter oder ein Gerät zur Parfümverbrennung. Bei Sueton ist überliefert, dass ein praeco auch zu den claudischen Säkularspielen, die allerdings in Zusammenhang mit den Jubiläumsfeiern der Stadt Rom zu verstehen sind, more sollemni eingeladen habe. ${ }^{47}$ Auffällig ist, dass Zosimus die Ankündigung des praeco mit denselben Worten überliefert wie Sueton, dass nämlich die Bürger zu den Säkularspielen kommen sollten, zu einem Fest, wie sie es weder je gesehen hätten noch je sehen werden. ${ }^{4}$ Diese Übereinstimmung lässt darauf schließen, dass der Wortlaut der Ankündigung des praeco zu Säkularspielen festgelegt war. Diese Ankündigung ist als ritueller Akt zu verstehen, worauf mit more solemni bei Sueton hingewiesen ist. Aus diesem Grund wurde der Herold in das Münzprogramm der augusteischen und domitianischen Prägungen zu den Säkularspielen aufgenommen wie andere rituelle Handlungen auch. ${ }^{49}$ Zosimus weist ausdrücklich darauf hin, dass der Verlauf des Festes schriftlich fixiert vorlag, worauf er mit der Schilderung der Ankündigung des Festes durch Herolde seine Darstellung beginnt. ${ }^{\circ}$ Wahrscheinlich handelte es sich bei den Aufzeichnungen um das inschriftliche commen-

Funktion, einen religiösen Anlass anzukündigen, und war wahrscheinlich als praeco einer Priesterschaft tätig. Ein ludio dagegen hatte innerhalb von Spielen die Funktion

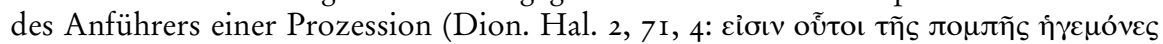
$x \alpha \lambda o \mu \varepsilon v o r$ - diese sind die sogenannten Anführer des Umzugs). Weil Dionysios das Aussehen eines ludio genau so beschreibt, wie die abgebildete Figur auf den Münzen aussieht, ist es überhaupt zu der Unklarheit in der Unterscheidung zwischen praeco und ludio gekommen. Die Erwähnung des Wortes audientiam, vorausgesetzt dass der vermutete Zusammenhang richtig ist, stärkt die Annahme, dass die auf den Münzen abgebildete Figur einen praeco darstellt.

46 Die Umschrift auf der augusteischen Münze lautet: AVGVST(us) DIVI F(ilius) LVDOS SAEC(ulares fecit); auf der domitianischen Münze: COS XIIII LVD(os) $S A E C$ (ulares) FEC(it).

47 Suet. Claud. 21: Quare vox praeconis irrisa est invitantis more sollemni ad ludos, quos nec spectasset quisquam nec spectaturus esset, cum superessent adbuc qui spectaverant, et quidam histrionum producti olim tunc quoque producerentur. Vgl. die Schilderung bei Zosimus, oben Anm. 44.

48 Für die severischen Spiele belegt Herodian. 3, 8, Io, dass Boten in Rom und ganz Italien auftraten, um zu den Säkularspielen einzuladen, wie man sie noch nicht ge-

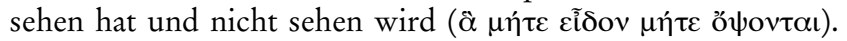

49 Die Münzabbildungen der augusteischen Spiele stellen folgende Akte dar, die alle in einem rituellen Zusammenhang verstanden werden müssen: den praeco, die Inschrift, die Verteilung der suffimenta und ein Opfer.

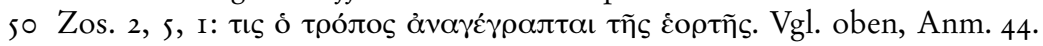


tarium zu den ludi saeculares, in welches Zosimus Einblick hatte, weil er in seiner Darstellung weitgehend mit dem augusteischen commentarium übereinstimmt. Es ist deshalb möglich, dass das Auftreten eines praeco am Anfang des augusteischen commentarium erwähnt war, auch wenn das Wort selbst in der Inschrift nicht mehr zu finden ist. Es könnte an dieser Stelle die Rede vom Auftreten des Herolds sein, der sich mit der üblichen Einladung zu den Säkularspielen an sein Publikum wendet. Die Charakterisierung der Spiele als einmaliges Ereignis im Leben der Menschen gehört zu den Kennzeichen von Säkularspielen, die möglicherweise auf etruskischen Einfluss zurückgehen. ${ }^{\text {II }}$ Im Orakel wird auf dieses Kennzeichen nur sehr verschlüsselt eingegangen. Es nennt als Abstand zwischen zwei Säkularfeiern nur die seit den augusteischen Spielen geltenden I I० Jahre, allerdings mit dem Zusatz »auch wenn du selbst es vergessen wirst «, womit vielleicht auf das Vergessen hingewiesen wird, das eintreten könnte, weil niemand mehr lebt, der an den letzten Säkularspielen dabei war. ${ }^{52}$ Es ist trotz des fragmentarischen Zustands von Fragment $\mathrm{C}$ noch lesbar, dass es in C I6 um den für die augusteischen Spiele konstruierten Abstand zwischen den Spielen von i I 0 Jahren geht. Somit beginnt der möglicherweise von einem Herold ausgerufene Text mit derselben Bestimmung wie der Orakeltext.

Im Anschluss bricht Fragment $\mathrm{C}$ ab, die nachfolgenden Fragmente, die seit ihrer Ausgrabung von I 890 bekannt sind, scheinen aber mit dem Text von Fragment $\mathrm{C}$ zusammenzugehören. Moretti vermutete, dass zwischen Zeile $\mathrm{C}_{\mathrm{I}} 7$ und dem Anfang des nächsten Fragments nicht viele Zeilen standen. ${ }^{53}$ Dies bestätigt ebenfalls der Charakter des nun folgenden Textes, der wie schon das Ende von Fragment $\mathrm{C}$ auf rituelle Bestimmungen $\mathrm{zu}$ den ludi saeculares eingeht.

I-23 Dieser nur sehr bruchstückhaft erhaltene Teil der Inschrift wurde von Mommsen als Brief des Augustus an das Kollegium der Quindecimviri interpretiert, zum einen wegen der Personalpronomina und Verbformen in der 2. Pers. Pl., ${ }^{54}$ zum anderen wegen des eindeutig als Brief erkenn-

5 I Cens. 17, 5: Sed licet veritas in obscuro lateat, tamen in una quaque civitate quae sint naturalia saecula, rituales Etruscorum libri videntur docere, in quis scriptum esse fertur initia sic poni saeculorum. Quo die urbes atque civitates constituerentur, de bis qui eo die nati essent eum qui diutissime vixisset die mortis suae primi saeculi modulum finire, eoque die, qui essent reliqui in civitate, de his rursum eius mortem, qui longissimam egisset aetatem, finem esse saeculi secundi. Daraus folgt, dass jeder Mensch nur einmal in seinem Leben Säkularspiele erleben kann.

52 Zos. 2, 6, I-3. Vgl. S. $24 \mathrm{I}$.

53 Moretti (1982-1984) $372 \mathrm{f}$.

54 Mommsen (189I) 247 (59I): »... Augustus hac epistula ad collegium scripta ludis formam et normam dedit." Die Briefform der Äußerung eines politischen Willens ist 
baren Teils am Anfang der severischen Inschrift.ss Dennoch kann die These, dass es sich hier um einen Brief des Augustus handelt, nicht länger aufrechterhalten werden. Der fragmentarische Text dieser Zeilen enthält rituelle Bestimmungen, wie die künftige Säkularfeier zu begehen sei. Augustus selbst hatte als magister der Quindecimviri nicht die Kompetenz, dieses Ritual zu bestimmen. Dieses konnte nur durch eine Befragung der sibyllinischen Bücher gegeben werden, welche allerdings im Sinne des Augustus manipulierbar war. ${ }^{56}$ Die Vorstellung, dass Augustus in einem Brief an das Kollegium der Quindecimviri Vorgaben ritueller Art für die Feier machen konnte, ist nicht begründbar. Dies widerspräche den Vorbereitungen religiöser Anlässe, und ein Brief hätte als Legitimation ritueller Handlungen nicht genügt. Das Orakel zur augusteischen Säkularfeier, das den Ablauf der Feier detailliert vorschreibt, wäre neben einem Brief des Augustus überflüssig und offensichtlich nur eine Farce. Die wichtige Rolle, die das Orakel einnahm, wird allein durch die Tatsache bezeugt, dass es überliefert wurde und dass auch die domitianischen und severischen Säkularspiele das Ritual, das dieses Orakel vorschrieb, übernommen haben.57 Der Text dieses Abschnitts ist in verschiedene Unterabschnitte gegliedert, was durch mehrere vacat in der Mitte der Zeilen erkennbar wird..$^{5}$ Der Inhalt bleibt wegen des fragmentarischen Textzustands zu unklar, als dass man eine detaillierte Gliederung vornehmen könnte. ${ }^{59}$ Aussagen über eine mögliche Funktion des Textes sind am Ende einer Betrachtung der einzelnen Abschnitte zu finden.

Das an diesen Text anschließende Edikt (24-28) wird mit eodem die eingeleitet, das heißt, der Text der Zeilen I-23 und eventuell auch Teile von Fragment $\mathrm{C}$ wurden an demselben Tag verlesen oder abgefasst, an dem das anschließende Edikt erlassen wurde. ${ }^{60}$ Auf das Edikt folgt ein

für die augusteische Zeit mehrfach überliefert, zum Beispiel F.I.R.A. II, Nr. 55. Die verschiedenen Formen der direkten Anrede: Z. I; 5: vos; Z. 6; 8: iubeatis; Z. I 3 : memineritis.

55 Act. Sev. 59-6I; bei Pighi (I94I) I 45; die beiden in der severischen Inschrift erhaltenen Briefe der severischen Herrscher enthalten keinerlei rituelle Anweisungen, sondern nur eine Einladung an das Kollegium der Quindecimviri in den palatinischen Apollotempel zu kommen, um den Einsatz der Quindecimviri an den verschiedenen Verteilstellen der suffimenta auszulosen. Ebenso enthält der zweite Brief von Septimius Severus an die Quindecimviri nur die Aufforderung zu einer beratenden Zusammenkunft (Act. Sev. 62-64).

56 Siehe Kap. A.ıo, S. $245 \mathrm{ff}$.

57 Das Ritual der domitianischen Feier ist aus den zahlreichen Münzprägungen bekannt (siehe Scheid [1998b] I3-34), das Ritual der severischen Feier durch die ebenfalls fragmentarisch erhaltene Inschrift.

58 Z. 6; I2; I4; 19.

59 Pighi (I94I) rogf. nimmt eine solche Gliederung dennoch vor.

60 Mommsen (I89I) 247 (59I). 
Dekret ohne Datumsangabe (29-36) und darauf eines mit der Datumsangabe $A D$ VIII $K A P R=25$. März $(37-45)$. Es ist anzunehmen, dass das undatierte Dekret (29-36) nicht an demselben Tag erfolgte, wie das ihm folgende, weil sonst die Datumsangabe von Z. 37 überflüssig wäre. ${ }^{61}$ Das aber bedeutet, dass der Text der Zeilen I-23 und das an ihn anschließende Edikt und Dekret (29-36) an irgendeinem Tag zwischen dem I7. Februar und dem 25. März verlesen und erlassen wurden. Mit der Integration von Fragment $C$ stellt sich die Frage, ob der Anfang des Textes schon in Fragment $\mathrm{C}$ zu setzen sei. Diese Frage bleibt unbeantwortbar, obwohl in C Is nach einem religiösen Text etwas Neues beginnt, das auf den I Iojährigen Abstand zwischen den Säkularfeiern eingeht und wohl eher rituelle Vorgaben anspricht. ${ }^{62}$

I-3 Es ist keinerlei Satzstruktur erkennbar, einzig das Personalpronomen vos macht deutlich, dass es sich um eine direkte Anrede, wahrscheinlich an die Quindecimviri handelt. Z. 2 scheint einen Hinweis auf den Ritus der Säkularspiele zu enthalten. Das entsprechende griechische Wort ( $\theta \dot{\mu} \mu \mathrm{s}$ ) für ritus findet sich auch im Text des Orakels. ${ }^{63}$ In Z. 3 sind die Chöre der je 27 Knaben und Mädchen gemeint, die nach dem Orakel getrennt auftreten sollten. ${ }^{64}$ Auf eine solche Anweisung könnte hier in der Inschrift Bezug genommen sein, die auch an anderer Stelle diese Chöre erwähnt. ${ }^{65}$

4-6 Z. 4 und 5 regeln das Datum und die Dauer der Säkularfeier. Das Datum der ersten Nacht wird nicht wie sonst in der augusteischen Inschrift nach dem offiziellen Kalender genannt, sondern in einer archaisierenden Formulierung angegeben. In dieser Form wird es in Z. $4 \mathrm{I}$ f. wiederholt, wo die Quindecimviri in einem Dekret Datum und Dauer der Säkularfeier festlegen. ${ }^{66}$ Die Formulierung des Datums an diesen Stellen könnte auf das Orakel zurückgehen, das zwar kein genaues Datum der Säkularspiele liefert, aber die ungewöhnliche Stunde der nächtlichen Opfer in ähnlicher Weise nennt. ${ }^{67}$

6I Mommsen (I89I) 247 (59I) vermutet, das Datum sei zufälligerweise ausgelassen worden oder befinde sich in dem nicht erhaltenen Teil. Eine Datumsangabe in der Mitte einer Zeile finden wir in dieser Inschrift nur in AB 6, alle anderen Datumsangaben stehen am Anfang einer Zeile.

62 Vgl. S. 80.

63 Zos. 2, 6, 10; 28.

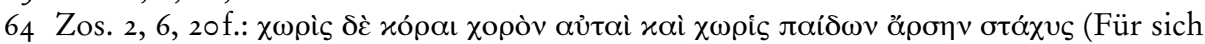
aber sollen die Mädchen einen Chor bilden, und für sich der männliche Spross der Kinder).

65 Z. $20 f . ; 73$ (?); 147 f.

66 Dass es sich bei diesen Angaben um die Dauer handelt, geht aus dem Akk. nonas in Z. 42 hervor.

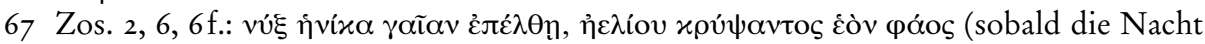


Zweimal ist das Wort iubeatis überliefert. ${ }^{68}$ Es scheint, als ob die Quindecimviri die für die Feier erforderlichen Riten autorisieren sollen. ${ }^{69}$ Offensichtlich nimmt dieser Text die später in Dekreten und Edikten angeordneten und dann im Festablauf tatsächlich stattgefundenen Riten vorweg, aber nicht in der Form eines anweisenden Briefes von Augustus. Die bislang festgestellten Parallelen zum Orakeltext könnten einen Schlüssel für das Verständnis der Funktion dieses Teils der Inschrift liefern.

7-I I Hier begegnet zum ersten Mal der auffällig häufige Gebrauch der Adverbien bene und diligenter. ${ }^{70}$ Dieses Drängen auf eine exakte Ausführung der für die Feier vorgeschriebenen Riten weist darauf hin, dass es in diesem Teil der Inschrift eindeutig um rituelle Vorschriften geht, deren Legitimation auf einer anderen Ebene zu suchen ist, als der einer politischen Willensäußerung. Einige Wörter des fragmentarischen Textes weisen auf das Orakel hin. ${ }^{71}$ Besonders der Gebrauch des Attributs milicheis $\mathrm{zu}$ deis, ein Wort, das außer an dieser Stelle nicht in der lateinischen Sprache verwendet wurde, unterstützt die Annahme, dass dieser Text auf dem Orakeltext gründet. ${ }^{2}$ Dieser Teil der Inschrift enthält Anweisungen, die im Orakel ebenfalls genannt sind: Es handelt sich um das Abholen von Räucherwerk (Z. 8: petere) zur kultischen Reinigung vor der Feier und die Ablieferung von Früchten (Z. I I: frugum). ${ }^{73}$ Betroffen davon sind, wie wir zusätzlich im Edikt von Z. 65 ff. erfahren, alle Freigeborenen. ${ }^{74}$

Die Abgabe der suffimenta, worunter Fackeln, Schwefel und Asphalt zu verstehen sind, beabsichtigte die kultische Reinigung aller freien Bürger und eventuell ihrer Wohnungen. ${ }^{75}$ Obwohl die Verteilung der suffimenta

die Erde überdeckt, und die Sonne ihr Licht verborgen hat); die Formulierung in der Inschrift, die den besonderen Zeitpunkt der Nacht kennzeichnen will, lautet Z. 4: nocte quo]I DIES INLVCI[scet k(alendis) Iun(iis).

68 Z. 6 und 8.

69 Vgl. CIL I'2, 58I, I 5-18; nach dem senatus consultum de Bacchanalibus dürfen private Riten nur abgehalten werden, wenn der praetor urbanus sie auf der Grundlage eines Senatsbeschlusses für Recht erklärt (iousisent). Die Verwendung von iubere in der augusteischen Inschrift scheint ebenfalls diesen Vorgang der Autorisierung von Riten $\mathrm{zu}$ meinen, nicht das Vorschreiben bestimmter Riten.

70 Z. 7: BENE ATQVE DILIGEN[ter; Z. Io: BENE FREQVENTESQVE; Z. I 3: DILI[genterque memineritis; Z. 23: DILIGENT[er meminerint.

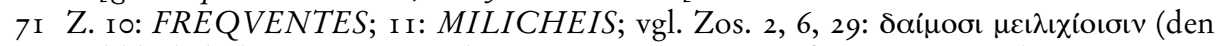

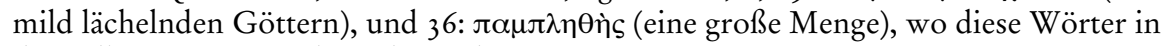
demselben Kontext gebraucht sind.

72 ThLL s. v. milichius.

73 Das Orakel geht auf diese beiden Handlungen in den Versen $25-30$ ein.

74 Zos. 2, 5, I; ebenso im Orakel (Zos. 2, 6, 3; 25, 27) wo dasselbe gemeint ist, wenn

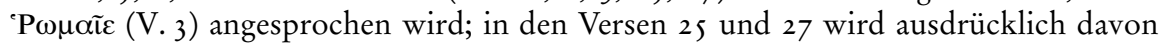
gesprochen, dass alle an den vorbereitenden Riten teilnehmen sollen.

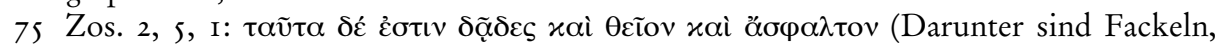


im ersten Teil der Inschrift einen breiten Raum einnimmt, ist nirgends davon die Rede, dass Frauen in besonderer Weise von diesen reinigenden Maßnahmen betroffen sein sollen, wie es im Orakel gefordert ist. ${ }^{76}$ Eine solche Bestimmung könnte wegen des fragmentarischen Zustands des Textes nicht überliefert sein. Frauen spielten an der Säkularfeier, die in besonderer Weise der Zukunft und damit der Reproduktion des römischen Volkes galt, eine wichtige Rolle, auf die noch näher eingegangen wird. ${ }^{77}$ Wie der eigentliche Reinigungsakt aussah, ist nicht überliefert, wahrscheinlich waren solche Maßnahmen in den Haushalten üblich, so dass keine detaillierten Vorschriften dazu abgegeben werden mussten. Als öffentlicher Akt scheint vor allem der Akt des Verteilens wichtig gewesen $\mathrm{zu}$ sein, er allein ist in den Quellen dokumentiert, und ebenfalls nur der Akt des Verteilens ist im Orakel angesprochen. ${ }^{78}$ Die Verteilung der suffimenta ist außerdem in Münzprägungen anlässlich der augusteischen und domitianischen Spiele dargestellt (siehe Anhang, Abb. 2 und 8). ${ }^{79}$ Dabei sitzen Augustus bzw. Domitian auf einem Schemel, der auf einem Podest steht, und reichen zwei vor ihnen stehenden Männern in einer toga (bzw. einem Mann, der von einem Kind begleitet ist) einen Gegenstand. Vor den Herrschern steht jeweils ein Korb, in welchem sich die suffimenta befunden haben. In gleicher Weise werden auch andere Mitglieder des Kollegiums der Quindecimviri diese Aufgabe ausgefüllt haben, da die Verteilung der suffimenta an mehreren Stellen erfolgte.

Unter der acceptio frugum ist der Empfang der von der Bevölkerung gebrachten Früchte zu verstehen. In der augusteischen Inschrift sind alle Angaben über die acceptio frugum fragmentarisch, sodass unsere Informationen über diesen rituellen Akt aus der Inschrift allein unklar bleiben. ${ }^{8 \circ}$ Die Angaben des severischen commentarium enthalten die zusätzlichen Informationen, dass vor der Annahme der Früchte von Severus ein

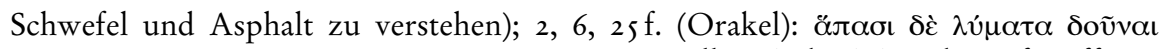

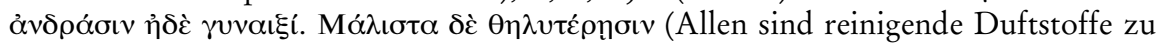
geben, Männern und Frauen. Besonders aber den Frauen).

76 An folgenden Stellen ist von der Verteilung der suffimenta die Rede: Z. 7-10; 29-30.

77 Vgl. Kap. A.I 2, S. $272 \mathrm{ff}$.

78 Das severische commentarium spricht zusätzlich von Auslosungen, an welchen Orten welche Gruppe von je drei Quindecimviri die suffimenta verteilen soll: Act. Sev. 59-62 (briefliche Einladung zur Auslosung); 64-65 (Auslosung); 79-84 (Einsatz der Quin-

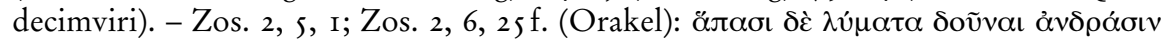

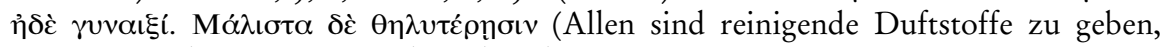
Männern und Frauen. Besonders aber den Frauen).

79 Eine Aufschrift AVG(ustus) SVF(fimenta) P(opulo dedit) bzw. SVF(fimenta P(opulo) $D$ (edit) macht deutlich, worum es bei diesen Abbildungen geht.

80 Von der acceptio frugum ist an folgenden Stellen die Rede: Z. 29-33; 34-36; 89. Eventuell enthielt auch das Edikt der Z.65-70 eine Bestimmung zur acceptio frugum, die allerdings nicht mehr erhalten ist. 
Gebet gesprochen wurde, dass die Quindecimviri zur Annahme auf speziell errichteten Tribünen Platz nahmen, und dass am 3. Juni nach dem Vortrag des carmen saeculare und nach der Beendigung der pompa, des lusus Troiae und des Wagenrennens die vom Volk abgegebenen Früchte an die Teilnehmer der Wettkämpfe abgegeben wurden. Restliche Früchte erhielten anschließend einige Beamte, die wahrscheinlich bei der Organisation mitgeholfen hatten. ${ }^{81}$ Weitere Informationen bieten auch hier Münzabbildungen zu den domitianischen Säkularspielen, die den Akt der acceptio frugum festhalten (siehe Anhang, Abb. 9a und 9b). ${ }^{82}$ Links sitzt Domitian auf einem Schemel, der auf einem Podest steht, und empfängt von zwei vor ihm stehenden Männern die fruges, welche sie aus einer patera in eine von Domitian gehaltene patera schütten. Neben dem Schemel stehen drei Körbe, in welche Domitian die Gaben umschüttet. In einer anderen Serie dieser Prägung schüttet einer der Männer die fruges in ein vor dem Podest stehendes Gefäß (Sack, Korb?). ${ }^{83}$ Sowohl der Kaiser wie auch die vor ihm stehenden Männer sind mit einer toga bekleidet, sie tragen keine Kopfbedeckung.

Die Aufschrift FRVG(es) AC(cepit) auf dem Podest bezeichnet den hier dargestellten Akt der acceptio frugum. Bei den fruges handelte es sich um Erstlingsfrüchte, das heißt zur Zeit der Säkularspiele, Anfang Juni, um noch nicht vollständig ausgereiftes Korn, nach Zosimus um Weizen, Gerste und Saubohnen. ${ }^{8}$ Die drei aufgestellten Körbe zeigen, dass die unterschiedlichen Früchte wahrscheinlich sortiert wurden. ${ }^{85}$ Die acceptio frugum stellt im Ensemble der Riten der Säkularspiele einen Eingangsritus dar, auf den offensichtlich - wie es die severische Inschrift zeigt während und am Ende der Feier wieder Bezug genommen wurde, indem das abgegebene Korn als Belohnung, vielleicht auch Bezahlung, eine Verwendung fand. ${ }^{86}$ Die Abgabe von Früchten, ebenso wie die Annahme der

8 I Act. Sev. 90-93; 96-I0I; 258.

82 Es existieren verschiedene Varianten dieser Prägung.

83 Scheid (I990a) 602f. weist zu Recht die These Piganiols (1923) 92 zurück, dass es sich bei den fruges auch um Wein gehandelt haben könnte, eine Vorstellung, auf die Piganiol durch Parallelen zum christlichen Ritual und durch die Identifikation eines der Gefäße als scyphus kommt. Eine neue Ergänzung in Act. Sev. 99 legt nahe, dass es sich um Körbe gehandelt hat: JIN COR[bibus $\cdot 9 \cdot$ p]OSITIS. Bei corbis handelt es sich um eine Bezeichnung für Getreidekörbe (Cato agr. I36).

84 Dass es Erstlingsfrüchte sind, steht im Orakel (Zos. 2, 6, 27 f.) und bei Zos. 2, 5, 4; an anderer Stelle (Zos. 2, 5, 2 und 2, 5, 4) differenziert Zosimus die fruges in oĩov xaì

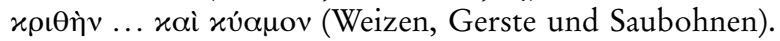

85 Vgl. Z. 69: GENERATIM CONFERRENT. Diese Formulierung sowie die auf der Münze erkennbaren drei Körbe legen eine sortierte Abgabe der fruges nahe.

86 Auch Zosimus erwähnt die Verteilung der abgegebenen Früchte als Lohn $(2,5,4)$ :

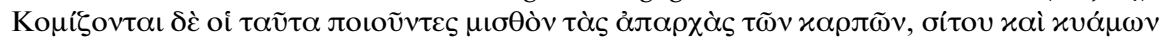


suffimenta, schien verbindlich für alle gewesen zu sein, die am Opfer teilhaben wollten. So betont auch das Orakel ausdrücklich, dass alle zu der acceptio frugum einen Beitrag zu leisten hätten und allen suffimenta zu verteilen seien, was darauf schließen lässt, dass diese Riten als Eingangsritus zu einem Opfer selbstverständlich waren. ${ }^{87}$

Im Gegensatz zum Orakel macht der Text auch Angaben, wo diese vorbereitenden Handlungen stattfinden werden: IN CAPITOLIVM ANTE AED [em Iovis Optimi Maximi und ante aedem D]IANAE. ${ }^{88}$ Die Frage, ob es sich um den Dianatempel auf dem Aventin oder um den in der Nähe der porticus Octaviae handelt, ist nicht mit Sicherheit zu entscheiden. Obwohl der Aventin, wo ein Dianatempel stand, an der Säkularfeier selbst keine Rolle spielte, ist seine Einbeziehung in die vorbereitenden Riten gut möglich, da auch Zosimus dies belegt. ${ }^{89}$ Die kultische Funktion des Aventin war mit den Iuno- und Dianatempeln bekannt. Als Zielpunkt von Prozessionen mit lustralem Charakter scheint die Ausgabe von suffimenta hier sinnvoll, außerdem waren bei der Verteilung an alle Bürger aus organisatorischen Gründen mehrere Annahme- und Ausgabestellen nötig. ${ }^{\circ}$ Der Abschnitt über die acceptio frugum und die Verteilung der

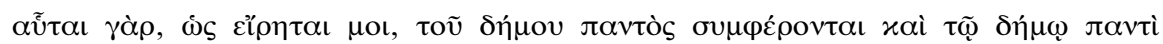

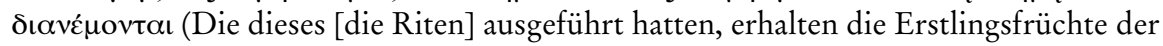
neuen Ernte als Lohn, nämlich Weizen, Gerste und Saubohnen: Diese nämlich waren wie man mir gesagt hat - vom ganzen Volk zusammengetragen worden und sind dem gesamten Volk wieder ausgeteilt worden).

87 Zos. 2, 6, 27. Dass die Passage des Orakels mit den Eingangsriten der Verteilung der suffimenta und der acceptio frugum (25-30) wegen des noch erkennbaren Akrostichons eine zusammenhängende Passage aus älteren sibyllinischen Versen ist, spricht ebenfalls dafür. Offensichtlich handelt es sich um ein gängiges Ensemble von Eingangsriten vor großen Opfern. Vgl. Kap. A.ıo, S. 244 f.

88 Z. 9; Kolb (1995) 330 über die Gestaltung des Iuppitertempels auf dem Kapitol in augusteischer Zeit. Zum Dianatempel auf dem Aventin ebenfalls Kolb (I995) i 24 f. und 345. Die Ortsangabe des Aventin ist an keiner Stelle der Inschrift erhalten. Auch in Z. I46, wo es um das Gebet und Opfer für Diana geht wird keine Ortsangabe gemacht, weil das Opfer und Gebet für Diana mit Sicherheit auf dem Palatin in Verbindung mit dem Apollo-Opfer stattgefunden hat. Mommsen (I 89I) 259f. (605f.) setzt aber aufgrund seiner Ergänzungen hier in Z. Io und in Z. 32 voraus, dass auch das Gebet und Opfer für Diana auf dem Aventin stattgefunden haben, somit also neben den Örtlichkeiten Kapitol und Palatin auch der Aventin bei der Säkularfeier eine Rolle gespielt habe. Vgl. die Angaben unten zu Z. 29-33, S. 97.

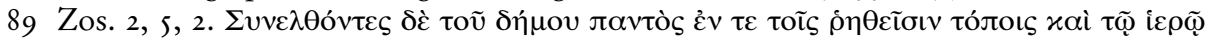

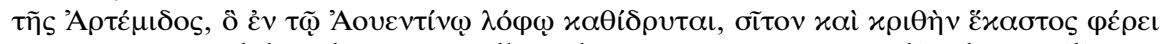

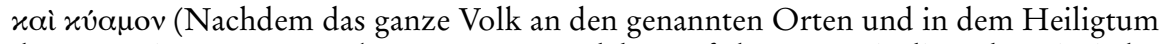
der Artemis zusammengekommen war, welches auf dem Aventin liegt, hat ein jeder Weizen, Gerste und Saubohnen gebracht).

90 Poe (I984) 6r ff. verweist darauf, dass zwischen dem Marsfeld, dem Austragungsort der ludi saeculares, und dem Aventin kultische Bezüge bestanden. Diese kommen 
suffimenta enthielt noch etwas Text am Anfang von Z. I2 und war danach abgeschlossen. Über das Orakel hinausgehend enthält er Angaben über den Zeitpunkt und Ort dieser Handlungen.

Hier wird auf eine alte Institution aufmerksam gemacht, wonach während der Festtage Streitigkeiten zu ruhen hatten. ${ }^{91}$ Dies galt für die Zeit der feriae publicae, die während der drei Tage dauernden Säkularfeier angesetzt waren. ${ }^{22}$ Diese Regelung wurde sowohl für die augusteische als auch für die severische Säkularfeier angewandt. ${ }^{33}$ Die Inschrift der severischen Feier spricht allgemein von einer Anordnung für Gerichtsferien neben den Bestimmungen zur Finanzierung, zum Zeitpunkt der Spiele und zur Aufhebung der Trauer der Frauen. ${ }^{94}$ Die augusteische Inschrift dagegen bezieht sich auf eine alte religiöse Regel, deren Wortlaut litibus et iurgiis se abstinerent sprichwörtlich war. ${ }^{95}$ Der Zusammenhang von feriae und dem Ruhen der Gerichtsbarkeit entstand aus der Vorstellung heraus, dass diese Tage der Verfügungsgewalt der Menschen entzogen und ganz den Göttern gewidmet sein sollten. Die Stimmung in der Bevölkerung sollte friedlich und spannungsfrei sein, damit die Götter ebenfalls Ruhe genießen können. ${ }^{96}$ Auf diese Vorstellung nimmt auch das Orakel Bezug mit der Formulierung »Ernst soll mit fröhlichem Lachen vermischt sein« und dem Wunsch, dass die Götter gnädig zu stimmen seien. ${ }^{97}$ Damit erhält auch das einleitende diligenter memineritis einen Sinn, der vielleicht die mehrfach im Orakel angesprochene Ermahnung zum Sich-Erinnern aufnimmt. ${ }^{98}$ Zweimal ist diligenter als Adverb zu dem Verb meminisse gebraucht (Z. I3 und 23), es scheint damit dieselbe Dringlichkeit der Erinnerung zu

besonders an den bei Livius überlieferten Lustrationsakten, die anlässlich der Geburt von Hermaphroditen vorgenommen wurden, zum Ausdruck (Liv. 27, 37 für das Jahr 207 v. Chr. und Liv. 3I, I 2 für das Jahr 200 v. Chr.).

9I Wissowa (I9I2) 432-449.

92 Z. 39 erwähnt feriae in einem Dekret der Quindecimviri. Bei den feriae der Säkularfeier wird es sich jedoch um feriae imperativae gehandelt haben, also außergewöhnliche Feiertage, die von Magistraten mit einem imperium angesetzt wurden.

93 Act. Sev. $29 \mathrm{f}$.; $45 \mathrm{f}$.

94 Scheid (I990a) $358 \mathrm{f}$. beobachtet eine Ausweitung dessen, was auf Stein überliefert ist, auch bei den Arvalakten aus severischer Zeit. Das Ritual selbst erfuhr dagegen keine substantielle Erweiterung. Pighi (I94I) I09 glaubt, dass die juristischen Bestimmungen, die die severische Inschrift enthielt, auch für die augusteische Feier galten. Das kann durchaus der Fall sein, ohne dass die augusteische Inschrift diese juristischen Bestimmungen der Überlieferung für würdig hielt.

95 Cic. div. I, IO2 erwähnt, dass bei kultischen Handlungen, die von Staats wegen angesetzt waren, was für die Säkularspiele zutrifft, Folgendes galt: ut litibus et iurgiis se abstinerent.

96 Cic. leg. 2, 55 beschreibt die Tage der feriae als dies quieti für die Götter.

97 Zos. 2, 6, 35 und $29 f$.

98 Zos. 2, 6, 3; 4; 33; 36 . 
enthalten wie das Orakel. Für das Ritual der Säkularfeier, das nach den augusteischen Bestimmungen nur alle i ı Jahre durchgeführt wurde, war ein solcher Erinnerungsakt von besonderer Bedeutung. Der ursprünglich als Brief des Augustus bezeichnete Text scheint sich besonders in diesen Hinweisen auf die Erinnerung an das Orakel zu lehnen, das speziell für die Säkularfeier erstellt worden war. Da das Orakel für den Anlass der augusteischen Spiele aus bestehenden Versen in Verbindung mit neu gebildeten geschaffen worden war, hat es für die Legitimation der Spiele eine wichtige Rolle gespielt. Sein Inhalt durfte nicht veröffentlicht werden, musste aber dennoch in irgendeiner Form den Weg in die Öffentlichkeit finden, um diese Funktion der Legitimierung zu erfüllen.

Die Bedeutung des Wortes audientiam, die schon zu Z. C Is angesprochen wurde, scheint in einem Zusammenhang mit der Funktion des Textes zu stehen. ${ }^{99}$ Ich habe hierin einen Ausruf des praeco verstanden, dessen ausgerufener Text schriftlich fixiert war und sich in den Archiven der Priesterschaft der Quindecimviri befand. Aufgrund dieser Zugehörigkeit und aufgrund seiner Bedeutung für die Spiele fand der Text Aufnahme in das commentarium. Mommsen verstand audientiam als Publikum an Gerichtsverhandlungen, indem er durch seine Ergänzung non esse praestandam das Wort audientiam mit der vorangehenden Zeile verband. ${ }^{100}$ Dabei trug Mommsen nicht der Tatsache Rechnung, dass sich vor audientiam ein vacat befindet. Dieses vacat weist darauf hin, dass das Wort audientiam im Text der Inschrift eine besondere Stellung einnahm, weil es durch die umgebende unbeschriebene Fläche ins Auge sticht. ${ }^{\text {Ior }}$ Für die Interpretation von audientiam bedeutet das, dass es sich an dieser Stelle durchaus um ein anderes Publikum handelt, als das von Mommsen vermutete. Es ist nicht davon auszugehen, dass mit der Wiederholung von audientiam der Ausruf des praeco zu Ende war, da im Folgenden weiter auf rituelle Bestimmungen $\mathrm{zu}$ den ludi saeculares eingegangen wird. Eher handelt es sich um die Wiederholung einer Formel, die den Status des Textes noch einmal festlegte oder einen zweiten praeco-Text einleitete.

I 5-I9 In Z. I s folgt mit vorgezogenem linkem Zeilenanfang ein längeres zusammengehörendes Textstück, das sich auf die Teilnahme der Matronen an der Säkularfeier bezieht. Der erhaltene Text macht Angaben, die Frauen betreffen, die älter als 25 Jahre sind (Z. I7: ...] MAIORES ANN(os) $X X V N A T A E)$. Wegen dieser Angabe kann man davon ausgehen, dass

99 Vgl. oben zu C I 5-I7, S. $78 \mathrm{ff}$.

I00 Mommsen (I89I) 244 (588).

I I Ähnlich auffällig wird das Kollegium der Quindecimviri in der Inschrift betont, die vor jedem Edikt - umgeben von zwei vacat - genannt werden. Besonders gut zu sehen ist dies in der erhaltenen Eingangszeile des Edikts über das Unterlassen der Trauer der Matronen, Z. I Iо. 
hier die Rede von den sellisternia ist, welche die Matronen im Anschluss an die Opfer abhielten. Auf diese Opfer scheint sich die Angabe in Z. Is zu beziehen. Die Datumsangaben von Z. I6, bei denen es sich mit großer Sicherheit um die Nächte des I., 2. und 3. Juni handelt, waren für die Matronen der Zeitpunkt der sellisternia für Iuno und Diana. ${ }^{102}$ I I $\circ \mathrm{Ma}-$ tronen waren ausgewählt worden, weil damit auf den neu festgelegten Abstand zwischen zwei Säkularfeiern hingewiesen werden konnte. sellisternia waren wie die lectisternia eine besondere Form des Opfers, bei dem man sich den Akt des Opferns als Bewirtung eines Gottes bzw. einer Göttin vorstellte, analog zu den menschlichen Tischsitten. lectisternia waren erstmals 399 v. Chr. als eine nach Graecus ritus ausgeführte Zeremonie eingeführt worden. Ihren Namen haben diese Einrichtungen von den Sitzgelegenheiten für die teilnehmenden Götter und Göttinnen: lectisternium nach lectum, der gepolsterten Liege für einen Gott, sellisternium nach sella für weibliche Gottheiten, weil diese nicht wie Götter auf einem lectum liegen können, sondern jede für sich auf einer sella sitzen. ${ }^{103}$ An den sellisternia wurden für die Göttinnen, zu deren Ehren sie veranstaltet wurden, Sessel aufgestellt, die dann während des Mahles leer blieben. ${ }^{\circ 04}$ Solche sellisternia haben $\mathrm{zu}$ verschiedenen Zeiten stattgefunden. Sofern sie als öffentliche Riten ausgeführt wurden, konnten sie einen sühnenden Aspekt enthalten, wie mehrere überlieferte Beispiele zeigen. $^{\text {ros }}$

Allgemein werden lectisternia und sellisternia den im vierten vorchristlichen Jahrhundert eingeführten Neuerungen im ritus Graecus zugeordnet. ${ }^{106}$ In neueren Analysen wird darauf hingewiesen, dass es sich zwar um einen neuen ritus in Rom handelte, dessen Einführung aber nicht unbedingt als Hellenisierung der römischen Religion zu verstehen

I02 Mommsen (I89I) 255 (600). Auch wenn das augusteische commentarium diese sellisternia nur im Anschluss an die Opfer der ersten und dritten Nacht überliefert (Z. IоIf., I 38 ) ist davon auszugehen, dass sellisternia im Anschluss an jedes Opfer stattfanden, also auch in der zweiten Nacht im Anschluss an das Ilithyia-Opfer und an alle Opfer am Tage. Vgl. die Tabelle auf S. 91.

I03 Wissowa (I9I 2) 423; Latte (1960) 242-244; Val. Max. 2, I, 2; Fest. p. 386 Lindsay; ein gemeinsames Mahl zu Ehren eines Gottes wurde demnach lectisternium genannt.

I04 Latte (I960) 244 weist darauf hin, dass an den lectisternia Götterbilder aufgestellt wurden, um die Teilnahme des Gottes an dem Ritus zu verdeutlichen. An den sellisternia der augusteischen Säkularfeier waren wahrscheinlich keine Bilder der beiden Göttinnen Iuno und Diana aufgestellt; die Inschrift selbst spricht nur vom Aufstellen der Sessel, Z. iо If.

Io5 Liv. 5, I3, 5-8 spricht von dem im Jahre 399 v. Chr. erstmals abgehaltenen lectisternium anlässlich einer Seuche; Tacitus Ann. I5, 44 erwähnt sellisternia unter den Sühneritualen nach dem Brand von Rom.

ı०6 Gagé (I955) I69-I77; 308-347; Latte (I960) 242-244. 
ist. ${ }^{107}$ Der griechische Einfluss bleibt unklar, es muss davon ausgegangen werden, dass die Einführung dieses Rituals ein Ausdruck des Wandels der römischen Religion ist, dass also durchaus uns unbekannte Formen der alten römischen Religion in dieses Ritual eingeflossen sein können, welches neben dem Opfer eine neue Möglichkeit darstellte, Störungen im Umgang mit den Göttern zu bereinigen.

Die Angaben in diesem Teil der Inschrift zu den sellisternia sind unvollständig und werfen Fragen auf, was den Ort der sellisternia betrifft. ${ }^{108}$ Auch aus der Darstellung der sellisternia im protokollarischen Teil der Inschrift erfährt man nichts über den Ort dieser Handlungen. ${ }^{109}$ In Z. I 8, die direkt an die Bestimmung für die Matronen anschließt, ist als Ort der Zusammenkunft der Matronen in Capitolium erhalten. Auch die severische Inschrift legt nahe, davon auszugehen, dass alle sellisternia von den Matronen auf dem Kapitol durchgeführt wurden. ${ }^{\text {Iо }}$ Ebenso ist im Edikt von Z. 78 f. als Ort der Zusammenkunft der Matronen das Kapitol erwähnt. Somit haben die sellisternia nicht am Ort der vorangegangenen Opfer stattgefunden, sondern immer auf dem Kapitol.

Für die sellisternia verrichteten die Matronen eigene Opfer, die sie anschließend verspeisten. Das severische commentarium erwähnt für die sellisternia des dritten Tages ein eigenes Opfer von Schweinen durch die Matronen - porcilias immolaverunt. ${ }^{\text {II }}$ Außerdem ist erwähnt, dass diese sellisternia wie die der beiden vorangegangenen Tage ausgesehen haben. Im augusteischen commentarium ist zwar gar kein Hinweis auf solche Opfer enthalten, es ist aber davon auszugehen, dass die Matronen auch an den augusteischen Säkularspielen eigene Opfer verrichteten, um sellisternia feiern zu können.

Das inschriftliche commentarium, das den Verlauf der ludi saeculares wiedergibt, erwähnt sellisternia der Matronen nicht nach jedem Opfer. Das bedeutet nicht, dass sie nicht stattgefunden haben, sondern dass das com-

I07 Scheid (I998a) I72-I76; BNP (I998) 63.

I08 Pighi (I94 I) I Io nimmt zu Recht an, dass in diesen Zeilen die Matronen aufgefordert werden, in der Nacht des I.,2. und 3. Juni zu sellisternia auf dem Kapitol zusammenzukommen.

Iо9 Z. голf.; I09; I38.

I IO Act. Sev. I78f.; an dieser Stelle ist von den auf das Opfer an die Ilithyien folgenden Spielen und sellisternia die Rede. Der fragmentarische Text enthält deutlich lesbar in der Angabe zu den sellisternia das Verb ascenderunt, was die Annahme stützt, dass die an den sellisternia teilnehmenden Matronen zu diesem Zweck das Kapitol erklommen haben.

I I I Darauf weist Act. Sev. 259f. hin: e]ADEM DIE IVLIA AVG. M[ater] CASTRORVM ET MATRO[nae ce]NTVM NOVE[m habuerunt $\cdot 32 \cdot] \mid$ [sellistern]IA SVA SICVT PRAEC[eden]TI BIDVO, PORCILIAS IMMOLAVERVNT [et] EISDEM CENA[verunt et antr]VAV[erunt.]. 
mentarium auf Vollständigkeit der Angaben verzichtet. Eine Gegenüberstellung mit dem severischen commentarium bekräftigt die Annahme, dass sellisternia der Matronen nach jedem Opfer abgehalten wurden. ${ }^{\text {I } 2}$

\begin{tabular}{l|lll} 
& I. Juni & 2. Juni & 3. Juni \\
\hline Act. Aug. nachts & I0I & - & I 38 \\
am Tag & I09 & I33(?) & - \\
Act. Sev. nachts & I49-154 & I78f. & 228 \\
am Tag & $\begin{array}{l}\text { siehe Angabe } \\
\text { für 3. Juni }\end{array}$ & $205 \mathrm{f}$. & 259f. (sicut prae- \\
& & & cedenti biduo)
\end{tabular}

Der Grund dafür liegt in der Struktur der gesamten Feier, die als immer wiederkehrende Elemente Opfer, ludi und sellisternia enthielt. Außerdem wurde mit dem Ritual des sellisternium nicht nur die Beziehung der Menschen zu den Göttern geordnet, es diente auch dazu, die Beziehungen der Bürger untereinander klarzustellen. Durch die Ehrung der Matronen als selbstständig Ausführende einer Kulthandlung mit Opfer, den sellisternia, erhielten sie eine ungewöhnliche Aufmerksamkeit, die in Zusammenhang mit der Aussage der augusteischen ludi saeculares steht: Die Sicherung der Nachkommenschaft, der Garantie für den Fortbestand Roms, lag zu einem wichtigen Teil in der Verantwortung der Matronen. Dies wurde durch die Ehrung der Matronen während der sechsmaligen sellisternia allen Römern vor Augen geführt. ${ }^{1{ }^{13}}$

20f. Im letzten Abschnitt des Textes ist das Lied der Knaben und Mädchen erwähnt, welches diese anlässlich der Säkularfeier gesungen haben. Aus dem weiteren Text der Inschrift ist dieses Lied als das carmen saeculare des Horaz zu identifizieren. ${ }^{14}$ Die Bedingung, dass beide Elternteile noch am Leben sein müssen, ist lesbar, ebenso ihre Aufgabe, einen Chor zu bilden, um ein Lied vorzutragen. Patrimi et matrimi ist eine nur im römischen Kult nachweisbare Qualifikation für Kinder, deren Vater und Mutter noch am Leben sind. ${ }^{\text {Is }}$ Auch das Orakel erwähnt diese Bestim-

I 2 Z. Iо I und I 38 für nächtliche sellisternia, Io9 und I 33 (?) für sellisternia am Tag. Das severische commentarium ist in der Angabe der sellisternia ebenfalls unvollständig, aber in erster Linie wegen des fragmentarischen Zustands des Textes.

I 3 Die Ehrung der Matronen fand wohl nicht im Rahmen der Verteilung des Opferfleisches statt, worin sich die Stellung der Männer untereinander widerspiegelte (vgl. Scheid [1985] I 97 ff.). Die Ehrung der Matronen drückte sich darin aus, dass ihnen eigene Riten zugestanden wurden. Diese Riten standen nach dem Opfer zwar an zweiter Stelle, gehörten aber zum rituellen Ensemble der Säkularspiele und wurden von den Matronen eigenständig durchgeführt.

I 4 Z. I 47-I 49 .

I I Koch RE XXXVI, 3 (I949) Sp. 2250-2252 s. v. patrimi et matrimi. Baudy DNP I (1996) 618-6I9, s. v. amphithaleis paides. 
mung als $\alpha \mu \varphi ı \theta \alpha \lambda \eta ́ s .{ }^{116}$ Diese Qualifikation war in der Ausübung des öffentlichen Kultes erforderlich. ${ }^{17}$ Über die Bedeutung dieser Qualifikation haben wir keinerlei Angaben, die Bedeutung des griechischen Wortes $\alpha \mu \varphi \imath \theta \alpha \lambda \eta ́ s ~ l e g t$ aber nahe, dass man sich darunter vom Tod unberührte Kinder vorstellte, deren Leben noch keine Beschädigung erfahren hatte, und die aufgrund dieser Makellosigkeit für kultische Beteiligung besonders geeignet waren. In welcher Beziehung diese Kinderchöre mit den Chören von Z. 3 stehen, kann nicht geklärt werden. Die letzten beiden Zeilen des Textes betreffen Opfer und Vorbereitungen der Spiele. Die abschließenden Worte diligen]TER MEMINERINT nehmen den Tonfall des Orakels wieder auf, wonach sich der Römer erinnern soll, die Riten der Säkularfeier gewissenhaft zu wiederholen.

Damit wird mit den letzten Worten dieses Textabschnitts noch einmal Bezug auf bereits existierende Vorgaben zu den rituellen Handlungen der Säkularfeier genommen. Der Text enthält Hinweise auf die wichtigsten Riten der Säkularspiele, nämlich auf die Chöre der Knaben und Mädchen, auf die Verteilung der suffimenta, auf die acceptio frugum, auf feriae und Aussetzen der Gerichtsbarkeit während der ludi saeculares, auf die sellisternia der Matronen, das carmen saeculare und am Schluss eher zusammenfassend auf Opfer und Spiele. Außer dem Hinweis auf den i Io-jährigen Abstand zwischen zwei Säkularfeiern und auf die Opfer an die bestimmten Götter - Angaben, welche das Orakel enthält - stimmt dieser Text mit den Angaben im Orakel überein. Es ist grob gesehen sogar die Reihenfolge des Orakels beibehalten, wobei der inschriftliche Text nicht vollständig ist und am Ende von Fragment $C$ wahrscheinlich die fehlenden Angaben über die zeitliche Berechnung und den Götterkanon der Säkularspiele machte. Entgegen Mommsens These von einem die Riten vorschreibenden Brief des Augustus liegt hier ein Text vor, der den Inhalt des Orakels wiederholte. Da der Orakeltext nicht veröffentlicht werden durfte, handelt es sich bei dem Dokument wahrscheinlich um eine Interpretation, lateinische Paraphrase oder sogar Übersetzung des Orakels durch die Quindecimviri. Dieser Text wurde in die Inschrift aufgenom-

I 6 Die mehrfach belegte griechische Übersetzung, die auch Zosimus gebraucht (Zos. 2,

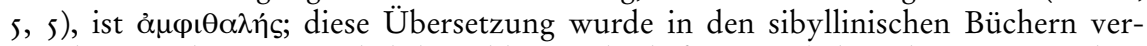
wendet, wie das ursprünglich bei Phlegon überlieferte Orakel zu den augusteischen Säkularspielen belegt (siehe Zos. 2, 6, 22).

I 7 Überliefert ist diese kultische Qualifikation in den commentarii der Arvalbrüder, wo sie als Helfer bei kultischen Handlungen und beim Mahl der Arvalbrüder auftreten. Allerdings handelt es sich im Gegensatz zu den Säkularspielen ausschließlich um Knaben. Vgl. Scheid (I998c) 49, 26; 69, 32; 78, 26 und andere Belege. Diese Knaben sind in den Arvalakten meistens als senatorum filii bezeichnet, stammen also aus der Oberschicht. 
men, weil er als schriftliches Dokument im Archiv der Quindecimviri seinen Platz hatte und als Dokument der künftigen ludi saeculares galt. Er enthielt die rituellen Bestimmungen der künftigen Feier und bildete eine Art Richtschnur für die Quindecimviri bei den Vorbereitungen. ${ }^{\text {II8 }}$ Die inschriftliche Fixierung sollte das Befolgen der Riten für künftige Zeiten sichern, was nicht allein durch die Überlieferung des Festprogramms im zweiten Teil der Inschrift geschehen konnte. Deshalb ist $\mathrm{zu}$ vermuten, dass hinter dem hier überlieferten Text als Autorität das Orakel stand, aber nicht, wie bisher angenommen, die Person des Augustus. Trotz des fragmentarischen Textzustands ist mehrmals eine sakrale Sprache zu erkennen, die die legitimierende Funktion dieses Textes verdeutlicht. ${ }^{\text {I9 }}$ Insofern hatte Mommsen recht in seiner Annahme, dass am Anfang der Inschrift ein autorisierender Text überliefert sein musste, der das neu zusammengestellte Ritual legitimieren sollte. Diese Aufgabe konnte jedoch nicht ein Brief des Augustus an die Quindecimviri erfüllen.

24-28 Dass das ius edicendi auch Priesterkollegien zustand, wird nur aus dem commentarium der augusteischen Säkularspiele abgeleitet. ${ }^{120}$ Andere direkte Belege für priesterliche Edikte sind nicht bekannt. Da die Edikte der augusteischen Inschrift jedoch eindeutig als solche $\mathrm{zu}$ verstehen sind, handelte es sich hier wohl um eine Sonderregelung für das Kollegium der Quindecimviri während der Vorbereitungen der ludi saeculares, die auf einem vorangegangenen magistralen Beschluss beruhte. ${ }^{\text {I2I }}$ Der amtierende Pontifex Maximus Lepidus, der die Aufgabe gehabt hätte, auf die Notwendigkeit einer Säkularfeier hinzuweisen und damit den Anstoß zu einer solchen Feier zu geben, spielt an der Vorbereitung der Spiele gar keine Rolle. ${ }^{122}$ Er war umgangen worden und das ius edicendi an das Kollegium der Quindecimviri übergeben worden. Damit war einer Maßnahme, die

I 8 Die zweifache Nennung von IVBEATIS (Z. 6; 8) und die Anrede in der 2. Person unterstützen die bereits von Mommsen geäußerte Vermutung, dass sich dieser Text an die Quindecimviri richtet.

I 9 Als Ausdrücke der Sakralsprache können die Datumsangabe (Z. 4), das mehrmalige memineritis (Z. 7(?); I3; 23) und die Wiederholung des im Orakel gebrauchten Wortes milicheus gelten.

I 20 Kipp, RE V,2 (I905) Sp. ı940f. s. v. edictum; Kipp führt als Beleg Z. I ı०f. an; gegen die Möglichkeit priesterlicher Edikte mit Ausnahme des pontifex maximus wendet sich Mommsen RStR I (I 876) 204.

I 2 I Das Kollegium der Quindecimviri der severischen Spiele hatte nicht das Recht, selbst Edikte zu veröffentlichen. Septimius Severus und seine Söhne sind in den Edikteinleitungen als Subjekt genannt, dem die Quindecimviri assoziativ angeschlossen sind: Act. Sev. 73-74; I I 2-I I 4 .

I 22 M. Aemilius Lepidus war nach seiner Niederlage gegen Augustus im Jahre 35 v. Chr. zwar als Pontifex Maximus im Amt geblieben, durch seine Verbannung nach Circei jedoch bedeutungslos geworden. Zur Umgehung des Pontifex Maximus bei der Planung der ludi saeculares vgl. Scheid (I999) $8 \mathrm{f}$. 
ohne die Autorität des Pontifex Maximus getroffen worden war, die nötige Legitimation verliehen.

Bei diesem Text handelt es sich um den Wortlaut eines Edikts der Quindecimviri. Alle zur Säkularfeier erlassenen Edikte waren im Archiv der Quindecimviri aufbewahrt und wurden in die Inschrift aufgenommen. In der Inschrift sind insgesamt fünf Edikte der Quindecimviri erhalten. Sie sind wegen ihrer Einleitungsformel edictum propositum est XVvir(i) $s$ (acris) f(aciunis) dic(unt) leicht $\mathrm{zu}$ erkennen. ${ }^{\mathrm{I23}}$ Manchmal geht dieser noch eine Datumsangabe voran. ${ }^{\mathrm{I} 4}$ Das Ende dieser Formel $X$ Vvir $s f$ dic ist in etwas größeren Buchstaben als der übrige Text ziemlich genau in der Mitte einer Zeile dargestellt und sticht aus dem sonst gleichförmigen Text heraus. ${ }^{\text {I2s }}$ Man kann deshalb an dieser Stelle das fehlende Element der Formel ergänzen, wie es Pighi auch getan hat. ${ }^{126}$ Dieses besondere Gestaltungselement hat die Aufmerksamkeit der Leser der Inschrift auf die Ediktanfänge der Quindecimviri gelenkt. Damit sollte nicht auf die besondere Wichtigkeit der Edikte hingewiesen werden, denn die Senatsbeschlüsse vor der Säkularfeier haben keinerlei besondere Gestaltung in der Inschrift erfahren. Es sollte vielmehr im Gesamtbild der Inschrift das Kollegium der Quindecimviri als Veranstalter der ludi saeculares hervorgehoben werden. Augustus als treibende Kraft hinter der Restauration dieser alten Feier trat dagegen in den Hintergrund.

Das erste Edikt der Quindecimviri trägt die Datumsangabe eodem die. Das heißt, dass das vor dem Edikt in der Inschrift wiedergegebene Dokument mit einem Datum versehen war und das Edikt an demselben Tag erlassen wurde, an dem das vorangehende Dokument vorgelesen oder erlassen worden war. ${ }^{\mathrm{I} 27}$ Aus den erhaltenen Zeilenanfängen geht in groben Zügen hervor, was der Inhalt dieses Edikts gewesen sein muss. Es scheint die Veröffentlichung der Anordnungen, wie sie das Orakel vorgeschrieben hat, für die Säkularfeier zu betreffen. Da die kultischen Handlungen den üblichen Rahmen sprengten, war es nötig, die Bürger vorher detailliert darüber zu informieren, was jeder Einzelne im Verlauf der Feier zu tun hatte (Z. 28). In Z. 24 wird vielleicht auf eine Begründung der besonderen Informationsmaßnahmen eingegangen, da die Riten der Säkularfeier wegen des Abstands von i ı० Jahren zwischen zwei Feiern niemandem bekannt sein können. Die Säkularfeier und die sie betreffen-

I 23 Edikte werden in folgenden Zeilen eingeleitet: Z. 46, 64, I I0, I 55, I62.

I 24 Z. 24, 64, I62.

I 25 Vollständig erhalten ist diese Formel in Z. I 10 und I 55.

I 6 Pighi (I94I) I Io.

I $27 \mathrm{Da}$ es sich bei dem vorangehenden Dokument um die Wiedergabe des Inhalts des Orakels handelt, der wahrscheinlich als Auftrag an die Quindecimviri formuliert war, könnte das Datum sich auf die Abfassung dieses Dokuments beziehen. Vgl. S. 8 If. 
den Bestimmungen scheinen wie üblich (Z. 26: MORE EXEMPLOQVE $M A I O R V M)$ in einer contio bekanntgemacht worden zu sein. Dieses Edikt regelt, dass auch diejenigen Bürger, die an der Versammlung gefehlt haben, erreicht werden. Nach Mommsen steht dieses Edikt in engem Zusammenhang mit dem nachfolgenden Dekret (Z. 29-45), welches die beschlossenen Regelungen für die verschiedenen kultischen Handlungen enthält. ${ }^{128}$ Das Edikt der Zeilen 24-28 ediziert keine Bestimmung, die die Feier direkt betrifft, sondern es stellt so etwas wie eine vorangehende Erklärung der Quindecimviri dar, dass sie als ausführendes Priesterkollegium die Aufgabe haben, den komplizierten Ablauf der Feier bekannt zu machen. Deshalb war für Mommsen eine Berufung auf einen Brief von Augustus an das Kollegium der Quindecimviri im Sinne einer Ermächtigung nötig. Nach der neuen Einschätzung des vorangehenden Textes als auf dem Orakel beruhenden Angaben, ist von einem solchen Zusammenhang ebenfalls im Sinne einer Autorisierung auszugehen. Als sicher ist anzunehmen, dass die Quindecimviri ihre Edikte und Dekrete hinsichtlich der Feier auf einer Tafel bekannt gemacht haben. ${ }^{29}$ Dieses Edikt macht noch keine detaillierten Angaben über Orte und Zeiten, es lieferte wahrscheinlich die Legitimation für alle folgenden Bestimmungen, die die Quindecimviri veröffentlicht haben.

29-45 Das umfangreiche Dekret enthält einzelne detaillierte Bestimmungen für die Bevölkerung. Dekrete beruhen nicht auf einem Recht, diese zu veröffentlichen, wie es bei einem Edikt mit dem ius edicendi der Fall ist, sie haben deswegen auch nicht von vornherein den verordnenden Charakter eines Edikts. ${ }^{13^{\circ}}$ Ihre Wirksamkeit erhalten Dekrete erst durch eine nachträgliche Anordnung der Magistrate oder durch eine vorangegangene Anfrage oder einen Auftrag der Magistrate. In manchen Fällen, wohl auch im Fall der Säkularfeier, erhalten Dekrete eine verordnende Wirkung, indem ein Priesterkollegium mit der Ausführung einer Feier oder der Entscheidung einer Frage beauftragt wird und seine Entscheidungen durch diesen Auftrag eine magistrale Billigung gewissermaßen im Voraus zugesprochen bekommen haben. ${ }^{13 \mathrm{I}}$ Dekrete halten sich nicht wie Edikte und Senatsbeschlüsse an gewisse vorgegebene sprachliche Muster. Dass in diesen Zeilen tatsächlich ein Dekret vorliegt, geht nur aus dem Inhalt der Bestimmungen hervor und dem Fehlen der üblichen Ediktformel am

I 28 Mommsen (I89I) 247 (59I).

I 29 Liv. I, 32, 2: sacra publica ex commentariis regis pontificem in album elata proponere in publico iubet.

I 30 Hesky, RE IV,2 (I90I) Sp. 2289-2306 s. v. decretum; Kipp, RE V,2 (I905) Sp. I940I 948 s. v. edictum.

I 3 I Solche Beispiele schildert Liv. 32, I und 4I, I6. 
Anfang des Textes. Das vorliegende Dekret ist in einzelne Themenkomplexe gegliedert, was durch den erhaltenen linken Rand mit vorgezogenem Zeilenanfang gut $\mathrm{zu}$ erkennen ist.

29-33 Die Angabe ISDEM CO(n)S(ulibus) ISDEM MAG(istris) XVVIR(orum) $S$ (acris) $F$ (aciundis) hat Mommsen als Datumsangabe verstanden, die aber wider jede Regel ohne Angabe des Tagesdatums gestaltet ist. ${ }^{122}$ Warum in Z. 37 mitten in den Anordnungen dieses Dekrets noch einmal eine Datumsangabe mit Tagesdatum auftaucht, ist nicht ganz klar. Offensichtlich handelt es sich bei der Angabe von Z. 29 um die Erwähnung der Konsuln und magistri der Quindecimviri, von denen schon vorher in der Inschrift die Rede gewesen sein muss (isdem). Damit könnte an dieser Stelle auf die Beziehung zwischen Priesterkollegium und Magistrat hingewiesen sein, die vielleicht in einem entsprechenden Dokument geregelt war. Die Angabe von Z. 29 hätte dann den Sinn, darauf hinzuweisen, dass es sich immer noch um dieselben Gremien handelt, deren Beziehung weiter oben geregelt war. ${ }^{133}$ Als Datum gälte in diesem Fall noch das in Z. 24 genannte eodem die; die erneute Datumsangabe von Z. 37 würde bedeuten, dass das Dekret am 25. März fortgesetzt wurde. Die Einleitungszeile des Dekrets hat Mommsen mit dem üblichen publizistischen Ausdruck relatum est ergänzt, der für die Wiedergabe von Senatsbeschlüssen verwendet wurde. Der erste und zweite Abschnitt des Dekrets regeln die von der Bevölkerung vor dem Beginn der Feier vorzunehmenden rituellen Handlungen: die Verteilung von rituellen Reinigungsstäbchen aus Schwefel, die hier noch allgemein purgamenta genannt werden, und die Abgabe von Früchten durch die Bevölkerung. ${ }^{134}$ Weil an diesen beiden Aktionen ungeheure Menschenmassen beteiligt waren, musste der Zugang zu den Verteil- und Abgabestellen minutiös geplant sein. So sind die verschiedenen Ortsangaben der folgenden Zeilen zu erklären. Es scheinen für beide Handlungen mehrere Orte vorgesehen zu sein: Auf dem Kapitol, vor den Tempeln des Iuppiter Optimus Maximus und des Iuppiter Tonans und auf dem Palatin, vor dem Apollotempel und in dessen porticus war die Abgabe der purgamenta und die acceptio frugum vorgesehen. Den Tempel des kapitolinischen Iuppiter hatte Augustus aufwendig restaurieren lassen, der Tempel des Iuppiter Tonans auf dem Kapitol geht auf eine Tempelgründung des Jahres 22 v. Chr. zurück, nachdem Augustus knapp einem Blitz-

I 32 Mommsen (I89I) 247 (59I); Mommsen ging davon aus, dass sich das Tagesdatum entweder weiter hinten im nicht erhaltenen Teil der Zeile befand oder versehentlich vergessen wurde. Er hielt eine Datumsangabe an dieser Stelle für wichtig, um erklären zu können, dass nach dem Edikt ein neues Dokument beginnt - ein Dekret.

I 33 Die Konsuln im Senatsbeschluss von AB 6ff.; die Mitglieder des Kollegiums der Quindecimviri in $\mathrm{C} 5 \mathrm{ff}$.

I 34 Vgl. oben zu Z. 7-I I, S. 83 f. (suffimenta); S. 84 f. (acceptio frugum). 
schlag entgangen war. ${ }^{135}$ Auch der im Jahre 28 v. Chr. geweihte Apollotempel auf dem Palatin wies durch seine Nachbarschaft zum Wohnhaus des Augustus und durch die Verbindung der Apolloverehrung mit politischen und militärischen Erfolgen auf die Person des Augustus hin. Seine besonders prachtvolle porticus diente diesem Ziel ebenfalls. ${ }^{136}$ Die abgrenzende Formulierung fruges autem (Z. 32) zeigt, dass eine zusätzliche Möglichkeit der acceptio frugum vor einem Dianatempel und in der dazugehörigen porticus geboten war. Mommsen hat am Ende von Z. 32 in Aventino ante aedem Dianae et ergänzt und damit den Dianatempel auf dem Aventin als Ort für die acceptio frugum angenommen. ${ }^{137} \mathrm{Da}$ aber in Z. 33 zusätzlich von der porticus des betreffenden Dianatempels die Rede ist, könnte auch der kleine Dianatempel im Circus Flaminius gemeint sein, in dessen Nähe sich die im Jahre 23 v. Chr. fertiggestellte porticus Octaviae befand. ${ }^{138}$ Beide Gebäudekomplexe wurden vielleicht als Einheit empfunden. Die Ortsangabe des Aventin fehlt im augusteischen commentarium, sie stammt auch in Z. Io und I I aus der Ergänzung in Aventino von Mommsen. Die in Z. 30-33 genannten Orte entsprechen zwar den in Z. 9 und ro genannten Ortsangaben, es ist aber letztlich nicht eindeutig zu klären, welcher Dianatempel als Ort für die acceptio frugum gemeint ist. Der Dianatempel auf dem Aventin hatte im Jahre 33 v. Chr. eine aufwendige Renovation erhalten, die von einem politischen Gefolgsmann des Augustus finanziert worden war, allerdings ist in Zusammenhang mit dieser Renovation nie von einer porticus die Rede. ${ }^{139}$ Für diesen Tempel spricht aber seine Verbindung mit Riten, die der Lustration dienten. ${ }^{10}$ Für den Dianatempel neben der porticus Octaviae spricht, dass er näher bei den anderen erwähnten Orten zur Verteilung der suffimenta liegt und dass in seiner Nähe mit Sicherheit eine porticus stand. Es bleibt jedoch ungeklärt, welcher der Dianatempel bei den Vorbereitungen der ludi saeculares eine Rolle spielte.

Wichtig ist, an dieser Stelle festzuhalten, dass in diesem Teil des Dekrets noch kein Termin für die Verteilung der suffimenta und die acceptio

I 35 Suet. Aug. 29,3 und 9I, 2; RG I9; die bei Sueton überlieferte Anekdote eines Traums des Augustus (9I, 2) weist eventuell auf eine Opposition gegen die Gründung des Tempels für Iuppiter Tonans hin, die als unzulässige Verknüpfung der persönlichen Geschichte des Augustus mit der Staatsreligion empfunden wurde; Latte (1967) 304.

I 36 Kienast (20I4) 230ff. und Kolb (1995) 334f. Zur augusteischen Baupolitik ist die umfangreiche Literatur bei Kolb (I995) 699 ff. angeführt.

I 37 Vgl. S. 86.

I 38 Es ist nicht bekannt, ob der Dianatempel auf dem Aventin eine porticus besaß. Es handelte sich bei der porticus Octaviae nicht um einen Neubau, sondern um eine Restaurierung und Umgestaltung der porticus Metelli; RG I9; vgl. Kolb (I995) $343 \mathrm{ff}$.

I 39 Suet. Aug. 29, 5; Kienast (20I4) 4II.

I 40 Vgl. oben zu Z. 7-I I, S. 86. 
frugum angegeben wird. Es sind jedenfalls keinerlei Spuren von Datumsangaben in den Fragmenten zu finden. Eine Zeitplanung scheint erst später vorgenommen worden $\mathrm{zu}$ sein. ${ }^{\mathrm{I} I \mathrm{I}}$

34-36 Diese drei Zeilen enthalten eine weitere Bestimmung zur acceptio frugum und vielleicht auch zur Verteilung der suffimenta. Es scheinen wegen des erwarteten großen Andrangs mehrere Stände eingerichtet worden zu sein, wo die Menschen vortreten und ihre Früchte abliefern sollten, beziehungsweise die suffimenta in Empfang nehmen sollten. Die augusteischen und domitianischen Münzen über diese beiden Maßnahmen zeigen diese Stände, eine Art von Podest, deutlich. ${ }^{142}$ Das gemeinsame Vortreten von zwei Personen, das ebenfalls auf den Münzen erkennbar ist, wird eine Art Rationalisierungsmaßnahme zur schnelleren Abwicklung der Aktion sein. Das in Z. 35 erwähnte item könnte sich auf die Verteilung der suffimenta beziehen, die an dieser Stelle in gleicher Weise geregelt wurde. Offenbar werden beide Handlungen - Verteilung der suffimenta und die acceptio frugum - immer zusammen geplant. ${ }^{\mathrm{I} 3}$ Über die folgende Z. 36 lässt sich nur sagen, dass sich der Konjunktiv von convenirent syntaktisch noch auf das $u t$ von Z. 34 bezieht und somit eine weitere, nicht genauer bestimmbare Angabe über das Verhalten der Bürger macht. ${ }^{\text {I44 }}$ Vielleicht wurde die vorangegangene Bestimmung ergänzt, indem in gewissen Fällen die Bürger auch zu dritt vortreten durften.

37 Diese Zeile führt eine Datumsangabe mit Tagesdatum. ${ }^{\text {I4s }}$ Offenbar wurde die Sitzung, in welcher das vorliegende Dekret erlassen wurde, unterbrochen und am 25. März des Jahres I7 v. Chr. fortgesetzt. Da außerdem ein Ort angegeben wird, kann man davon ausgehen, dass die Fortsetzung der Sitzung der Quindecimviri an einem neuen Versammlungsort stattfand. ${ }^{146}$ Der erste Teil der beschließenden Sitzung fand anschließend an die Verlesung der rituellen Anweisungen, die auf dem Orakel beruhen (I-23), und an den Erlass des Edikts über die Information der Bevölkerung (24-28) statt. Das Kollegium der Quindecimviri verfügte nicht über ein eigenes Versammlungslokal und traf sich zu seinen Sitzungen wohl in

I 4 I Vgl. unten zu Z. 46-49, S. iorf.

I 42 Vgl. oben zu Z. 7-ı I. Zu den entsprechenden Münzen siehe Anhang, Abb. 2, 8, 9a und $9 \mathrm{~b}$.

I43 Dies war schon in Z. 7-I I der Fall; ebenso in Z. 30-33, wo es um die Orte für diese beiden Maßnahmen geht.

I 44 Auch die bisherigen Editoren standen dieser Zeile eher ratlos gegenüber. Mommsen (I 89I) 247f. (59I) glaubte, es handele sich hier um eine Zusammenkunft der Quindecimviri, die in der folgenden Z. 37 und mit Datums- und Ortsangabe noch einmal aufgenommen werde und der Fortsetzung des Dekrets diene.

I45 Vgl. oben zu Z. 29, S. $97 \mathrm{f}$.

I46 Wenn kein Ortswechsel stattfindet, wird eine Ortsangabe mit ibidem notiert; vgl. Z. 58 . 
dem Vorraum (PRO AEDE) eines Tempels. ${ }^{\text {I47 }}$ Wahrscheinlich handelt es sich um den Vorraum des palatinischen Apollotempels, in dem seit einiger Zeit die sibyllinischen Bücher aufbewahrt waren, deren Aufsicht den Quindecimviri oblag. ${ }^{148}$ Außerdem wird in der severischen Inschrift der Tempel des palatinischen Apollo als Versammlungsort der Quindecimviri genannt. ${ }^{149}$ Z. 37 bildet die Einleitung zu der folgenden Fortsetzung des Dekrets, sie wird nicht viel mehr Angaben als Datum und Ort der Sitzung enthalten haben, vielleicht noch eine Erwähnung des Kollegiums der Quindecimviri als tagendes Gremium. ${ }^{\text {Iso }} \mathrm{Da}$ die nächste Zeile mit einem vorgezogenen linken Zeilenanfang beginnt, ist es gut möglich, dass Z. 37 nicht bis an den rechten Rand ausgeschrieben war.

$3^{8}$ Diese Zeile hat den Charakter einer Einleitungszeile zu dem Inhalt der folgenden Verhandlungsgegenstände der Quindecimviri. Die Formulierung scheint einer üblichen Formel zu entsprechen, die in Z. 43 noch einmal aufgenommen wird.

39-42 Inhalt dieses Beschlusses sind die weiteren rituellen Anlässe der Säkularfeier, die an den Tagen der Feier selbst stattfinden sollten. Dazu gehören ludi, feriae und die sellisternia der Matronen. Iudi saeculares haben anschließend an jedes Opfer stattgefunden, Feiertage waren der i., 2. und 3. Juni, sellisternia für die Matronen sind zwar nur dreimal überliefert, fanden aber nach jedem Opfer statt. ${ }^{\text {ISI }}$ Mit LOEDI (Z. 39) sind hier nur die sogenannten ludi sollemnes gemeint, das heißt sakrale Spiele, die als öffentliche Spiele in Zusammenhang mit einem Opfer ausgerichtet wurden. ${ }^{122}$ Sie finden nicht wie andere Spiele in einem circus statt, sondern in

I 47 Mommsen (I89I) 247 (59If.) meint, dass die Ortsangabe pro aede hier wie in aede gebraucht wird.

I48 Der genaue Zeitpunkt der Überführung der sibyllinischen Bücher vom Iuppitertempel auf dem Kapitol in den Apollotempel ist nicht bekannt. Vgl. Kap. A.ro, S. 239 f.

I 49 Act. Sev. 64 .

I 50 Eine Aufzählung der Namen der an diesem zweiten Teil des Dekrets anwesenden Quindecimviri enthalten die Zeilen $44 \mathrm{f}$.

is I Vgl. oben zu Z. I 5-ı 9, S. 90 f. mit Anm. i 2. Die Act. Aug. erwähnen keine ludi nach dem Iuno-Opfer und nach dem Apollo- und Diana-Opfer. Da nach diesen Opfern mit der supplicatio der Matronen am 2. Juni und der Aufführung des carmen saeculare am 3. Juni die ludi saeculares nicht anschließend an das Opfer stattfanden, könnte ihre Dokumentation an dieser Stelle vernachlässigt sein. Das severische commentarium dagegen verzeichnete $l u d i$ wahrscheinlich nach jedem Opfer, wegen des fragmentarischen Textzustands ist dies allerdings nicht zu beweisen. Nächtliche $l u d i$ sind erwähnt in Act. Sev. [I 45f.], I78f. und 228; ludi nach den Opfern am Tage [I7I], $208 \mathrm{f}$. und $233 \mathrm{f}$.

I 52 Wissowa (I9I2) 4I4 erwähnt den Unterschied zwischen sacra sollemnia und sacra bonoris causa; der Gegensatz zwischen ludi sollemnes und ludi honorarii wird in Z. I 6 angesprochen. Mit dem Attribut sollemnis ist das belegt, was rituell gefordert ist, im Fall der Säkularspiele, was das Orakel vorgeschrieben hat. 
oder nahe bei einem Heiligtum oder Altar. ${ }^{\mathrm{IS3}}$ Nur ludi sollemnes waren mit feriae verbunden. Sie waren weniger aufwendig als die sogenannten ludi honorarii, welche zusätzlich ausgerichtet wurden, und beriefen sich auf eine andere Tradition. Während die ludi honorarii auf Tarquinius Priscus zurückgehen sollten, wurden als Gründer der ludi sollemnes Romulus oder Numa angegeben. ${ }^{154}$ Die altertümliche Schreibweise loedi will vielleicht auf diesen Unterschied anspielen. Die ebenfalls an der Säkularfeier stattfindenden ludi honorarii fanden erst nach Abschluss der drei Feiertage statt und wurden in einem Edikt der Quindecimviri nach dem Abschluss der rituellen Handlungen angekündigt. ${ }^{\text {IS }}$

Das Dekret der Zeilen 39-42 beschäftigt sich somit mit der weiteren rituellen Gestaltung der Säkularfeier, wozu neben den Opfern, die hier nicht erwähnt sind, ludi und sellisternia gehören. Von den Opfern war auch in dem fehlenden Text wohl kaum die Rede, da der verbleibende Freiraum für Angaben dazu nicht ausreichen würde. Das Dekret scheint sich nicht generell mit der Durchführung aller Riten zu befassen, sondern einzig mit der Durchführung derjenigen, an denen eine größere Anzahl von Bürgern aktiv einbezogen war.

In den Z. $4 \mathrm{I}$ und 42 folgen Datumsangaben, die in ihrer Formulierung an den Text erinnern, der den Inhalt des Orakels wiedergab. ${ }^{156}$ Dabei bezieht sich das Dekret auf ein vorher erlassenes Edikt (Z. 40), vielleicht auf das in Z. 24-28 überlieferte, welches die Information der Bevölkerung zum Ziel hatte. Mit den Datumsangaben wird der Zeitraum umrissen, an welchem die erwähnten loedi, feriae und sellisternia stattfinden sollten, nämlich beginnend in der Nacht vom 3r. Mai auf den I. Juni bis zum 3. Juni. Z. 42 scheint an Z. 28 des ersten Edikts der Quindecimviri anzuknüpfen und regelt vielleicht das Verhalten jedes Einzelnen.

43-45 Den Abschluss des Dekrets bildet die Aufzählung der Quindecimviri, die beim Erstellen des Dekrets anwesend waren. Eingeleitet wird diese Aufzählung von Namen durch eine Formel, die die Beschlüsse des Dekrets in Z. 38 einleitete. Z. 43 enthielt möglicherweise keine weiteren Angaben, weil die nächste Zeile mit einem vorgezogenen linken Zeilenanfang beginnt. Die in Z. 44 f. mit vier Namen erhaltene Aufzählung einiger Quindecimviri ist mit Sicherheit nicht vollständig, weil die Aufzählung mit Agrippa beginnt und mit nur zwei Zeilen auskommt. ${ }^{57}$ Für die vollstän-

I 53 Mommsen (I89i) 269 (6I6f.); Wissowa (I9I2) 455.

I 54 Wissowa (I9I2) 45 I ff.

I 55 Z. I $53 \mathrm{ff}$.

I 6 Z. 4 f.; wobei die Zeilen 4If. als Grundlage für die Ergänzungen in Z. 4 f. gedient haben; allerdings ist die Formulierung für eine Datumsangabe so gesucht, dass man von einem Bezug der beiden Stellen zueinander ausgehen muss.

I 57 Dass die Aufzählung mit Agrippa beginnt, geht daraus hervor, dass es sich um eine 
dige Aufzählung der Quindecimviri werden sonst in jedem Fall mehr als zwei Zeilen benötigt. ${ }^{158}$ Deshalb kann man davon ausgehen, dass die Aufzählung hier eine Anwesenheitsliste der Quindecimviri darstellt, die beim Abfassen dieses Dekrets beteiligt waren. Eine Ergänzung der Liste ist in beiden Zeilen nicht mit Eindeutigkeit vorzunehmen, da zwischen L. Censorinus und M. Lollius acht Namen möglich sind und der verbleibende Raum von etwa 73 Buchstaben in Z. 44 verschiedene Möglichkeiten zulässt. ${ }^{159}$

46-49 Die Einleitungszeile für das anschließende Edikt beginnt ohne Datumsangabe, weswegen man annehmen muss, dass es an demselben Tag erlassen wurde, wie der zweite Teil des vorangehenden Dekrets, also am 25. März (Z. 37). Der erste Teil des Dekrets (Z. 29-36), der die Orte für die Verteilung von suffimenta und die acceptio frugum regelte, enthielt noch keine Datumsangabe. Diese wird jetzt zu einem späteren Zeitpunkt in der Form eines Edikts verkündet.

Die Frage, welche Bestimmungen per Edikt und welche per Dekret zu regeln waren, ist nicht zu klären. Der Unterschied der beiden Formen lag vermutlich in der Wirkung auf die Adressaten: Einem Edikt kam grundsätzlich ein befehlender Charakter zu, was bedeutet, dass Bestimmungen, die per Edikt veröffentlicht wurden, vom Publikum anders zur Kenntnis genommen wurden und befolgt werden mussten. Deshalb sind diejenigen Bestimmungen, die den reibungslosen Ablauf der Säkularfeier sicherstellten, wohl eher in einem Edikt erlassen worden, während Dekrete eher zusätzliche und detailliertere Angaben zu Anordnungen machten, die schon per Edikt angeordnet waren. ${ }^{160}$ Für die größere Bedeutung der Edikte spricht deren auffällige Gestaltung in der Inschrift. Durch die bereits beschriebene Eingangsformel fällt jedes Edikt dem Betrachter der Inschrift ins Auge, während die Dekrete, ununterscheidbar vom übrigen Text, nicht auf den ersten Blick erkennbar sind.

Das Edikt der Zeilen 46-49 legt einen bestimmten Zeitraum für die Verteilung der suffimenta und wahrscheinlich auch für die acceptio frugum fest. Da beide Aktionen immer miteinander genannt sind, ist anzunehmen, dass auch an dieser Stelle von beiden die Rede ist. ${ }^{161}$ Die Erwähnung

Zeile mit links vorgezogenem Zeilenanfang handelt, die zweite Zeile der Aufzählung dagegen wird mit einer Einrückung begonnen. Dasselbe gilt für die Aufzählung der Quindecimviri in Z. I $50-152$.

I 58 C 5-8 und Z. I $50-152$.

I 59 Nach der von Hoffman Lewis (I952) 289-294 erstellten Senioritätsliste des Kollegiums. Die Anzahl der verbleibenden Buchstaben nach Pighi (I94I) i I I.

I60 Vgl. oben zu Z. 24-28, S. $94 \mathrm{f}$.

I6 I Z. 8-I I; 30-36; eventuell auch 69-70; 76 und 82 . 
von quo minore molestia legt nahe, dass die Verteilung organisatorisch nicht einfach zu bewältigen war, weswegen sie an verschiedenen Daten möglich war. ${ }^{162}$ Als Daten sind der 28., 29., 30. und 31. Mai genannt. ${ }^{163}$ Was genau an welchem dieser Tage zu erfolgen hatte, lässt sich nicht mit Sicherheit sagen, aber sicher ist, dass alle diese Handlungen vor dem Beginn der Säkularfeier, also vor der Nacht vom 3r. Mai auf den I. Juni, angesetzt waren.

50-63 Senatus consultum. Es handelt sich um zwei verschiedene Senatsbeschlüsse, die beide am 23. Mai gefällt wurden. Der erste (Z. 50-57) befasst sich mit einer Ausnahmeregelung zugunsten der durch die lex de maritandis ordinibus von Theaterbesuchen ausgeschlossenen ehelosen Bürger. Der zweite (Z. 58-63) mit der Dokumentation der Spiele für die Nachwelt.

5of. Wie im ersten mit praescriptio erhaltenen Senatsbeschluss (AB 6ff.) ist auch hier die übliche Reihenfolge der Angaben nicht gewahrt. Der Senatsbeschluss beginnt mit der Angabe des Datums, daran schließt sich die Angabe des Ortes der Versammlung. In saeptis] IVLIS ist als Ergänzung zu stützen, denn schon der Senatsbeschluss von AB 6 fand in der curia IJVLIA statt. ${ }^{164}$ Diese wurde seit ihrer Fertigstellung im Jahre 26 v. Chr. für Senatszusammenkünfte genutzt. ${ }^{165}$ Der Name des Verhandlungsleiters wird erst im zweiten Teil des Senatsbeschlusses, der relatio, genannt (Z. 52). Nach der Angabe von Zeit, Ort und Zeugen des Senatsbeschlusses ist als einleitende Formel ein senatus consultum factum est zu ergänzen, das in dieser Inschrift jedem Senatsbeschluss vorangestellt ist, so wie auch bei keinem Edikt die entsprechende Einleitungsformel fehlt. ${ }^{166} \mathrm{Am}$ Ende von Z. 50 ist die Ergänzung scribendo adfuerunt als Einleitung für die in

I62 Dies entspricht der Möglichkeit, diese Aktionen an verschiedenen Orten vorzunehmen, Z. 3 Iff. und 34f. Bei Livius 22, I0, 8 wird beschrieben, wie anlässlich der Spiele unter Fabius nach der Niederlage am Trasimenischen See, die Männer aufgefordert werden, die suffimenta mit Frauen und Kindern gemeinsam abzuholen. Eine solche Regelung, wonach Familien gemeinsam zu erscheinen hätten, macht verständlich, dass mit großen Menschenmassen gerechnet wurde, weswegen die Verteilung an mehreren Orten und zu unterschiedlichen Zeitpunkten eingerichtet wurde. Außerdem ist gut denkbar, dass die Frauen beim Abholen der suffimenta ihre Männer begleiten mussten, da nach den Angaben des Orakels Frauen die reinigenden Maß-

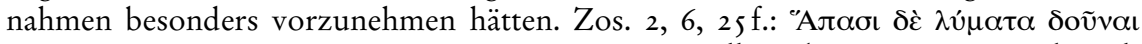

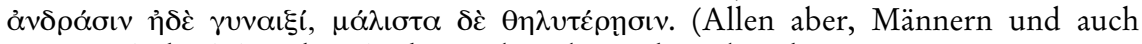
Frauen, sind reinigende Mittel zu geben, besonders aber den Frauen).

I63 Siehe Z. 68; dort wird davon ausgegangen, dass die Teilnehmer SVFFITIQVE AD LVDOS VENIRE[nt, was bedeutet, dass die Aktion zu Hause stattgefunden hatte.

I64 AB 8.

I65 Kolb (1995) 357 .

I66 Erhalten ist die Einleitungsformel für Senatsbeschlüsse in AB 6 und Z. 58 . 
Z. 50 und 5 I genannten Zeugen sinnvoll. Drei von ihnen sind mit ihren Namen erhalten, es dürften mehr gewesen sein, die möglicherweise noch in Z. 50 verzeichnet waren. ${ }^{67}$ Der erstgenannte Q. Aemilius Lepidus wird von Mommsen mit Vorbehalten als der in Z. i 50 erwähnte Quindecimvir identifiziert, Konsul des Jahres 2I v. Chr. ${ }^{168}$ Die beiden folgenden Zeugen L. Cestius und L. Petronius Rufus waren Senatoren, die außer der Erwähnung an dieser Stelle nicht bekannt sind.

52-57 Zuerst wird der Verhandlungsleiter, der Konsul des Jahres I7 v. Chr., C. Silanus, genannt. Hinsichtlich des Inhalts der folgenden Zeilen bestehen keine Unsicherheiten, weil dieser durch eine formale Analyse rekonstruierbar ist. Die wichtigsten Ergänzungen wurden auf diese Weise bereits von Mommsen vorgenommen. Sein leitender Gedanke war die Tatsache, dass jeder Senatsbeschluss sein Thema zweimal nennt: einmal in der relatio des Verhandlungsleiters, wo es eingeleitet mit $v(e r b a) f(e c i t)$ ecerunt) vorgetragen wird, und zum zweiten Mal im eigentlichen Beschluss, eingeleitet mit der Formel $q($ uid) $d(e) e(a) r(e) f($ ieri) $p$ (laceret) $d(e) e(a) r(e) i(t a) c\left(\right.$ ensuerunt). ${ }^{169}$ In diesem Fragment liegt in Z. $52-55$ die relatio vor. Die nicht wörtliche, aber inhaltliche Wiederholung gewisser Satzelemente zeigt, dass ab Z. 56 der eigentliche Senatsbeschluss beginnt. ${ }^{100}$ Demnach ist davon auszugehen, dass sich am Ende von Z. 55 die oben erwähnte Einleitungsformel zum Beschluss befunden haben muss. Die relatio des Senatsbeschlusses ist etwa zwei Zeilen länger als der Beschluss selbst, weil die Zeilen $52 \mathrm{f}$. zusätzlich Augustus und Agrippa als Initianten der Säkularfeier aufgrund ihrer tribunicia potestas enthalten. ${ }^{171}$ Daneben ist wohl auch auf die Seltenheit des Anlasses eingegangen worden. ${ }^{172}$ Der in Z. 53 eingeleitete, sich auf $l u d o s$ beziehende Relativsatz muss unklar bleiben, ebenso wie die Frage, ob die Angaben von Z. 54 syntaktisch zu ihm gehören. Inhaltlich hat Mommsen in Z. 53 einen Hin-

I67 Vgl. oben zu AB 6-10, S. $77 \mathrm{f}$.

i68 Mommsen (I89) 240f. ( 583 f.); Pighi (I94I) i I ; Mommsen spricht nur die Vermutung aus, dass der hier genannte Aemilius Lepidus identisch mit dem Quindecimvir sein könnte; er wagt nicht, eine entsprechende Ergänzung in Z. 50 vorzunehmen. Diese findet sich erst bei Pighi. Zu Aemilius Lepidus vgl. Kap. A.8, S. 222.

I69 O’Brien Moore, RE Suppl. VI (I935) Sp. 800-8 I 2 s. v. senatus consultum.

I70 Eine Übersicht über die Übereinstimmungen von relatio und consultum enthält der Kommentar zur Textkonstitution zu Z. 52-57, S. 54.

I7 I Augustus hatte die tribunicia potestas seit dem 26. Juni 23 v. Chr. ununterbrochen bis zu seinem Tode inne; Agrippa zum ersten Mal seit dem I. Juli (oder 26. Juni) I 8 v. Chr.; Kienast/Eck/Heil (2017) 65. Vgl. oben zu AB I, S. 7I.

I72 Eine Erwähnung der Seltenheit (vielleicht sogar mit Angabe des I ıо-jährigen Abstandes zwischen den Feiern in Z. 52) ist deshalb zu erwarten, weil sonst der in Z. 56 erwähnte Umstand, dass jeder Mensch eine solche Feier nur einmal im Leben sehen kann, unverständlich bleibt. 
weis darauf vermisst, dass möglichst viele Menschen bei dieser Feier dabei sein sollen; dieser Zusammenhang entstand für ihn wahrscheinlich als Begründung für die Aufhebung einer der Sanktionen der lex Iulia de maritandis ordinibus, weswegen er in einem mit quod eingeleiteten Kausalsatz eine entsprechende Ergänzung vornahm. Das etiam quod von Z. 54 macht eine vorangehende erste Begründung wahrscheinlich.

Die Erwähnung der tribunicia potestas von Augustus und Agrippa beim Senatsbeschluss zu künftigen Säkularspielen zeigt, dass diese Spiele von Staates wegen veranstaltet wurden. Augustus und Agrippa haben an den Spielen selbst eine herausragende Rolle als opfernde Quindecimviri gespielt, die Spiele wurden aber vom Senat beschlossen, weil Augustus und Agrippa aufgrund ihrer tribunicia potestas die Macht hatten, den Senat dazu zu veranlassen. ${ }^{173}$ In Z. 52 wurde vielleicht mit POST COMPLVR[a portenta auf mögliche Vorzeichen hingewiesen, die eine Konsultation der sibyllinischen Bücher veranlasst haben und als Ausgangspunkt der Planungen für die Säkularspiele gelten können. ${ }^{174}$

Sowohl relatio wie auch consultum enthalten zwei Ebenen, zum einen die in beiden Formulierungen an erster Stelle genannte Begründungsebene, zum anderen die daraus entstehenden Folgen. Die Begründungsebene enthält die zwei Elemente, die - wie schon erwähnt - in der relatio mit quod eingeleitet sind. Dieselben zwei Begründungselemente enthält auch das folgende consultum. Es handelt sich um die Hinweise auf den hohen Stellenwert dieses religiösen Anlasses (Z. 54: PROPTER RE[ligione]M; Z. 56: RELIGIO[nis] CAVSA) und auf die Seltenheit dieses Anlasses (Z. 55: NEQVE VLTRA QVAM SEMEL VLLI MO(rtalium). Dieser zweite Teil der Begründung ist in der relatio zum größten Teil verloren gegangen und fand sich im zweiten Teil von Z. 54. Auch wenn wir nicht den genauen Wortlaut der verlorenen Zeilenenden kennen, können wir durch solche strukturellen Überlegungen den Inhalt genau bestimmen. Aufgrund von dieser Art Überlegungen ist den bisherigen Ergänzungen von Z. 53 nicht zuzustimmen. Es war nicht der Wunsch der Organisatoren, möglichst viele Menschen an der Säkularfeier anzutreffen, sondern eher, den Unverheirateten den Zugang zu einem so wichtigen religiösen Anlass nicht zu verwehren. Dazu gehört auch der Hinweis, dass jeder Mensch höchstens einmal in seinem Leben eine Säkularfeier erleben

I73 Ferrary (200I) I 23f. sieht in der Erwähnung der tribunicia potestas von Augustus und Agrippa in dem Senatsbeschluss zur Planung der Säkularspiele ihre außerordentliche Bedeutung, betont aber, dass die Teilnahme von Augustus und Agrippa an den Säkularspielen nur in ihrer Funktion als Quindecimviri bestand.

I74 Satterfield (20I6) analysiert bei Iulius Obsequens (7I) überlieferte portenta vor den ludi saeculares und stellt einen Zusammenhang zwischen der Befragung der sibyllinischen Bücher und der anschließenden Planung der Säkularspiele her. 
kann. Die hier erwähnte lex de maritandis ordinibus verfügte eine Ehepflicht für Männer im Alter von 25 bis 60 Jahren, für Frauen von 20 bis so Jahren. Eine solche Ehepflicht bestand auch nach einer Scheidung oder dem Tod des Ehepartners. Ehelosigkeit wurde mit Sanktionen geahndet, wovon der Ausschluss von Theaterveranstaltungen und Spielen nur eine war. Der unter dem Begriff >Ehegesetze< zusammengefasste Gesetzeskomplex war ein wichtiger Bestandteil der augusteischen Politik und wurde von Augustus zeit seines Lebens verfolgt. ${ }^{175}$ Die Teilnahme der Unverheirateten an den Riten der Säkularfeier war deshalb wichtig, weil es in diesen Riten um die Zukunft des römischen Staates und den Erhalt der Bevölkerung ging. Gerade die Unverheirateten als mögliche künftige Erzeuger von Nachkommen konnten deshalb aus religiösen Gründen nicht ausgeschlossen werden. Ein Ausschluss der Unverheirateten von der Feier hätte die Ehegesetze zusätzlich der Autorität berauben können, weil damit den Unverheirateten ein neues Argument gegeben worden wäre: Aufgrund ihrer Unerwünschtheit an den Riten der Säkularfeier hätten sie keinen Grund, einen Beitrag für den Erhalt des populus Romanus zu leisten. Auf religiöse Gründe verweist die Inschrift selbst sowohl in relatio wie in consultum mit dem erhaltenen Hinweis propter religionem, beziehungsweise religionis causa. Damit verbunden waren aber auch politische Interessen, hinter denen die Befürchtung stand, dass ein Ausschluss der Unverheirateten zu einer Desavouierung der gerade erst erlassenen Gesetze führen konnte. Es kann also trotz der Aufhebung der Sanktionen nicht von einer Aufweichung der Ehegesetze gesprochen werden, sondern man muss davon ausgehen, dass die Aufhebung der Sanktionen als religiöse Notwendigkeit empfunden wurde. Ob für die ludi bonorarii, die nach der Säkularfeier vom 5. bis zum I I. Juni stattfanden, diese Ausnahmeregelung weiterbestand, ist nicht klar, denn weder für die Aufhebung der Sanktion in diesem Senatsbeschluss wird das Datum einer Geltungsdauer genannt, noch wird in dem Edikt, welches die ludi honorarii anordnet, nochmals etwas über eine Aufhebung gesagt. ${ }^{176}$ Überliefert ist eine weitere Ausnahmeregelung aus dem Jahr I 2 v. Chr., welche den caelibes erlaubte, an öffentlichen Gastmahlen aus Anlass der Geburtstagsfeierlichkeiten für Augustus teilzunehmen. ${ }^{177}$ Mit diesem Zugeständnis an die Unverheirateten ging die Erwartung einher, dass sie das aus religiösen Gründen erhaltene Zugeständnis nicht in irgendeiner Weise ausnutzen. Darauf spielt die Formel sine frande sua (Z. 55 relatio; Z. 57 consultum) an. Es wurde also von den Unverheirateten im Gegenzug

I75 Kienast (2014) I 16 und I65ff.

I76 Z. I 55 ff.

I77 Baltrusch (1989) I63f. mit Quellen. 
erwartet, dass ihre Teilnahme an den Riten keinen anderen Grund hatte, als einen Beitrag zum Erhalt des populus Romanus zu leisten. Dieser religiöse Hintergrund wurde in allen bisherigen Interpretationen des Senatsbeschlusses vernachlässigt. Grund dafür war das Nichternstnehmen oder Übersehen solcher Formulierungen wie propter religionem.

58 Diese Zeile leitet den zweiten Teil des Senatsbeschlusses ein, der am selben Tag gefasst wurde. Die Zeile war nicht vollständig ausgefüllt, ${ }^{178} \mathrm{ihr}$ gesamter Wortlaut ist erhalten. Das einleitende senatus consultum factum est ist auch im Senatsbeschluss von AB 6 erhalten, und es scheint wie die entsprechende Formel bei Edikten jedem Senatsbeschluss in dieser Inschrift vorangestellt zu sein. ${ }^{179}$ Die nötigen Angaben von Datum, Ort und Zeugen sind als Wiederholungen in abgekürzter Form wiedergegeben.

59-63 Dieser zweite Senatsbeschluss regelt die Dokumentation der Säkularfeier, indem er festlegt, dass eine marmorne und eine eherne Inschrift (columna) an dem Ort aufgestellt werden sollen, an welchem die Säkularfeier stattgefunden hat. Auf diesen Inschriften sollte ein commentarium (Z. 62) der Spiele verzeichnet sein. Wie in dem vorangegangenen Senatsbeschluss führt auch hier eine formale Analyse zu Ergänzungsmöglichkeiten. ${ }^{180}$ Durch die erhaltene Beschlussformel zerfällt dieser Senatsbeschluss eindeutig in relatio und consultum. Erhalten sind in der relatio Angaben über den Zweck einer solchen Dokumentation (Z. 59: PE[rti]NERE AD CONSERVANDAM MEMORIAM TANTAE R[eligionis $\cdots$ ), weiter werden die Marmor- und Bronzesäule erwähnt, auf welche ein commentarium eingetragen werden soll (Z. 59f.: [commentarium ludorum] $\mid S A E$ CVLARIVM IN COLVM[n]AM AHENEAM ET MARMOREAM IN$S C R I B I \cdots)$ und Angaben über den Ort, an welchem diese Säulen, beziehungsweise Inschriften, aufgestellt werden sollten (Z. 6of.: ST[atui .. EO LOCO VBI LVDI FVTV[ri s]INT). Dieselben Angaben hat der folgende Beschluss enthalten. Die Bestimmungen über die zu errichtenden Inschriften sind in eine Art Ermächtigung gefasst, dass ein Konsul oder beide (Z. 6r: VTI CO $(n) S(u l)$ A(lter) A(mbo)VE ) die nötigen Maßnahmen veranlassen sollen. Dabei sind die Angaben über den Zweck der Dokumentation verstümmelt, weswegen man in Anlehnung an Z. 59 mit Mommsen in Z. 6I folgendermaßen ergänzen kann: AD F[uturam memoriam tantae religionis ...]. Die Konsuln sollten den Prätoren, die dem Staatsschatz vorstehen, befehlen, den Handwerkern die nötige Summe auszuzahlen (Z.63: PRAETORIBVSQVE Q(ui) [a(erario)] P(raesunt)

I78 Die darauffolgende Z. 59 beginnt nämlich mit einem links vorgezogenen Rand.

I79 Vgl. oben zu Z. 50; von diesem übergeordneten senatus consultum factum est ist syntaktisch der quod-Satz abhängig, in dem die Senatsbeschlüsse referiert werden.

I 80 Eine Übersicht über die Übereinstimmungen von relatio und consultum enthält der Kommentar zur Textkonstitution zu Z. 59-63, S. 56f. 
INPERENT VTI REDEMPTORIBVS EA[m pecuniam dandam adtribuendam curent].

Dieser zweite Teil des Senatsbeschlusses hat wegen unterschiedlicher Lesarten und Ergänzungen schon früher Anlass zu Diskussionen gegeben. Es ist interessant, dass es sich auch in diesem Fall um religionsgeschichtliche Fehleinschätzungen handelt. ${ }^{181}$ Die Lesart und Ergänzung von Z. 59 durch Cavallaro zu R[eligionis $\cdots$ ] erhält zusätzlich eine Bestätigung durch den ersten Senatsbeschluss, wo ausdrücklich darauf hingewiesen wird, dass die Säkularfeier propter religionem beziehungsweise causa religionis veranstaltet wird. ${ }^{182}$ Damit wird möglicherweise auf eine alte rituelle Einrichtung der Säkularspiele eingegangen: Beide Darstellungen des Ursprungsmythos der Säkularspiele enthalten als wichtiges Element die Inschrift. Als Valesius' Arbeiter bei den Ausschachtungsarbeiten für den Altar für Dis und Proserpina auf einen bereits vorhandenen Altar stoßen, entdecken sie auf diesem Altar eine Inschrift, die diesen als Altar dieser Götter ausweist. ${ }^{1{ }^{8} 3}$ Zosimus schildert zusätzlich, dass damit Valesius besser unterrichtet worden ist, was er zu tun hatte. ${ }^{184}$ Poplicola, der Ausrichter der Spiele, die als erste in der Reihe der Säkularspiele überliefert sind, ließ nach den Opfern eine Inschrift auf diesem Altar anbringen, die ihn als Opferer, die mit Opfern bedachten Götter und die rituellen Handlungen, die ausgeführt wurden, aufzählt. ${ }^{185}$ Damit gibt uns der Mythos einen Hinweis, dass das Aufstellen einer Inschrift mit Angaben über die ausgeführten Riten zum Wesen der Spiele gehörte, die später als Säkularspiele verstanden worden sind. Eine solche Dokumentation der Riten leuchtet auch ein, wenn der Abstand zwischen zwei Feiern i Io Jahre, oder wie es in der etruskischen Säkulartheorie formuliert ist, so groß sein musste, dass niemand mehr lebte, der bei der letzten Feier schon am Leben war. Es

I8 I Dazu gehört die von Cavallaro (I979) 68ff. verbesserte Ergänzung Mommsens, die im Kommentar zur Textkritik besprochen ist, S. $56 \mathrm{f}$.

I 82 Z. 54 und 56; auch die severische Inschrift enthält diese Begründung für den Anlass der Säkularfeier: Act. Sev. 30.

I 83 Zos. 2, 2, 4; Val. Max. 2, 4, 5.

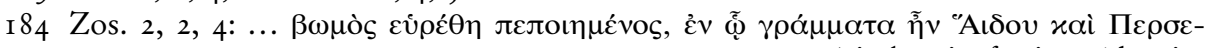

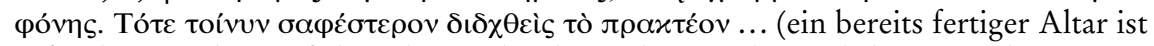
gefunden worden, auf dem die Buchstaben »dem Hades und der Persephone« eingemeißelt waren. Da war Valesius besser darüber unterrichtet, was er zu tun hatte).

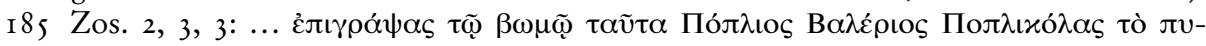


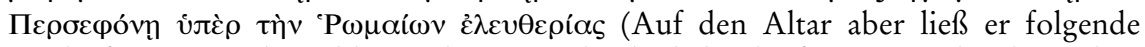
Inschrift setzen: Ich, Publius Valerius Poplicola, habe die feuerspeiende Ebene dem Hades und der Persephone geweiht und dem Hades und der Persephone zu Ehren Prozessionen für die Befreiung der Römer durchgeführt.) Valerius Maximus (2, 4, 5) dagegen erwähnt nur, dass Poplicola die Opfer an dem Altar ausrichtete, den Valesius gefunden hatte, und diesen anschließend wieder im Erdreich begrub. 
gehörte offensichtlich zum Wesen von Säkularfeiern, dass das Wissen über die an einer Feier auszuführenden Riten durch eine Inschrift übermittelt wurde, wie es im Ursprungsmythos Valesius erfahren hatte. Mit dem Beschluss der Aufstellung einer Inschrift scheint die augusteische Feier auf einen alten Ritus zurückgegriffen zu haben, der wahrscheinlich verloren gegangen war, aber doch durch den Mythos mit der Säkularfeier verbunden war. Dass die inschriftliche Fixierung von großer Bedeutung war, geht auch aus einigen Münzabbildungen hervor (siehe Anhang, Abb. 3, 6, 7 und 19). Auf allen drei erhaltenen Serien zu Säkularspielen ist eine Inschrift abgebildet.

Da auf den Münzabbildungen der Säkularspiele nur rituelle Handlungen wiedergegeben werden, ist auch das Aufstellen der Inschrift als solche zu verstehen. Die inschriftliche Dokumentation der Riten hatte einen religiösen Sinn. Welche Wichtigkeit diesem Element der Riten beigemessen wurde, kann vielleicht aus der Tatsache ermessen werden, dass dieses das einzige rituelle Element ist, das auf den Münzprägungen aller drei kaiserzeitlichen Säkularspiele vorhanden ist. ${ }^{186}$

Wir müssen also bei der Interpretation von den Formulierungen propter religionem und religionis causa in den Senatsbeschlüssen davon ausgehen, dass damit auf rituelle Elemente hingewiesen wurde, über die wir keine direkten Informationen mehr haben und die eventuell nur noch über eine Interpretation des Mythos zu erschließen sind. Mit diesen Formulierungen scheint gemeint gewesen zu sein, dass eine Handlung, die propter religionem ausgeführt wurde, ihren Ursprung in einer anderen Form der Überlieferung hatte als dem mos maiorum. Sie hatte ihren Ursprung in einem ursprünglich religiösen Akt, dessen Überlieferung durch einen Mythos stattfand. Es ist interessant, dass es im zweiten Senatsbeschluss um die MEMORIA TANTAE R[eligionis ...] geht, ebenso in der severischen Inschrift bei der inschriftlichen Fixierung um die MEMORIA TANTAE RELIGIONIS. ${ }^{187}$ Religio scheint hier die Verbundenheit mit etwas zu meinen, was im Mythos ausgedrückt wird, also das zu befolgen und inschriftlich weiterzugeben, was der Mythos vorgibt. Obwohl der Mythos der Säkularspiele in keiner zeitgenössischen Quelle der Spiele überhaupt nur erwähnt ist, scheint er an der Feier selbst eine Rolle gespielt zu haben, die aus dem inschriftlichen Text des commentarium nicht hervorgeht. Es ist in den Inschriften der Säkularspiele nirgends erwähnt, dass die Opfer oder die rituellen Reinigungen religionis causa durchgeführt worden seien. ${ }^{188}$ Damit sind offenbar nur Handlungen gemeint, die

I 86 Vgl. Kap. A.6, S. I94f.

I87 Act. Sev. 30.

I 88 Weder Inschrift noch Orakel erwähnen den Mythos. Dennoch ist es unerlässlich, 
als Riten ausschließlich mit der Säkularfeier verbunden waren und zur besonderen Prägung dieser Feier gehörten.

Durch diesen zweiten Senatsbeschluss vervollständigt sich unser Wissen um die Topografie des Anlasses. Die beiden Säulen sollten dort aufgestellt werden, wo die Spiele stattfinden würden (Z.6r ff.). Der Fundort von I 890 am nordwestlichen Ende des Corso Vittorio Emanuele befindet sich in dem Gebiet, das in Rom mit Tarentum bezeichnet wurde und gemäß aller Quellen als Austragungsort der Säkularfeier eine Rolle spielte.

64-89 Mit einer auffälligen Einrückung des Textes um sechs Buchstaben beginnt ein längerer Abschnitt, dessen Zuordnung wegen des fragmentarischen Zustands des Textes nicht immer eindeutig vorgenommen werden kann. So glaubte Mommsen, in dem vorliegenden Textstück, welches wie die vorher aufgezeichneten Dokumente Vorbereitungen vor dem eigentlichen Fest regelt, Elemente zu erkennen, die protokollarisch die Ausführung dieser Vorbereitungen wiedergeben. ${ }^{189}$ Damit kam er jedoch zu einer Einteilung dieses Abschnitts, die mit der bisher beobachteten strengen formalen und funktionalen Gliederung des Textes nicht zu vereinbaren ist. Aus dem bisherigen Ablauf der Inschrift zeigt sich, dass sie in ihrem ersten Teil amtliche und priesterliche Entscheide wiedergibt, welche die Säkularfeier betreffen. Es handelt sich dabei wahrscheinlich um eine Veröffentlichung der Schriftstücke, die vor der Feier die unterschiedlichen Phasen der Planung festhielten. Diese Schriftstücke wurden im Archiv der Quindecimviri aufbewahrt. ${ }^{190}$ Eine Unterbrechung des Edikts und seine stillschweigende Fortsetzung nach der Schilderung einer bestimmten Handlung entsprechen nicht der bisherigen Aufzeichnungspraxis der Inschrift. Im bisherigen Text wurde jedes neue oder fortgesetzte Dokument

dass die Geschichte als solche, welche die Verbundenheit der Feier mit dem Ort der Feier am nördlichen Tiberufer erklärte, in irgendeiner Weise den Teilnehmern der Feier vorgeführt wurde. Am besten kann man sich eine Vermittlung des Mythos über die anschließend an die Opfer aufgeführten ludi Latini vorstellen. Vgl. S. I 35 f.

I 89 Mommsen (I 89I) 249ff. ( $593 \mathrm{ff}$.) teilte die Zeilen folgendermaßen ein: 64-75 Edikt; 76 ohne Angabe; 77 acta (das heißt protokollarische Aufzeichnung); 78-8I Edikt; 82 acta; 83-85 Ansage der Spiele; 86-88 ohne Angabe; 89 acta. Dasselbe Problem stellte sich auch bei Pighi (194I) I I f.: Pighi erkannte dem größten Teil des Abschnitts den Status eines Edikts zu, konnte aber Z. 76 und 89 nicht eindeutig zuordnen. Vgl. Kommentar zur Textkonstitution Z. 77, S. 58 f. und Z. 82, S. 60.

I 90 Sini (1983) I 5 ff. über die Art der Akten, die in den Archiven der Priesterschaften aufbewahrt wurden. Scheid (1994) I76ff. wendet sich gegen die Vorstellung (u. a. Nordens), dass die Priesterbücher einen normativen Ritualtext enthielten, eine Art Sakralcodex. Er geht davon aus, dass die Priesterbücher der Quindecimviri neben Dokumenten, die die Verwaltung des sibyllinischen Orakels betrafen, die Dokumente über die Organisation der ludi saeculares enthielten, die in der Inschrift vollständig transkribiert sind. 
mit einer Datumsangabe eingeführt und als Dokument kennlich gemacht. ${ }^{191}$ Eine solche Datumsangabe, die sich auf ein Dokument bezieht, ist zwischen Z. 64 und 89 nicht mehr zu erkennen. ${ }^{192}$ Die in Z. 77, 82 und 89 gemachten Datumsangaben beziehen sich nicht auf ein Dokument, sondern nennen bestimmte Handlungen für bestimmte Tage. Diese strenge Einteilung nach den angegebenen Daten lässt sich nicht nur im ersten Teil der Inschrift beobachten, sondern auch im rein protokollarischen zweiten Teil, der die einzelnen Aktionen der Feier immer mit einer Datumsangabe am Anfang der Zeile einführt. ${ }^{193}$ Möglicherweise hat eine bereits hier absehbare Knappheit an beschreibbarer Fläche zu gewissen Änderungen der Redaktionsprinzipien geführt.

Der protokollarische zweite Teil enthält mehrere Verweise auf vorher erlassene Vorschriften, auf die mit quibus denuntiatum erat Bezug genommen wird. ${ }^{194}$ Entsprechende Vorschriften müssen in diesem Textabschnitt enthalten gewesen sein, es lässt sich aber nicht eindeutig bestimmen ob in Form eines Edikts oder Dekrets.

64 Das Edikt wurde einen Tag nach dem vorangegangenen Senatsbeschluss am 24. Mai erlassen, das bedeutet zwei Tage vor dem Beginn der vorbereitenden rituellen Handlungen. ${ }^{195}$ Damit bleibt genug Zeit, um die im Edikt bestimmten Anordnungen auf Tafeln überall zu verbreiten oder durch einen Herold ausrufen zu lassen.

65-70 Das erste Wort des Edikts bestätigt, dass es sich hier um die Vermittlung der wichtigsten organisatorischen Bestimmungen handelt. Im ersten Abschnitt geht es um die Verteilung der suffimenta. Wir erfahren, dass alle freien Bürger suffimenta holen sollten, wahrscheinlich in beschränktem $\mathrm{Maß}$, das heißt nur einmal. ${ }^{196}$ Vielleicht wird an dieser Stelle vorgeschrieben, dass die Ehefrauen beim Abholen der Reinigungsmittel ebenfalls eine besondere Funktion hatten (Z. 66: coningesque). Eine solche besondere Aufgabe der Frauen ist sogar sehr wahrscheinlich, weil das Orakel die Abgabe von suffimenta an Frauen ausdrücklich vorgibt. ${ }^{197}$ Der weitere Text enthielt als wichtigste Information wohl die Daten (Z. 67), wann die Bevölkerung diese suffimenta in Empfang nehmen konnte. Der einzige

I9I Z. 24; 29; 46; 50; 64; vgl. Kommentar zu Z. 82, S. I I 5.

I92 Davon kann man mit großer Sicherheit ausgehen, weil die Datumsangaben sich immer am linken Rand einer Zeile befinden und dieser gut erhalten ist.

I93 Z. 90; I03; II5; I19; I34; I39.

I94 Z. Iо I (quibus denuntiatum erat XVvirorum verbis) sellisternia; I 23 supplicatio; I 47 carmen saeculare.

I95 Vgl. Z. 67; ab dem 26. Mai konnten suffimenta abgeholt werden.

I96 Zu der Ergänzung [se]mel von Z.66 siehe den Kommentar zur Textkonstitution. [se]mel ergibt sich in meiner Lesart und scheint nach ne amplius quam sinnvoll, da eine quantifizierende Angabe zu erwarten ist.

I 97 Zos. 2, 6, 25 f. Vgl. S. I02, Anm. I62. 
hier lesbare Ort, vor dem Tempel des Iuppiter Optimus Maximus, wird neben anderen Orten auch im Dekret der Quindecimviri von Z. 30 genannt. Dieses Edikt wird die im Dekret genannten Orte nicht gesamthaft noch einmal wiederholt haben, weil der verbleibende Raum in Z. 69 dafür nicht ausreichen würde. Deshalb wird hier eher eine zusätzliche Angabe zu der Verteilstelle auf dem Kapitol gemacht worden sein. Die Tatsache, dass man nicht mehr als einmal suffimenta erhielt, deutet auf einen gewissen Andrang der Bevölkerung hin, sich reichlich mit suffimenta zu versorgen. Auch die Errichtung von Podesten (Z. 69) scheint eine Reaktion auf die Bewältigung großer Menschenmassen zu sein. ${ }^{198}$

Bereits in Z. 48 war in Form eines Edikts von der Verteilung der suffimenta die Rede gewesen. Dort war als Datum für die Verteilung der 28. Mai angegeben. In diesem Edikt sind dagegen drei Tage (26., 27. und 28. Mai) dafür vorgesehen. Das Edikt von Z. 48 ist im Anschluss an das Dekret vom 25. März (Z. 29-45) erwähnt und wurde an demselben Tag erlassen wie der zweite Teil des vorangehenden Dekrets - also am 25. März (Z. 37). Wahrscheinlich hat zu diesem Zeitpunkt - zwei Monate vor der Feier - noch niemand eine detaillierte Planung vornehmen können, und es war im Edikt vom 25. März ein einziger Tag für die Verteilung der suffimenta vorgesehen (Z. 48) - nämlich der 28. Mai. Somit scheint die Bestimmung des vorliegenden Edikts eine Revision oder Erweiterung dieses früheren Edikts zu sein, insofern als eine Verteilung der suffimenta hier für drei Tage auf die beiden vorangehenden Tage erweitert wird. Die Zeilen 69 und 70 beziehen sich mit großer Wahrscheinlichkeit auf Bestimmungen zur acceptio frugum, da beide Handlungen immer zusammen genannt sind und das Verb conferre in Z. 69 dazu passt. ${ }^{199}$ Nach Zosimus setzten sich die fruges aus Weizen, Gerste und Saubohnen zusammen, die wahrscheinlich getrennt (generatim) in die drei vor dem Podest stehen Körbe ausgeleert wurden. ${ }^{200}$ Auch hier scheinen die Angaben des Dekrets vom 25. März (Z. 29-45) erweitert worden zu sein.

7If. Diese zwei Zeilen betreffen die sellisternia der Frauen. Das quoque schließt vielleicht an das Vorangegangene an, wo ebenfalls Frauen in die Bestimmungen aufgenommen waren (Z. 66: coninges). Das Wort sternere

I98 Die Ergänzung TRI/bunalia von Mommsen ist nach Z. 34 vorgenommen. Weil dort die tribunalia in Zusammenhang mit der acceptio frugum erwähnt sind, könnte auch hier angenommen werden, es ginge im Weiteren um diesen Teil der Vorbereitungen. Da die acceptio frugum aber später im Dekret (Z. 82, 89) erwähnt ist, können die tribunalia - vielleicht dieselben wie bei der acceptio - hier durchaus in Zusammenhang mit der Verteilung der suffimenta erwähnt sein. Auch Münzabbildungen zeigen für beide Akte gleiche Podeste, vgl. Anhang, Abb. 2, 8, 9a und 9b.

I99 Vgl. oben zu Z. 46-49, S. Iо If.

200 Vgl. oben zu Z. 7-I I, S. 85, Anm. 84. 
kann im Zusammenhang mit sellisternia nur das Ausbreiten von Decken und Tüchern meinen, mit denen die Sitze für die Göttinnen ausgestattet wurden. ${ }^{201}$

73-75 Diese drei Zeilen bieten wegen des verstümmelten Textes kaum Angaben über die hier angeordnete Aktion. Als Beteiligte sind Frauen und Knaben genannt, in welcher Weise, geht jedoch aus dem Text nicht hervor. ${ }^{202} \mathrm{Da}$ sonst pueri immer nur in Zusammenhang mit puellae als Teilnehmer des Chores auftreten, muss man vermuten, dass die Mädchen im Folgenden auch erwähnt waren. ${ }^{203}$ Es ist fraglich, ob eine weitere Knabengruppe mit einem lusus Troiae an der augusteischen Säkularfeier eine Rolle spielte. Seltsam ist die Verwendung des Wortes feminae für Frauen, die sonst in der Inschrift nie mit dieser rein biologischen Bezeichnung ihres Geschlechts auftreten, sondern entweder allgemein als mulieres, als matronae oder matres familiae. ${ }^{204}$ Die Verwendung von feminae gibt keinen Hinweis auf die Bedeutung dieser Zeilen. Bei allen anderen verstümmelten Textstellen erhält der Text durch die Erwähnung derselben Aktion an einer anderen Stelle in der Inschrift einen Sinn. Auf der Suche nach solchen parallelen Textstellen fallen für die Zeilen 73-75 die Zeilen ı० I und I 47 auf. In Z. Iо I geht es um die I I० Matronen, die am sellisternium der ersten Nacht teilnehmen. Sie werden erwähnt als $C X$ matronae quibus denuntiatum erat XVirum verbis. In Z. I 47 geht es um die $27 \mathrm{Kna}-$ ben und ebenso viele Mädchen, die für den Chor ausgewählt waren pueri [x]XVII quibus denuntiatum erat patrimi et matrimi et puellae totidem. Der Zusatz quibus denuntiatum erat bezieht sich wahrscheinlich in beiden Fällen auf den verstümmelten Teil dieses Edikts der Quindecimviri, denn denuntiare wird als terminus technicus für das Verkünden von Edikten gebraucht. ${ }^{205}$ Die Zeilen 73-75 könnten somit Angaben über die Frauen und Kinder enthalten, die als Teilnehmerinnen der sellisternia und Chormitglieder eine besondere Rolle spielten. Ihrer Sonderstellung scheint schon vor der Feier durch eine gemeinsame Handlung, die sie gesondert von den übrigen Bürgern (Z. 74: separatim) vollzogen, Ausdruck verliehen zu sein. Z. 75 mit der Erwähnung der Göttin Ops weist diese Aktion in einen sakralen Zusammenhang, das Verb positum erit

20 I Serv. ad Aen. 1,702: Antiqui stratis tribus lectis epulabantur: unde et triclinium sterni edicitur.

202 Es handelt sich möglicherweise um einen indirekten Fragesatz, auch die in Z. 74 erhaltene Verbendung ]RENT deutet auf einen Konjunktiv hin.

203 Z. 3; 20; 2 I; $147 \mathrm{ff}$.

204 mulieres Z. 7I; matronas Z. 78; I0I; matres familiae Z. 80; I09; I 23.

205 Darauf verweist der Sprachgebrauch in der Inschrift selbst. Im Edikt der Quindecimviri zur Unterlassung der Trauer der Matronen heißt es: statuimus offici nostri esse per edictum denuntiare feminis (Z. I I 3 f.). 
deutet darauf hin, dass diese Gruppe am Opstempel auf dem Kapitol etwas abzulegen hatte. Das bisher bekannte Wissen über die Göttin Ops ist zu gering, als dass wir diese Handlung näher bestimmen könnten. Sie scheint eine Funktion als Erntegottheit gehabt zu haben, ihr Kult wurde schon in frühester Zeit vom Pontifex Maximus und den Vestalinnen im Verborgenen ausgeübt. Bereits in der Zeit der Republik, im Jahre I86 v. Chr., erhielt die Göttin Ops einen Tempel auf dem Kapitol, etwa 60 Jahre später einen zweiten auf dem Forum. ${ }^{206}$ Dass Ops auch in augusteischer und späterer Zeit noch verehrt wurde, belegen neben dieser Stelle ein Altar der Ops Augusta und etliche Weihinschriften. ${ }^{207}$

Der Inhalt der Zeilen 73-75 bleibt also weiterhin im Dunkeln, abschlieBend lässt sich nur konstatieren, dass sich diese Zeilen wahrscheinlich an die Teilnehmerinnen der sellisternia wenden und an die Kinder der Chöre. Es geht nicht um ein Auswahlverfahren, denn dieses hätte zumindest für den Chor schon viel früher stattfinden müssen, da eine knappe Woche für die Einstudierung des Chores zu wenig Zeit bietet. Eher geht es um einen rituellen Akt vor der Säkularfeier, der in Beziehung zu einer zwar alten, aber an der Säkularfeier sonst nicht beteiligten Göttin steht.

In dieser Zeile wird noch einmal (VT ERAT CONSTITVTV[m) auf die suffimenta eingegangen. Da die folgende Zeile aber wieder mit einem vorgezogenen Rand beginnt und somit etwas Neues einleitet, kann es sich nur um eine kurze zusätzliche Bestimmung handeln. Die Bestimmungen $\mathrm{zu}$ der Verteilung der suffimenta waren schon einmal revidiert worden (Z. 65-67), durch eine zusätzliche Anordnung hat der komplizierte Prozess der Verteilung hier möglicherweise eine weitere Zusatzbestimmung oder Revision erfahren. Die Funktion dieser Zeile als protokollarische Schilderung oder als Teil des Edikts bleibt unklar. ${ }^{208}$

77 Diese Zeile enthält eine kurze Bestimmung an eine Gruppe, die schon vorher in einem Edikt angesprochen war (quibus edictum erat). Die beschriebene Handlung ist für den 29. Mai vorgesehen. Aus dem folgenden Text (Z. 89) geht hervor, dass für den 29., 30. und 3r. Mai die acceptio

206 Zu Ops: Wissowa (I9I 2) 203 f.; Latte (I960) I 29; Kolb (I995) 8I; der Tempel auf dem Kapitol ist bei Liv. 39, 22, 4 belegt. Macr. Sat. 3, 9, 4: Macrobius erwähnt, dass die Opfer für Ops heimlich dargebracht werden mussten, weil sie die geheime Schutzgöttin Roms war, deren Name nicht verraten werden durfte, um vor einer evocatio sicher zu sein. Wissowa (I9I2) 338 glaubt, dass das in späterer Zeit betriebene Rätselraten um den angeblich geheimen Schutzgott oder -göttin Roms nicht viel mit der tatsächlich ausgeübten Religion zu tun habe, sondern eher mit »Spitzfindigkeiten der Studierstube $\ll$.

207 Wissowa (1912) 204.

208 Pighi hat die in Z.67 enthaltenen Angaben des Datums für die Verteilung der suffimenta noch einmal in seiner Ergänzung von Z. 76 wiederholt, weil er Z. 76 für die protokollarische Schilderung der Verteilung der suffimenta hielt. 
frugum vorgesehen war, worauf sich wahrscheinlich das Edikt der Zeilen 46-49 bezog. Deshalb ist in Z. 77 davon auszugehen, dass hier die Durchführung der acceptio frugum des 29. Mai erwähnt wurde. Damit würde diese Zeile die Schilderung einer der vorbereitenden Handlungen darstellen und nicht mehr zum vorangegangenen Edikt gehören. ${ }^{209}$ Am 26., 27. und 28. Mai fand die Verteilung der suffimenta statt, am 29. Mai begann die acceptio frugum. ${ }^{210}$

$78 \mathrm{f}$. Auch diese zwei Zeilen scheinen sich auf bereits gemachte Aussagen in einem vorher erwähnten Edikt zu beziehen (Z. 78: MATRONAS QVI$B V S$ DENVNTIATVM E[rat). Es geht um die Matronen, die schon in Z. 7I f. erwähnt sind, allerdings dort als mulieres. ${ }^{211} \mathrm{Da}$ hier als Ortsangabe das Kapitol genannt ist, könnte es sich um die supplicatio der matres familiae oder um die sellisternia der Matronen handeln.

8of. Diese Zeilen enthalten ein weiteres die Frauen betreffendes Edikt, das mit der Formel B(onum) $F$ (actum) noch einmal als Edikt gekennzeichnet wird. ${ }^{212}$ Diese selten verwendete Ausdrucksweise soll vielleicht den Status des Textes als Edikt noch einmal ins Gedächtnis rufen, welches in Z. 77 unterbrochen war.

Auch hier wird eine die Frauen betreffende Bestimmung der Feier ausgeführt. Mommsen und Pighi gingen von einer Bestimmung aus, welche die schon in Z.7I und 72 erwähnten sellisternia betrifft. Weil die teilnehmenden Frauen in Z. 80 als matres familiae bezeichnet werden, könnte hier die Teilnahme der Frauen an der supplicatio gemeint sein, denn die Teilnehmerinnen der supplicatio werden im commentarium stets als matres familias bezeichnet. ${ }^{23}$ In der Darstellung der supplicatio wird bei der Erwähnung der Matronen auf ein vorher ergangenes Edikt eingegangen, womit diese Zeilen gemeint sein könnten, da an keiner anderen Stelle eines Edikts die supplicatio erwähnt ist. Die Verwendung des Attributs

209 Pighi (I94I) II3, der ebenfalls davon ausging, dass hier die protokollarische Wiedergabe der acceptio frugum erwähnt wird, hielt das Edikt in Z. 76 für abgeschlossen. Deshalb ergänzte er in Z. 77 eine neue Einleitungsformel für ein Edikt, um dem folgenden Text die Rückkehr in den Status eines Edikts zu ermöglichen. Vgl. Kommentar zur Textkonstitution zu Z. $76 \mathrm{f} .$, S. $58 \mathrm{f}$.

2 I 0 Vgl. Z. 67 (Daten für die Verteilung der suffimenta) und 89 (acceptio frugum).

2 I I Vgl. Z. IOI, I 23 und I47, dort wird auf ein vorangegangenes Edikt ebenfalls mit denuntiatum erat Bezug genommen.

2I 2 Für diese Formel eines Ediktanfangs führt Mommsen (I89I) 255 (600) folgende Belege an: das Edikt eines praetoris urbani CIL VI 3I6I4 und 3I6I5; Suet. Caes. 80, 2; Vitell. I4, 4. Es fällt auf, dass die angeführten Beispiele nach bonum factum alle mit ne weitergeführt werden. Nach den Zeugnissen von Plaut. Poen. I6, 46 und Tertull. de pudic. I muss diese Formel aber als Edikteinleitung anerkannt werden. Für Z. 80 ist die auf bonum factum folgende Konstruktion nicht rekonstruierbar.

2 I3 Z. I23: Deinde matribus famil[ia]s nuptis quibus denun[tiatum erat $\cdots$ M. Agrippa]. 
sollemnis ist nicht eindeutig genug, um eine Entscheidung für supplicatio oder sellisternia zu treffen. ${ }^{214}$

Der in diesem Edikt erwähnte Zeitpunkt h(ora) I setzt den Beginn der Feierlichkeiten sehr früh an, nämlich etwa 4.30 Uhr am frühen Morgen. Es sieht so aus, als seien die Feierlichkeiten der ersten Nacht in die des ersten Tages ohne Unterbrechung übergegangen. Denn anschließend an das Opfer des ersten Tages für Iuppiter finden sellisternia statt und auch Spiele, ohne dass die Spiele, die in der vorangegangenen Nacht begonnen waren, unterbrochen worden wären. ${ }^{215}$ Das bedeutet, dass die in der Nacht zusammengekommenen Menschen gleich anschließend im Morgengrauen an den Opfern und anschließenden Riten des ersten Tages teilgenommen haben. Diese Riten dürften einen großen Teil des Vormittags beansprucht haben. Am Abend des I. Juni begannen bereits die Feierlichkeiten der zweiten Nacht.

82 Diese Zeile erwähnt das Datum des 30. Mai in Zusammenhang mit der acceptio frugum. Mommsen und mit ihm Pighi hielt diese Zeile für eine protokollarische Schilderung der acceptio frugum. ${ }^{216}$ Gliederndes Kriterium aller Angaben im commentarium ist eine strenge chronologische Ordnung. Dokumente und protokollarische Schilderungen werden jeweils mit der Angabe des Tagesdatums eingeführt. ${ }^{217}$ Deswegen ist auch an dieser Stelle Mommsen zuzustimmen und die Angabe von Z. 82 für die protokollarische Schilderung des zweiten Tages der acceptio frugum am 30. Mai. zu halten. ${ }^{218}$

Mit eodem modo ist wohl gemeint, dass die acceptio frugum in gleicher Weise durchgeführt wurde wie die vorher stattgefundene Verteilung der suffimenta. ${ }^{219}$

2 I4 Nach Fest. p. 384-386 ist sollemne sacrum ein Opfer, quod omnibus annis praestari debet. Nach Ernout-Meillet (1967) 633 handelt es sich bei sollemnis um ein »adjectif de la langue religieuse s'appliquant à des cérémonies, rites, coutumes solennellement suivis et célébrés à date fixe«. Somit sind die Riten, die in der Inschrift als sollemnis bezeichnet werden, solche, die regelmäßig anlässlich einer Säkularfeier wiederholt werden. Bei einer Wiederholung nach i I 0 Jahren, was nach der augusteischen Berechnung für die Riten der Säkularfeier gilt, kann man allerdings kaum noch von einer Wiederholung sprechen, weil alle, die den vorangehenden Ritus gesehen hatten, inzwischen gestorben sind. Offenbar sollte mit der Bezeichnung sollemnis aber gerade doch auf den Wiederholungscharakter der Riten hingewiesen werden.

2 Is Z. I09.

2 I6 Mommsen (I89I) 25 I (595); Pighi (I94I) I I3.

217 Die Datumsangaben: Z. 67 (a.d. VII aut VI aut V k. Iun. = 26., 27., 28. Mai); Z. 77 (a.d.IV k. Iun. = 29. Mai); Z. 82 (a.d.III K. Iun. = 30. Mai); Z. 89 (prid. k. Iun. = 3. Mai).

2 8 Hier liegt dasselbe Problem der Zuordnung des Textes vor wie in Z. 77.

2 I9 Die acceptio frugum wurde auf dieselbe Art wie die Verteilung der suffimenta auf Podesten durchgeführt und somit an denselben Orten, die im Dekret von Z. $30 \mathrm{ff}$. 
83-85 Diese Zeilen beziehen sich auf die Spiele, die nach allen Opfern als ludi Latini aufgeführt wurden. Aus der verstümmelten Datumsangabe der folgenden Zeile geht nur hervor, dass es sich gegebenenfalls um ein Datum vor dem I. Juni handeln kann. ${ }^{220}$ Die hier erwähnten ludi Latini stehen wahrscheinlich in keinem direkten Zusammenhang mit dieser Datumsangabe, weil über ludi Latini vor dem eigentlichen Beginn der Säkularfeier nichts bekannt ist. Letzteres liegt nahe, weil die abschließenden Angaben des Edikts sich auf die Informationen über die Riten der Säkularfeier selbst zu beziehen scheinen. ${ }^{221}$ Für die Durchführung dieser Riten war eine eigene Informationskampagne vorgesehen, die sinnvollerweise auch vor dem eigentlichen Beginn der Säkularfeier stattfand und deren Ablauf in diesen Zeilen angesprochen war. Es ist davon auszugehen, dass alle verordnenden Texte der Zeilen 64-89 nicht die Riten der Säkularfeier selbst betroffen haben, sondern nur die Ereignisse, die diesen Riten voranzugehen hatten, um die Teilnahme der gesamten Bevölkerung daran sicherzustellen. Eine solche Annahme drängt sich auf, weil die Anordnungen über die Opferriten und ludi selbst nicht in sechs Zeilen möglich wäre und auch nicht in einem priesterlichen Entscheid veröffentlicht werden mussten. Offenbar betrafen die Entscheidungen, die die Quindecimviri vor dem Beginn der Säkularfeier trafen, die Riten nur insofern, als die Bevölkerung in großer Menge daran teilnahm. Die eigentliche Ausübung der Riten, die durch die Priester und ihre Diener vorgenommen wurde, ist nicht in den Dokumenten dieses commentarium angesprochen.

86-88 Diese Zeilen betreffen die Benachrichtigung der Bevölkerung, um an den Opferriten teilnehmen zu können. Die aenatores oder aeneatores, wie sie sonst heißen, bildeten ein Kollegium, dessen Mitglieder in der Kaiserzeit inschriftlich als Empfänger von Getreidespenden erwähnt sind. ${ }^{22}$ Wir besitzen keine Angaben über ihre Tätigkeit und können ihre Aufgaben nicht klar von denen anderer Musikerkollegien abgrenzen. ${ }^{223}$ Vielleicht waren diese Blechbläser an der Säkularfeier beauftragt, mit verschiedenen Signalen die Bevölkerung $\mathrm{zu}$ informieren und $\mathrm{zu}$ dirigieren. Mommsen

bestimmt worden waren. Das Podest, auf welchem die Quindecimviri die Früchte mit Schalen in Empfang nehmen, ist auf den Münzen gleich dargestellt wie der Ort für die Verteilung der suffimenta. Vgl. Anhang, Abb. 2, 8, 9a und 9b.

220 Deshalb ist am Ende von Z. 83 noch ein a(nte) $d($ iem) einzufügen.

22 I Vgl. Z. 85: ludos Latinos; 86: caerimonias sacro[rum.

222 CIL VI 10220, I022 I und I0222.

223 Auch die bei Fest. p. I 8 gelieferte Erklärung gibt nichts her: aenatores cornicines dicuntur, id est cornu canentes. Mommsen (I89I) 257 (603) unterscheidet zu Recht die auf den Münzen abgebildeten tibicines und fidicines, die an den Opfern teilnehmen, von den hier erwähnten Blechbläsern; siehe Anhang, Abb. Iо, I I-I 3 , I 5 und 20. 
hat ihre Aufgabe in diesem Teil der Inschrift im rituellen Bereich gesehen, obwohl Z. 87 eher auf eine signalgebende Funktion zur Benachrichtigung der Bevölkerung hinweist. ${ }^{22}$

89 Diese letzte Zeile vor der Darstellung der Feierlichkeiten der Säkularfeier selbst ist noch einmal der acceptio frugum gewidmet. Es scheint sich hier um die protokollarische Schilderung des dritten Tages der acceptio frugum zu handeln.

Das Edikt der Zeilen 64-75 ist am 24. Mai erlassen worden; in ihm wird bestimmt, dass die Verteilung der suffimenta am 26. Mai beginnen soll. ${ }^{225}$ Das bedeutet, dass für die Veröffentlichung der hier getroffenen Anordnungen nur der dazwischen liegende Tag des 25 . Mai möglich war. Dieses Edikt und auch der folgende, nicht mehr genau bestimmbare Text machen in vielem den Eindruck, dass hier kurzfristig auf die Erfordernisse der Organisation des Großanlasses ludi saeculares reagiert wurde. Die Anordnungen und gewisse Modifikationen früherer Anordnungen scheinen nötig geworden zu sein, weil der große Andrang der Bevölkerung bereits abzusehen war. Offensichtlich war mit der Berechnung der Teilnehmerzahlen erst im letzten möglichen Augenblick klar geworden, dass hier lenkende Maßnahmen erforderlich waren. Die Information der Bevölkerung war wahrscheinlich über andere Instrumente wie das Aufstellen von Tafeln und den Ausruf von Herolden geregelt. ${ }^{226}$ Dennoch hat man erst eine Woche vor dem Beginn der ludi saeculares festgesetzt und vielleicht auch erst gewusst, in welcher Art die Abgabe der suffimenta und die acceptio frugum stattfinden soll. Die Organisation dieser zwei vorausgehenden rituellen Handlungen scheint das Nadelöhr der Organisation an den Tagen vor dem Fest gewesen zu sein. Offensichtlich war die Teilnahme wirklich aller Bürger vorgesehen.

Mit Z. 90 beginnt der zweite Teil der Inschrift, der vorwiegend der Schilderung der an der Säkularfeier stattgefundenen Handlungen gewidmet ist. Er ist mit 78 Zeilen wesentlich kürzer als der erste vorwiegend dokumentarische Teil mit etwa I 20 Zeilen. ${ }^{27}$ Einziges gemeinsames Merkmal ist seine ebenfalls strenge chronologische Orientierung. Im ersten Teil besteht diese darin, dass alle Dokumente, die vor der Säkularfeier von amtlicher oder priesterlicher Seite erstellt wurden, in der Reihenfolge ihrer Abfassung aneinandergereiht sind; insofern geben sie eine Art

224 Mommsen (I89I) 257 (602f.).

225 Z. $65-70$.

226 Kloft (1996) $58 \mathrm{f}$.

227 Diese Zeilenzahl ergibt sich durch die Aneinanderreihung der Fragmente AB, C und der bereits bekannten 89 Zeilen und einiger weniger Zeilen vor AB. 
Planungsgeschichte wieder, die am Ende mit der protokollarischen Schilderung der vor der Säkularfeier durchgeführten Riten unterbrochen ist. Der zweite Teil gibt den Ablauf des eigentlichen Festes wieder, wobei jedes Ereignis mit seinem Datum eingeführt wird. Wurden an dem betreffenden Anlass Gebete gesprochen, so enthält das Protokoll außerdem den Wortlaut der gesprochenen Gebete.

90-IO2 Diese Zeilen enthalten eine Darstellung der Riten der ersten Nacht der Säkularfeier. Es handelt sich um alle Angaben, die das Opfer an die Moiren betreffen, sowie eine Wiedergabe des Opfergebets im vollständigen Wortlaut. ${ }^{228}$ Die Angaben werden mit der Erwähnung der Riten abgeschlossen, die auf das Opfer folgten.

9of. Diese ersten zwei Zeilen schließen mit NOCTE INSEQVENTI direkt an die Darstellung der Dokumente und rituellen Handlungen vor der Feier selbst an, das heißt, die nun erwähnte Opferhandlung fand in der Nacht statt, die auf den Vortag der Kalenden des Juni folgte, also in der Nacht vom 3 I. Mai auf den r. Juni. ${ }^{29}$ So wie hier werden alle folgenden Darstellungen der Opfer eingeleitet, wobei immer die wichtigsten Angaben, die das Opfer betreffen, in gleicher Reihenfolge genannt werden: der Zeitpunkt, der Ort, die betroffenen Gottheiten, der Ausführende des Opfers, die Art des Opfers und die Art des Opferritus.

Im Fall des Moiren-Opfers handelt es sich um das erste der drei Opfer, die in der Nacht am Tiberufer dargebracht wurden und welche die Inschrift verzeichnet. Der Zeitpunkt und der Ort sind die eindeutig zum Ritus der Säkularspiele gehörenden Merkmale, die dieses Opfer als Opfer der ludi saeculares ausweisen. Diese Angaben werden auch an erster Stelle gemacht. Sehr wahrscheinlich gingen diesen Opfern für die Moiren einleitende Opfer an Dis Pater und Proserpina voraus, die in diesem Heiligtum beheimatet waren. ${ }^{23^{\circ}}$ Alle Gottheiten der Säkualarfeier waren nur in dieses Heiligtum Eingeladene, worauf der Tatbestand hinweist, dass an provisorischen Holzaltären für sie geopfert wurde und nicht auf den offenbar im Heiligtum befindlichen Steinaltären, die Dis Pater und Proserpina gehörten. Auch Zosimus erwähnt für die augusteischen Spiele Opfer an Dis und Proserpina, allerdings ohne Angabe, an welcher Stelle im Festablauf diese zu platzieren sind. ${ }^{231}$ Auch wenn die augusteische

228 Daneben ist nur das Suppikationsgebet an Iuno vollständig wiedergegeben; Z. I $25-$ I 3 I.

229 Vgl. Z. 89: Prid(ie) K(alendas) IVN(ias).

230 Vgl. Kap. A.7, S. $205 \mathrm{ff}$.

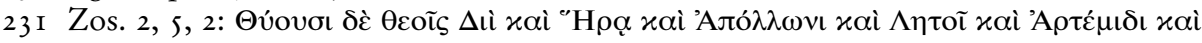

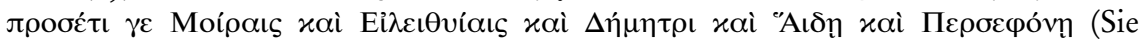
opfern folgenden Gottheiten: dem Zeus, der Hera, dem Apollo, der Leto, der Ar- 
Inschrift dies nicht verzeichnet, werden die Bewohner des Heiligtums im Tarentum ebenfalls mit Opfern bedacht worden sein. ${ }^{232}$

Die Gottheiten, deren Opfer die Inschrift als erstes erwähnt, haben in der römischen Religion sonst keine Erwähnung. ${ }^{233}$ Die Tatsache, dass die augusteischen Säkularspiele nicht wie die historisch belegten Spiele von 249 v. Chr. ausschließlich dem Dis Pater und der Proserpina galten, ist als augusteische Neuerung interpretiert worden. ${ }^{234}$ Dies muss in jedem Fall bejaht werden, doch stellt sich die Frage, warum die Moiren (und auch die Ilithyien und Terra Mater) als Gottheiten geeignet waren, an die Stelle von Dis Pater und Proserpina zu treten. Über die Eignung dieser Gottheiten lassen sich nur Spekulationen anstellen, wie dies in der Forschung auch immer wieder getan wurde. Nach Wissowa eigneten sich die Moiren, weil sie aufgrund ihrer Identifikation mit einer ursprünglich als Geburtsgöttin Parca verehrten Gottheit wohl eher als Göttinnen, die die Reproduktion gegünstigten, verehrt wurden, denn als Schicksalsgöttinnen wie die griechischen Moiren. ${ }^{235}$ Wuilleumier und Coarelli halten es für möglich, dass die Moiren in einer Kultgemeinschaft mit Proserpina standen, deren Heiligtum zusammen mit Dis Pater aus einer Anlage mit zwei kleinen Tempeln bestand. ${ }^{23}$ Die augusteische Gestaltung der ludi saeculares hat großes Gewicht auf die in den alten Spielen und vor allem im Ursprungsmythos noch erkennbare Aussage der Bewahrung der Nachkommenschaft gelegt als Grundlage eines gesunden Staates. Wahrscheinlich wurden deshalb in den nächtlichen Opfern Gottheiten berücksichtigt, die einerseits dem traditionell chthonischen Charakter dieser Feier entsprachen und andererseits den Gedanken der Reproduktion ausdrückten. Die Moiren boten sich eventuell als Göttinnen der neuen ludi saeculares an, weil sie einer-

temis und außerdem den Moiren, den Ilithyien, der Demeter, dem Hades und der Persephone).

232 Act. Sev. I 8 schildert vor dem Moiren-Opfer ein sacrum bostiae praecidaneae, wo von den erwähnten Göttern aber nur der Name des Iuppiter (Z. I 24) erhalten ist. Vgl. S. I 22, Anm. 252.

233 Wissowa (I9I2) 264f. Es kam zu einer Identifikation der römischen Geburtsgöttin Parca (Parica) mit den drei griechischen Moiren aufgrund einer falschen Ableitung ihres Namens von pars. Gell. 3, i6, iof. (Varro).

234 Zos. 2, 4, I erwähnt diese Spiele mit Opfern für Dis und Proserpina; belegt sind diese Spiele außerdem bei Cens. 17, 8, Iof. (Varro); Liv. perioch. 49.

235 Nach Wissowa (I9I2) 264f. ist die Verehrung des Schicksals der römischen Religion fremd.

236 Wuilleumier (I932) I $34 \mathrm{ff}$. hat erstmals darauf hingewiesen, dass der Kult im Tarentum verschiedenen Umformungen unterworfen war, dass der Kult von Dis Pater und Proserpina nur eine Station innerhalb der verschiedenen Gestaltungen des Kultes war. Nach Coarelli (I997) 97 wurde mit dem Kult der Moiren wohl an den Kult von Dis Pater und Proserpina angeschlossen, da Proserpina mit den Moiren in einer Kultgemeinschaft stand. 
seits aufgrund der alten Identifikation mit einer altrömischen Geburtsgöttin - wie Wissowa meinte - dem Reproduktionsgedanken der ludi saeculares entsprachen und durch ihre eventuelle Kultgemeinschaft mit Proserpina im Kult des Tarentum ohnehin mit dem Kultort der ludi saeculares verbunden waren. Nachweisbar sind solche Beziehungen allerdings nicht.

Als Darbringer der drei nächtlichen Opfer, die als die eigentlichen Opfer der ludi saeculares gelten können, fungiert in jeder der drei Nächte Augustus. Nach Zosimus haben ihm bei den zahlreichen Opfern für die Moiren die Quindecimviri zur Seite gestanden. ${ }^{237}$ Die Inschrift allerdings erwähnt dies nicht an dieser Stelle, sondern nennt die anwesenden Quindecimviri erst bei Abschluss aller Riten der ersten Nacht und des ersten Tages. ${ }^{23^{8}}$ Augustus nimmt bei diesen Opfern die Hauptrolle ein, die ihm als Herrscher und magister des ausführenden Priesterkollegiums der Quindecimviri gebührte. ${ }^{239}$

Als Opfertiere sind neun Schafe und neun Ziegen weiblichen Geschlechts angegeben. Obwohl es das commentarium nicht erwähnt, werden die Ziegen und Schafe schwarz gewesen sein, wie es das Orakel verlangt. ${ }^{24}$ Dunkle Opfertiere waren den chthonischen Gottheiten vorbehalten. AuBerdem wird mit der schwarzen Farbe der Opfertiere auf den Ursprungsmythos der Säkularfeier angespielt: Auch der mit seinen kranken Kindern tiberaufwärts fahrende Valesius opferte an derselben Stelle, auf dem sogenannten Tarentum, der Proserpina und dem Dis Pater schwarze Opfertiere, gemäß einem Traum seiner genesenden Kinder. ${ }^{241}$ Obwohl das commentarium nirgends den Mythos erwähnt, muss eine Beziehung bestanden haben. Diese ergab sich nicht durch verbale Bezugnahme, sondern durch den Ort des Geschehens, durch die Zahl und Farbe der Opfertiere und andere nicht überlieferbare Gesten und Handlungen. ${ }^{242}$ Es

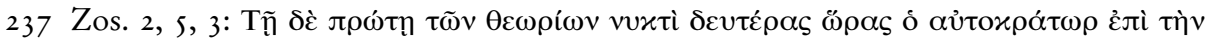

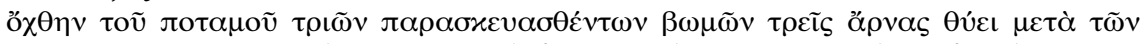
$\Delta \varepsilon \varkappa \alpha \tau \varepsilon \dot{v} v \varepsilon \dot{\alpha} v \delta \rho \tilde{\omega} v$ (In der ersten Nachtfeier, um die zweite Stunde, opfert der Kaiser zusammen mit den Quindecimviri an der Böschung des Flusses auf drei errichteten Altären drei Lämmer).

238 Vgl. unten zu Z. I07, S. I 39.

239 Die Rolle des Augustus erinnert an diejenige, die im Ursprungsmythos der ludi saeculares der Vater Valesius innehatte, der aus Sorge um seine Nachkommenschaft die Opfer vollbrachte (Zos. 2, 2, 3 f.). Auch die legendären Spiele des Valerius Poplicola von 504 v. Chr., die als erste Säkularspiele überliefert sind, haben in Valerius Poplicola den um den Erhalt des Volkes besorgten Landesvater, der die Opfer darbringt (Plut. Poplic. 2I).

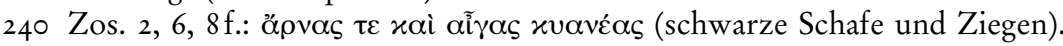

24I Zos. 2, 2, 3 f.

242 Neben Zosimus überliefert Val. Max. 2, 4, 5 diesen Mythos. Auf die Tatsache, dass 
ist nichts über die den Moiren üblicherweise dargebrachten Opfer bekannt, somit werden die Organisatoren der Riten Opfergaben ausgewählt haben, die zur Aussage der Feier passten.

Das Attribut prodigivus für die Opfertiere gibt an, dass es sich um ein Opfer handelt, das vollständig verbrannt wurde und nicht wie anderes Opferfleisch dem Verzehr der Menschen diente. ${ }^{243}$ Solche Holokaustopfer waren für chthonische Gottheiten die Regel, weil man mit den Göttern der Unterwelt nicht gemeinsam speist, eine Vorstellung, die hinter dem Fleischopfer mit anschließendem Verzehr stand. ${ }^{244} \mathrm{Im}$ augusteischen commentarium werden nur die Opfer für die Moiren als prodigivas bezeichnet, im severischen auch das Sauopfer für Terra Mater. ${ }^{245}$ Es ist also davon auszugehen, dass alle nächtlichen Tieropfer auf dem Tarentum auf diese Art durchgeführt wurden.

Neben dieser Angabe der Verbrennungsart der Opfer steht die Angabe des Achivo ritu, das heißt, dass die Ausführenden des Opferritus nach griechischem Ritus handelten. Als deutliches, auch von Weitem wahrnehmbares Kennzeichen des Achivus oder Graecus ritus galt die Kopfbedeckung der ausführenden Priester, die das Opfer mit unverhülltem Haupt und einem Lorbeerkranz auf dem Kopf durchführten. ${ }^{246}$ Außerdem trugen die Opfernden bei den Opfern eine tunica fimbriata, im Gegensatz zur toga praetexta. ${ }^{247}$ Die Anwesenheit von Musikern während

der Mythos nicht in den Gebeten und Gesten der teilnehmenden Bevölkerung erscheint, weist auch Scheid (I993b) i i f f. hin.

243 Fest. p. 296, 2 Iff.; 297, 5f.: Prodigivae hostiae vocantur, ut ait Veranius, quae consumuntur.

244 Latte (I960) 39I f. Auch Zos. 2, 5, 3 geht auf diese besondere Art des Opferns ein: Tñ

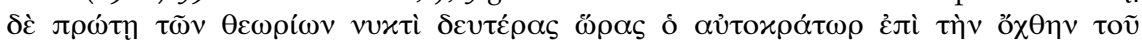

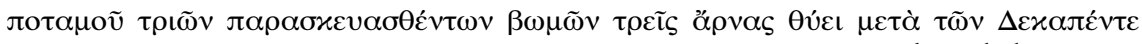

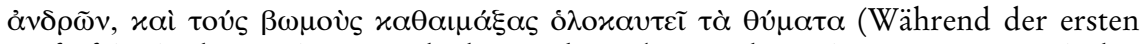
Opferfeier in der zweiten Stunde der Nacht verbrennt der Kaiser zusammen mit den Quindecimviri auf drei Altären, die an der Uferböschung des Flusses aufgestellt waren, drei Lämmer als ganze Tiere, nachdem er die Altäre mit deren Blut besprengt hatte). Vgl. Verg. Aen. 6, 253, wo Aeneas der Proserpina ein nächtliches Opfer darbringt, welches er ebenfalls nach den Vorschriften der Sibylle durchführt $(6,236)$. Servius gibt folgenden Kommentar zur Stelle: solida inponit taurorum viscera flammis non exta dicit, sed carnes, nam "viscera" sunt quicquid inter ossa et cutem est: unde etiam visceratio dicitur, ut diximus supra (I, 2 I I), ergo per "solida viscera" bolocaustum significat, quod detractis extis arae superinponebatur. quae nonnumquam abluta et elixa etiam ipsa reddebantur: unde infert "fundens ardentibus extis". quamquam alii pro parte totum velint, ut per exta totum animal intellegatur.

245 Act. Sev. 225.

246 Zum Achious ritus: Scheid (1996) I 5-3 I. Nach Scheid (S. 2 I) gibt es keine erkennbare Regel, die gewisse Rituale nach römischem, andere nach griechischem Ritus vorschreibt.

247 Ein Kleiderwechsel ist in dem detaillierteren commentarium der severischen Säku- 
des Opfers, wie sie auf einigen Münzabbildungen zu erkennen ist, war ebenfalls ein Kennzeichen des ritus Graecus. ${ }^{24^{8}}$ Es ist nicht klar, ob während der Opferzeremonie nach griechischem Ritus auch griechisch gesprochen wurde.

Die ersten zwei Zeilen enthalten zwar die wichtigsten Angaben über das Opfer, sparen aber gewisse Handlungen aus, die als praeliminaria gelten. Dazu gehört die rituelle Reinigung des Geländes, wo die drei Altäre aufgestellt wurden, die im severischen commentarium aufgezeichnet ist. ${ }^{249}$ Auch an der augusteischen Feier muss sie stattgefunden haben, besonders wenn man davon ausgeht, dass das Gelände des Tarentum während langer Zeit brachgelegen hatte und durch gelegentliche Überschwemmungen des Tibers verwüstet war. Desgleichen sagt das augusteische commentarium nichts von dem dreimaligen Besprengen des Altars mit Wasser und dem Händewaschen der am Opfer beteiligten Personen. ${ }^{20}$ Es wird im Gegensatz zum severischen commentarium außerdem nicht erwähnt, dass es sich bei den drei Altären um eigens für diese Opfer errichtete Holzaltäre für in das Heiligtum eingeladene Götter gehandelt hat, die nach den Opfern wieder abgerissen wurden. ${ }^{251}$ Das severische commentarium enthält zusätzlich vor der Erwähnung der ersten Opfer an die Moiren die Angabe eines sacrum hostiae praecidaneae, ein Opfer am Tage vor dem Beginn der Säkularspiele, das möglicherweise allen Göttern der Säkularspiele, auf jeden Fall mehreren Göttern galt. ${ }^{252}$ Ebenso fehlen im augusteischen commentarium die Angaben über die Riten, die der eigentlichen Tötung des Opfers und dem Gebet vorangingen: die praefatio mit der Verbrennung von Wein und Weihrauch und die immolatio. Das severische commentarium erwähnt dreimal eine praefatio des Opfers,

larspiele verzeichnet: Act. Sev. I 56 (Iuppiter-Opfer), I79f. (Iuno-Opfer), 223 f. und 229 (Terra-Mater-Opfer).

248 Siehe Anhang, Abb. I0-I3, Is und 20; vgl. Scheid (1998b) 25.

249 Act. Sev. IO2-I I I. Eine lustratio luci ist auch im Kult der Arvalbrüder bekannt. Diese rituelle Reinigung umfasste die Säuberung und Pflege des Geländes kurz vor den Opfern, vgl. Scheid (I990a) 447-45 I. Im Kult der dea Dia der Arvalbrüder ist diese Reinigung des Geländes ebenfalls nicht aufgezeichnet, weil sie kein wichtiges Element der Riten darstellt.

$250 \mathrm{Im}$ severischen commentarium ist das Besprengen des Altars verzeichnet: Act. Sev. I 67 f.; i 78 .

$25 \mathrm{I}$ Act. Sev. 223f. Man kann davon ausgehen, dass es neben diesem dritten Holzaltar, der hier für Terra Mater erwähnt ist, einen ersten für die Moiren und einen zweiten für Ilithyia gegeben hat. Auch Zos. 2, 5, 3 spricht davon, dass die drei Altäre für die drei Opfer am Tiberufer nicht fix waren, sondern extra errichtet worden sind ( $\tau \rho \tilde{\omega} v$ $\pi \alpha \rho \alpha \sigma x \varepsilon v \alpha \sigma \theta \varepsilon \dot{v} \tau \omega v \beta \omega \mu \tilde{\omega} v)$.

252 Act. Sev. I 18-136. Die Bezeichnung sacrum hostiae praecidaneae stammt von Pighi; der stark fragmentarische Text enthält ein Gebet, das Formulierungen der folgenden Opfergebete erkennen lässt. Siehe den Sachkommentar zu dieser Stelle in Act. Sev. 
die zu jedem Opfer gehörte, im augusteischen commentarium aber überhaupt nicht festgehalten ist. ${ }^{253}$

Die Verbrennung von Wein und Weihrauch als praefatio des Opfers diente dazu, das Opfer zu eröffnen, die Götter zu begrüßen und den Rangunterschied zwischen Opfernden und Göttern klarzustellen. Der Akt stellt eine eigentliche Einladung an die Götter dar, dem Mahl beizuwohnen. Dabei wurden Wein und Weihrauch auf einem kleinen Herd verbrannt, der in der Nähe des Altars aufgestellt war. Die dabei gesprochenen Worte sind in keiner Quelle überliefert, bekannt ist nur, dass die praefatio sich an Ianus oder Vesta richtete. ${ }^{254}$

Zwischen praefatio und immolatio steht im Ablauf des Opfers das Opfergebet. ${ }^{25 s}$ Die augusteische Inschrift erwähnt nach den Angaben von Z. 90 und 9r über die Rahmenbedingungen des Opfers den gesamten Wortlaut des Gebets, sagt aber nichts über praefatio oder immolatio. Dies wertet Scheid als Wortlastigkeit der commentaria zu den ludi saeculares im Gegensatz zu den commentarii der Arvalbrüder, die das Hauptgewicht auf die Aufzeichnung der Gesten legen. ${ }^{256}$

Der Ablauf des Opfers wird sich nach den Angaben des severischen commentarium wie folgt abgespielt haben: Nach der praefatio wird die Stirn des Opfertiers mit Wein begossen, dann das Tier mit mola salsa bestreut und anschließend wird mit einem Messer eine Linie über den Rücken des Tieres von der Stirn zum Schwanz gezogen. ${ }^{257}$ Dieser Akt symbolisiert einerseits den Akt des Tötens und weist andererseits durch das Bestreuen von mola und das Begießen mit Wein dem Tier einen höheren Wert zu. ${ }^{258}$ Damit war die praktische Tätigkeit der Priester, in diesem Fall des Augustus und der Quindecimviri, beendet, denn den eigentlichen Akt des Tötens führten Opfersklaven durch. Das auguste-

253 Act. Sev. I79-I8I; 223f.; 229f. Zur Verbrennung von Wein und Weihrauch: Scheid (I990a) 33I-333.

254 Cato agr. I34, I: thure vino Iano Iovi Iunoni praefato.

255 Cato agr. I4 I.

256 Scheid (I990a) 336. Allerdings besteht zwischen dem augusteischen und dem severischen commentarium ein großer Unterschied. Obwohl das severische commentarium das Vorbild des augusteischen klar erkennen lässt, enthält es deutlich mehr Angaben über rituelle Gesten. Es stimmt aber, dass im Vergleich mit den commentarii der Arvalbrüder die commentaria der ludi saeculares deutlich weniger ausführlich diese rituellen Gesten beschreiben.

257 Act. Sev. i 80f. (Iuno-Opfer); 224f. (Terra-Mater-Opfer). Nach der hier geschilderten Handwaschung und immolatio folgt in beiden Fällen das Gebet. Auch bei den anderen Tieropfern wird das severische commentarium diese Angaben enthalten haben, sie sind aber wegen des schlechten Zustands dieser Inschrift nicht mehr erhalten.

258 Vgl. Scheid (1990a) 333-336. 
ische commentarium enthält einen Hinweis auf die immolatio nur durch die Wahl des Verbs: Caesar Augustus inmolavit (Z. 90). 59

Das eigentliche Schlachten wird weder in den commentarii der Arvalbrüder noch in denen der ludi saeculares dargestellt. Das Opfertier wurde nach der immolatio abgestochen, ausgeblutet, auf den Rücken gedreht, auf der Bauchseite geöffnet und der Eingeweideschau ausgesetzt. ${ }^{260}$ Es begann die Tätigkeit der haruspices, die den einwandfreien Zustand der Eingeweide, insbesondere der Leber, bestätigen mussten. Diese Handlungen konnten lange Zeit in Anspruch nehmen und es ist für die Säkularspiele anzunehmen, dass die Schlachtung, Begutachtung und anschließende vollständige Verbrennung der je neun Ziegen und Schafe die ganze Nacht gedauert haben.

All diese Tätigkeiten erwähnt das augusteische commentarium nicht. Der Grund dafür kann nur vermutet werden: Es handelte sich bei der Durchführung der Opfer um die an allen Staatsopfern gleich durchgeführten Gesten eines Opfers, die als bekannt vorausgesetzt wurden. In diesem Fall begnügt sich das augusteische commentarium damit, nur das festzuhalten, was als besondere Bedingung des jeweiligen Opfers verstanden wurde. Dazu gehörte neben der betroffenen Gottheit der ungewöhnliche Ort des Opfers, die nächtliche Stunde und die Art der Opfertiere. Die Aufzeichnung des commentarium setzt voraus, dass das Opfer mit allen dazugehörenden Riten durchgeführt wurde und lässt keinerlei Bestreben nach einer Vollständigkeit der Schilderung erkennen. Das Bestreben, das hinter einer solchen Auswahl steht, kann man als Ökonomie der Darstellung verstehen, deren Grundgedanke war, die durchgeführten Riten festzuhalten, aber nur insoweit diese Riten als unbekannt vorausgesetzt werden konnten. Die Frage nach den Kriterien dessen, was der Aufzeichnung für würdig befunden wurde, muss für jede Inschrift gestellt werden. Denn gerade bei der Schilderung der Opferriten wird im Vergleich zwischen dem augusteischen und severischen commentarium deutlich, dass das severische commentarium anderen Kriterien der Aufzeichnungspflicht nachging. ${ }^{26 \mathrm{I}}$

259 Das severische commentarium verzeichnet vor der haruspicatio des Ochsen für Iuppiter das Abschneiden einer Stirnlocke: Act. Sev. 165.

260 Vgl. Scheid (I990a) 336-338. Scheid geht davon aus, dass in den commentarii der Arvalbrüder die Schlachtung und Eingeweideschau nicht erwähnt wird, weil sie keinen Dialog mit den Göttern darstellen, wie dies bei der praefatio und der immolatio der Fall ist, dass es sich also um eine eher profane Tätigkeit handelt. Aus diesem Grund war es möglich, dass diese Handlungen von Opferdienern durchgeführt werden konnten und nicht von Priestern.

26I So verzeichnet das severische commentarium außerdem, dass zwischen praefatio und immolatio der opfernde Herrscher die Kleidung gewechselt hat. Nach der praefatio legte er die toga praetexta ab, um sie gegen eine tunica fimbriata zu tauschen. Vgl. 
Den Abschluss der Angaben über das Opfer bilden die Worte precatus est hoc modo. Damit wird auf das folgende, vollständig wiedergegebene Gebet übergeleitet, es wird aber auch deutlich, dass dieses Gebet während der immolatio vom Opfernden, wahrscheinlich Augustus, gesprochen wurde. Während er und die Quindecimviri die dazugehörenden Gesten ausführten, hat wohl Augustus allein gleichzeitig das Gebet rezitiert. Erst nach dem Gebet und der abgeschlossenen immolatio kamen die Opferdiener zur Tötung des Tieres.

92f. Das Gebet beginnt mit einer direkten Anrede der Göttinnen. Anschließend wird unter Berufung auf die sibyllinischen Bücher der gesamte Akt des Opfers und Gebets legitimiert. ${ }^{262}$ Das Orakel für die Säkularfeier enthält zwar nicht den Wortlaut der Gebetstexte, wohl aber die Anweisungen für den Festablauf. ${ }^{263}$ Es ist nicht anzunehmen, dass diese Gebetstexte in anderen Orakeln überliefert waren, sondern eher, dass ihre Überlieferung in den Archiven des Kollegiums der Quindecimviri und durch die inschriftliche Aufzeichnung gesichert war. Da Gebetstexte in der römischen Religion nicht freigesprochen wurden, sondern immer sorgsam überwacht und schriftlich fixiert waren, muss man davon ausgehen, dass auch die Texte dieser Gebete irgendwo aufgeschrieben waren, gerade wenn solche Gebete speziell für den Anlass der Säkularfeier zusammengestellt worden waren. Die Organisatoren der Säkularfeier waren um eine Dokumentation der Feier sehr bemüht, was sich dem vorangehenden Senatsbeschluss über die Aufstellung zweier Inschriften entnehmen lässt. Es muss davon ausgegangen werden, dass die Säkularfeier des Jahres I7 v. Chr. auch im Hinblick auf künftige Säkularfeiern eingerichtet wurde. Für diese künftigen Feiern mussten Vorlagen geschaffen werden, die man wahrscheinlich bei den Vorbereitungen von 17 v. Chr. vermisst

Anm. 257. Siehe auch Kap. B.4, S. 380 und 383 f. Scheid (I998b) $23-26$ weist darauf hin, dass die domitianischen Münzprägungen, die die Opferszene darstellen, mit ihren Abbildungen einen Widerspruch zu den tatächlichen Gesten der Opfernden bilden. Denn während einer Szene, die Scheid als praefatio des Moiren-Opfers interpretiert, ist der Kaiser bereits mit einer tunica fimbriata bekleidet, welche nach dem severischen commentarium erst während der immolatio getragen wurde (siehe Anhang, Abb. ıо). Scheid plädiert dafür, dass die Münzabbildungen nicht als eine Abbildung der Realität verstanden werden sollten, sondern als eine Konstruktion verschiedener Elemente der Opferhandlung, deren Absicht es war, die Aussage zu verdichten.

262 Mommsen (I89I) 263f. (6Iof.); Diehl (I934/35) 26r. Diehl weist auf den alten, wohl auf die Etrusker zurückgehenden Brauch hin, wonach Gebete unter Berufung auf libri verlesen werden mussten, bleibt aber seltsam unbestimmt, um welche Art von Büchern es sich dabei handelt. Er scheint nicht die Existenz eigener Priesterbücher des Kollegiums der Quindecimviri in Rechnung zu stellen, sondern wie Mommsen eher an die von den Quindecimviri beaufsichtigten sibyllinischen Bücher zu denken. 
hatte. ${ }^{264}$ Aus dem severischen commentarium geht hervor, dass die dort aufgezeichneten Gebete mit denen der augusteischen Säkularfeier identisch sind und dass der Text der Gebete von einem der Söhne des Severus vorgesprochen oder vom Imperator selbst gelesen wurde. ${ }^{265}$ Schon weiter oben wurde klar, dass der erste Teil der Inschrift Schriftstücke aus dem Archiv der Quindecimviri enthält. Solche Archive enthielten neben diesen organisatorischen Schriftstücken auch die rituellen Texte, die für das betreffende Kollegium relevant waren. ${ }^{266}$

Die ersten zwei Zeilen nehmen eine Sonderstellung innerhalb des Gebets ein, denn sie sind für das jeweilige Opfer mit den nötigen Angaben versehen, die der Nachwelt überliefert werden mussten. Diese Zeilen lauten also in jedem Gebet etwas anders. Deshalb werden im augusteischen commentarium diese zwei Zeilen jedes Gebets vollständig wiedergegeben, während der Rest, der die immer gleichen Bitten enthält, nur im ersten Gebet an die Moiren vollständig zitiert wird. In allen anderen Opfergebeten werden die stets gleichen Bitten mit cetera uti supra abgekürzt. $\mathrm{Zu}$ den in jedem Gebet wechselnden Angaben gehört mit der Anrede der Name der betroffenen Gottheit - hier die Moiren - und die Angabe des dargebrachten Opfers - hier je neun weibliche Ziegen und Schafe. Im Moirengebet werden alle drei Moiren kollektiv angesprochen, weshalb man davon ausgehen muss, dass auch das Opfer den Göttinnen gemein-

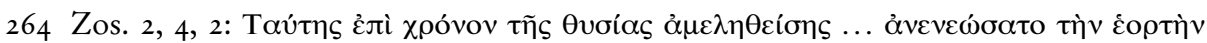

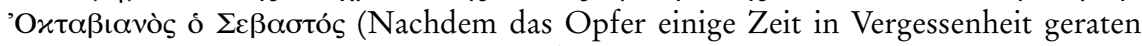
war ... erneuerte Octavianus Augustus das Fest).

265 Act Sev. I79f.: [... Ibi Severus Aug(ustus)]|[praeeun]TE ATONINO AVG(usto) FILIO [suo; ebenso Act. Sev. 224; Act. Sev. 23i: HAC PREC[a]TION[e quam le]GIT IPSE.

266 Rohde (I936) 7If.; Rohde grenzt das commentarium der Säkularfeier scharf gegen andere Priesterbücher ab, vor allem wegen der sprachlichen Form des zweiten Teils, der als protokollarische Festschilderung in der Vergangenheitsform geschrieben ist, wogegen Priesterbücher in der Form von Anweisungen gehalten waren. Er hält das commentarium für eine neue Form, die den besonderen Ursachen der Entstehung der Säkularfeier zuzuschreiben ist. Rohde hält es aber für möglich, auf eine Vorlage von Kultvorschriften, auf die Ateius Capito zurückgegriffen hat, zu schließen, zumindest was den Inhalt solcher Priesterbücher betrifft. Hinter diesen Spekulationen nach der Gestalt uralter Priesterbücher oder Ritualbücher steht eine romantische Vorstellung von den Grundlagen der römischen Religion und einer ursprünglich ungebrochenen Einheit zwischen Kult und Ritus. Vgl. Scheid (1 994) I76f. Es ist ebenso möglich, dass sich die Gestalt der sogenannten Priesterbücher ständig wandelte und von dem jeweiligen Gebrauch bestimmt war. So könnten die Aufzeichnungen zu den augusteischen ludi saeculares davon geprägt sein, einerseits auszudrücken, dass die Spiele nach dem mos maiorum geplant und angesagt worden waren, und andererseits für die Nachwelt eine brauchbare Vorlage für künftige Spiele zu schaffen. Die Forderung nach einem normativen Urtext erübrigt sich dann. 
sam galt. ${ }^{267}$ Außerdem enthalten diese Zeilen die Berufung auf eine Legitimation, nämlich die Vorschrift des Orakels zu diesem Opfer. Es folgt die Angabe derer, die von dem Opfer profitieren sollen. Diese bleiben in jedem Opfergebet gleich - der populus Romanus und die Quiriten. Die Gebetsformeln quarum rerum ergo und quodque melius siet sind aus Cato bekannt. ${ }^{268}$ In seiner Analyse der Gebete der Säkularfeier hat Diehl nachweisen können, dass die bei Cato überlieferten Privatgebete zahlreiche Parallelen zu den Gebeten der Säkularopfer aufweisen. Neu jedoch ist für die Säkularfeier der Zusatz p(opulo) R(omano), Quiritibus als von den Göttern zu berücksichtigende Gruppe. Damit wird der bei Cato erkennbare Rahmen eines Privatgebets gesprengt und das Gebet zu einem "Staatsgebet«, wie Diehl es nennt. ${ }^{269}$ Solche Gebete zugunsten des Staates sind in der römischen Geschichte schon immer bekannt. ${ }^{270}$ Dass an einem Anlass wie der Säkularfeier für das Wohlergehen des Staates gebetet wurde, erstaunt nicht weiter. Da uns der Wortlaut von nur sehr wenigen Gebeten bekannt ist und diese eine große Übereinstimmung in den Formeln haben, müssen wir davon ausgehen, dass den 'Schöpfern< eines neuen Gebets zur Säkularfeier nur ein geringer Freiraum blieb. Das zeigt auch das zweite vollständig überlieferte Gebet des commentarium, das Supplikationsgebet der Matronen an Iuno, das mit dem hier vorliegenden Opfergebet an die Moiren - abgesehen von einem Zusatz in der Gebetsformel, der es als Supplikationsgebet erkennen lässt - völlig identisch ist. Möglichkeiten zu inhaltlichen Anpassungen bestanden - wie in diesem Fall geschehen - in der Einleitung des Gebets, die die Möglichkeit bot, den Namen der angebeteten Gottheit, die Opfergabe und den >Absender<

267 Im Gegensatz dazu verzeichnet das commentarium für die Opfer an die Ilithyien Gebete an jede einzelne der Göttinnen, das heißt, jede der drei Ilithyien erhielt ihre drei Arten von Opferkuchen. Vgl. Z. i I s-i i 8.

268 Cato agr. I4I, if.; Diehl (I934/35) $358 \mathrm{ff}$. liefert eine Zusammenstellung aller Gebetsformeln der Inschrift und anderer überlieferter Gebete.

269 Diehl (1934/35) 268f.; 368. Die Formulierung "Staatsgebet« wirft einige Fragen auf. Für Diehl bedeutete »Staatsgebet« offensichtlich eine Art unredlicher Verdrehung eines rituellen Textes. Da der Bestand an rituellen Gebetstexten jedoch nicht verschiedene Vorlagen umfasste, sondern nur eine einzige, die mit kleinen Eingriffen an den jeweiligen Anlass angepasst wurde, kann diese Einschätzung nicht übernommen werden. Das Gebet der Säkularspiele beruht auf dem üblichen Gebet, das zu verschiedenen Anlässen in ähnlichem Wortlaut gebetet wurde. Es wurde in diesem Fall auf den gesamten populus Romanus ausgeweitet, weil die Säkularspiele ein Fest der gesamten Bürgerschaft waren. Dass Säkularspiele und die dazugehörigen Opfer ein Anlass der gesamten Bürgerschaft waren, geht aus ihrer Geschichte, ihrer Aussage (Erhalt des Staates durch Sicherung der Nachkommenschaft) und aus der Inschrift selbst hervor: Z.65 (OMNES LIBE[ri]).

270 Diehl (1934/35) $358 \mathrm{ff}$. berücksichtigt in seiner Zusammenstellung die wichtigsten bei Livius überlieferten Staatsgebete. 
des Gebets, das heißt denjenigen, dem Gebet und Opfer nutzen sollten, einzufügen.

Als Attribut zu den Opfertieren ergänzt Pighi richtig propriis. Damit wird ausgedrückt, dass das Opfer in Art, Farbe und Geschlecht zu der betreffenden Gottheit passt. Die Opfertiere für die chthonischen Göttinnen des Tarentum mussten nach dem Orakel weiblich und dunkel sein. ${ }^{27}$ Bei quaeso precorque handelt es sich um die übliche Einleitungsformel für die Bitten eines Gebets. ${ }^{272}$ Die Wendung sacrum fiat ist als Formel für andere Gebete nicht belegt. ${ }^{273}$ Dieser Ausdruck hat an dieser Stelle die Funktion, die Opfergabe schon am Anfang und nicht erst am Ende des Gebets nennen zu können, weil die folgenden Opfergebete nach der Einleitung abgekürzt wurden und die Opfergaben für die folgenden Götter in den abgekürzten Gebeten sonst nicht erwähnt wären. ${ }^{274}$ Die hier vorliegenden Gebete stellen eine Kombination aus zwei bei Cato überlieferten Gebetstypen dar, die einerseits erlaubt, eine längere Liste von Bitten aufzuführen und andererseits doch das Opfer gleich am Anfang zu nennen, wie es sonst nur in einem kurzen Gebet der Fall ist.

93-99 Der zweite Teil des Gebets enthält die Erwartungen der Opfernden an die Gottheit für dieses Opfer, die in Form von finalen Sätzen ausgedrückt sind. Dabei handelt es sich durchweg um Bitten der Stärkung und Erhaltung des römischen Staates und seiner leitenden Kräfte. Der Wortlaut der Bitten beruht zum Teil ebenfalls auf Formulierungen aus Privatgebeten, wie sie bei Cato überliefert sind. Die verschiedenen Bitten lassen sich folgendermaßen gliedern:

27I Zos. 2, 6, 7-9.

272 Cato agr. I34, 2: bonas preces precor; 1 34, 3: bonas preces bene precor; I39: bonas preces precor - diese Formel ist in den catonischen Gebeten verwendet, wenn keine inhaltlich ausgeführten Bitten folgen, sondern allgemein um die Gunst der Gottheit gebetet wird. In dem Lustrationsgebet an Mars folgen auf die Formel te precor quaesoque (Cato agr. I4I, 2) mehrere mit uti eingeleitete Nebensätze, in welchen die verschiedenen Bitten an den Gott formuliert sind, ähnlich wie in dem vorliegenden Moirengebet.

273 Diehl (1934) 359 führt folgende Parallelstelle aus Liv. 25, I 2, Io an: decemviri Graeco ritu hostiis sacra faciant. Es handelt sich hier aber nicht um ein wörtlich zitiertes Gebet, sondern um ein gesungenes carmen, welches den Römern nahelegt, die ludi Apollinares zu gründen.

274 In den bei Cato überlieferten Gebeten geschieht die Nennung der Opfergabe in den kurzen Gebeten entweder durch den Zusatz eines Ablativs zu precor, wobei das Opfer später nicht mehr erwähnt wird (Cato agr. I34, 2f.; I39), oder das Opfer ist nur am Ende eines längeren Gebets nach der Aufzählung der verschiedenen mit uti eingeleiteten Bitten genannt, wie dies in dem Lustrationsgebet an Mars (Cato agr. I 4 I, 3) der Fall ist. 
I. uti vos imperium maiestatemque p(opuli) R(omani),]| QVIRITIVM DVELLI DOMIQVE AV[xitis

2. utique semper Latinus obtemperassit,

3. sempiter-] NAM VICTORIAM VALETVDINE[m p(opulo) R(omano), Quiritibus duitis

4. faveatisque p(opulo) R(omano), Quiritibus legionibusque p(opuli) $R$ (omani),] $\mid Q V I R I T I V M$

5. REMQVE P(ublicam) POPVLI R(omani), [Quiritium salvam servetis maioremque faxitis,

6. uti sitis] VOLENTES PR[opitiae p(opulo) R(omano),] |QVIRITIBVS, XVVIR(or)VM COLLEGI[o, mibi, domo familiaeque,

7. uti huius] SACRIFICI ACCEPTRICES SITIS VIIII AGNARVM | FEMINARVM ET VIIII CAPRARV[m feminarum propri]ARVM INMOLANDARVM

Im Folgenden werden die einzelnen Bitten der Reihe nach untersucht: I. Bitte, Z. 93 f.: [uti vos imperium maiestatemque p(opuli) R(omani),] | QVIRITIVM DVELLI DOMIQVE AV[xitis. Die Einfügung des Wortes imperium hat erstmals Mommsen vorgenommen, sie ist in dieser Form im Gebet an Terra Mater des severischen commentarium erhalten, womit diese Ergänzung gestützt ist. ${ }^{275}$ Es handelt sich bei dieser Formulierung nicht um eine Gebetsformel, aber wahrscheinlich um eine traditionelle offizielle Wendung, obwohl keine direkte alte Quelle dies belegt. ${ }^{276}$ Duelli domique ist wegen der altertümlichen sprachlichen Form als alte Form erkennbar, ebenso wie auxitis. ${ }^{277}$

2. Bitte, Z. 94: [uti semper Latinus obtemperassit]. Diese Formulierung des Gebets hat zu vielfältigen Diskussionen Anlass gegeben. Es handelt sich um eine Ergänzung, die durch den Fund neuer Fragmente der severischen Inschrift im Jahre 1930 möglich wurde. ${ }^{278}$ Auch dafür findet sich kein

275 Act. Sev. 226; Diehl (1934) 359 führt als weiteren Beleg Liv. 26, 3 I, I an: Non adeo maiestatis ... populi Romani imperiique huius oblitus sum ... Es handelt sich hier aber nicht um ein Staatsgebet, wie Diehl meint, sondern um eine Senatsrede des Konsuls Marcellus aus dem Jahre 2 ro v. Chr. Auch die zweite von Diehl angeführte Liviusstelle (Liv. 2, 27, I I) enthält den Ausdruck nicht aus einem Staatsgebet, sondern es werden die Worte des Konsuls Appius Claudius aus dem Jahre 495 v. Chr. wiedergegeben. Insofern wird der Gebetstext nicht durch diese Parallelstellen von Livius gestützt. Man kann aber davon ausgehen, dass es sich um eine an feierlichen Anlässen gebräuchliche Ausdrucksweise handelte.

276 Harris (1985) 266; anders Gundel (1963) 30If., der diese Formulierung für eine Schöpfung des Ateius Capito hält.

277 Diehl (1934) 359 führt für auxitis an: Liv. 29, 27, 3 (ebenfalls ein Gebetstext); für duelli domique: Plaut. asin. 559.

278 Über die neuen Funde: Romanelli (1931); Hülsen (1932). Vgl. Act. Sev. I 86 und 232. 
alter Paralleltext und doch stimmt man allgemein überein, dass es sich wahrscheinlich um ein Element eines alten magistralen oder kultischen Textes handelt. ${ }^{279}$ Grund ist die Anspielung auf die alte Bundesgenossenschaft zwischen Römern und Latinern, die wegen Unabhängigkeitsbestrebungen der Latiner mehrmals gefährdet war, worauf offenbar schon in alten kultischen Texten angespielt wurde. ${ }^{280}$ Auch das Orakel der augusteischen Sibylle spricht den Zusammenhalt ganz Italiens an. ${ }^{28}$ Da zur Zeit der augusteischen Säkularfeier dieser Zusammenhalt zwar nicht gefährdet war, jedoch die Integration der italischen Bevölkerung eine wichtige Voraussetzung der augusteischen Politik war, konnte dieser alte Passus in einem neuen Zusammenhang erscheinen und gleichzeitig als eine uralte Forderung die augusteischen ludi saeculares an republikanische Zeiten anknüpfen lassen. ${ }^{282}$

3. Bitte, Z. 94 f.: [sempiter-] NAM VICTORIAM VALETVDINE[m p(opulo) R(omano), Quiritibus duitis. Die Bitte um valetudo ist aus den bei Cato überlieferten Privatgebeten bekannt, allerdings nicht in Verbindung mit victoria, sondern salus. ${ }^{283}$ Die Bitte um salus enthält wie die um victoria bereits die Komponente der Überlegenheit über andere. Durch die Verbindung mit victoria wird die ursprünglich persönliche Bitte um körperliche Unversehrtheit und Überlegenheit in den politischen Bereich transferiert.

4. Bitte, Z. 95 f.: [faveatisque p(opulo) R(omano), Quiritibus legionibusque p(opuli) R(omani),]|QVIRITIVM. Für diese Bitte liegt keinerlei Vorbild aus älteren Texten vor. Das Verb faveatis ist im augusteischen und severischen commentarium ergänzt, es scheint sich um eine allgemeine Fürbitte $\mathrm{zu}$ handeln, hier unter Einbeziehung der römischen Legionen, die nicht in die anderen Bitten einbezogen sind. ${ }^{284}$ Mit der Adressierung

279 Die Existenz dieser Bitte im Gebet der Säkularfeier wird für die Datierung republikanischer Säkularfeiern genutzt, indem man davon ausgeht, dass eine Bitte um Unterwerfung der Latiner damals in das Säkulargebet oder ein Staatsgebet aufgenommen wurde, als sie aktuell war. Dies war Mitte des vierten vorchristlichen Jahrhunderts der Fall, sodass die Aufnahme dieses Passus des Gebets anlässlich der Säkularspiele von 348 v. Chr. geschehen sein könnte, dazu Taylor (1934) I03-107. Auch Harris (1985) I2 If. hält es für möglich, dass schon zahlreiche alte kultische Texte die Eroberungspolitik Roms zum Inhalt hatten und dass das augusteische Gebet der Säkularfeier in diesem Sinne keine Neuerung darstellt, sondern auf alte Formulierungen zurückgreift. Vgl. Kap. A.5, S. I $72 \mathrm{f}$.

280 Taylor (I934) I I 2-I I 5 .

28 I Zos. 2, 6, $36 \mathrm{ff}$.

282 Scheid (r993b) I $20 \mathrm{ff}$.

283 Diehl (1934) 360 zitiert Cato, agr. I4I,3: duisque duonam salutem valetudinemque; Liv. I0, I9, I7: si nobis victoriam duis.

284 Act. Sev. I 86. 
dieser Bitte an die den Nachwuchs fördernden Göttinnen des Tarentum wird klar, worauf die Macht des populus Romanus beruht, die nur erhalten bleiben kann, wenn die Götter den Bestand des römischen Volkes und seiner Legionen durch genügend Nachwuchs sichern. Als Inhaber des imperium consulare hatte Augustus die absolute Befehlsgewalt über die Legionen inne, der Einbezug der Legionen in das Gebet ist daher auch als Ausdruck der Verantwortung des patronus zu verstehen. ${ }^{285}$

5. Bitte, Z. 96: REMQVE P(ublicam) POPVLI R[(omani), Quiritium salvam servetis maioremque faxitis. ${ }^{286}$ Die überlieferten Gebete bieten nur für die Formulierung salvam servetis eine Parallele. ${ }^{287}$ Das Element maiorem faxitis fehlt bei Cato und ebenso in den Gebeten der Arvalbrüder. Es handelt sich wiederum um eine sehr allgemeine Bitte um Gesunderhaltung, die hier durch die Verknüpfung mit maiorem faxitis wieder gesteigert wird und einen politischen Charakter erhält. Vielleicht liegt in dieser Bitte noch eine vage Anlehnung an die ursprüngliche Aussage der Säkularspiele, die wohl im Anschluss an eine gesundheitliche Bedrohung und Dezimierung der Bevölkerung stattgefunden haben. ${ }^{288}$

6. Bitte, Z. 96f.: uti sitis] VOLENTES PR[opitiae p(opulo) R(omano),] | QVIRITIBVS XVVI(or)RVM COLLEGI[o, mibi, domo familiaeque. Alle bei Cato überlieferten Gebete enthalten diese Formel, was darauf hinweist, dass es sich um eine der klassischen Gebetsformeln handelt. ${ }^{289}$ Damit weist dieses Gebet nach den Bitten, die inhaltlich die Stärke, Bewahrung und Überlegenheit des Staates betrafen und vielleicht aus allgemein bekannten Formulierungen in das Gebet integriert worden waren, wieder eine typische Gebetsformel auf. Die Catostellen zeigen, dass die Reihenfolge der ins Wohlwollen der Götter einbezogenen Personen variieren kann. In dieser Weise wurde im augusteischen Gebet der Kreis des populus Romanus und der Quiriten erweitert. Darüber hinaus werden nämlich erstmals die Quindecimviri eingeschlossen. Auch Augustus selbst, seine Familie und alle Sklaven werden in das Gebet einbezogen.

285 Ende I 8 v. Chr. wurde Augustus das imperium consulare verliehen; Agrippa war das imperium proconsulare am I. Juli I 8 v. Chr. verlängert worden. Vgl. Kienast/Eck/ Heil (2017) 57 und 65.

286 In der Abkürzung von p(ublicam) und Ausschreibung von populi liegt wahrscheinlich ein Fehler des Steinmetzen vor.

287 Cato agr. I4I, 3: pastores pecua salva servassis; in den Arvalakten ist diese Wendung ebenfalls mehrfach überliefert. Vgl. Scheid (I998c): 5a-e, I 3; 48, 48; 54, 58, I9; 59, I, 5: eosque salvos servaveris ex periculis.

288 Kap. A.I 2, S. 268 f.

289 Cato agr. I 34, 2; I 39; I4 I, 2; in den bei Cato überlieferten Gebeten wird diese Bitte immer direkt als erste nach dem einleitenden precor uti angeführt, in den kurzen Gebeten bleibt sie die einzige ausgesprochene Bitte. Daraus schließe ich, dass es sich um die wichtigste und gleichzeitig auch die allgemeinste Bitte des Gebets handelt. 
7. Bitte, Z. 97f.: uti huius] SACRIFICI ACCEPTRICES SITIS VIIII AGNARVM |FEMINARVM ET VIIII CAPRARV[m feminarum propri]arum inmolandarum. Diese letzte Bitte des Gebets gibt noch einmal die Opfergabe an und bittet die Moiren um deren Annahme. Wir finden in den Gebetsvorlagen bei Cato zwar keine vergleichbare sprachliche Formulierung, wohl aber am Ende des Lustrationsgebets an Mars den im Imperativ formulierten Wunsch, der Gott solle sich durch das Opfer geehrt zeigen, das heißt, er soll es annehmen. Diese Bitte ist bei Cato zweimal hintereinander fast gleich formuliert. ${ }^{290}$ Einer dieser Bitten entspricht wohl das acceptrices sitis VIIII agnarum. ${ }^{291}$

98f. Die bei Cato gebrauchte Formel harum rerum ergo ... macte ... wird nach der Bitte acceptrices sitis auch im commentarium gebraucht, allerdings wird im Zusammenhang damit nur ein Opfertier erwähnt (Z. $98 \mathrm{f}$.: HARVM RERVM ERGO MACTE HAC AGNA FEMINA | INMOLANDA ESTOTE FITOTE [volentes] PROPITIAE P(opulo) R(omano), QVIRITIBVS, XVVIR(or)VM COLLEGIO, MIHI, DOMO, FAMI$L I A E$ ). Diese Formulierung hängt mit der gleichzeitig ausgeführten Geste beim Opferritus zusammen, das heißt, während Augustus an einem Tier die immolatio vornahm, sprach er dabei jedes Mal diese Worte. Auf diese Weise wurde dieser Teil achtzehnmal wiederholt. Die einmalige Aufzeichnung mit nur einem Opfertier in der Inschrift hat stellvertretenden Charakter, weil man sie nicht achtzehnmal aufführen wollte und konnte. Um aber dennoch alle Opfertiere den Moiren auch in der Überlieferung zu empfehlen, wurde vorher die Bitte um Annahme aller Tiere ausgesprochen und inschriftlich verzeichnet (uti acceptrices sitis). Erst dann wird die klassische Opferformel überliefert, die für jedes einzelne Tier ausgesprochen wurde und dann tatsächlich jede immolatio begleitete. Auch grammatikalisch lässt sich diese Interpretation stützen: Die von quaeso precorque abhängigen Bitten, die alle mit uti eingeleitet werden, sind in Z. 98 abgeschlossen. Danach beginnt eine neue Satzkonstruktion, wobei die Göttinnen mit Imperativen aufgefordert werden (estote fitote [volen-

290 Act. Sev. I87; Cato agr. I4I, 3: Harunce rerum ergo, fundi terrae agrique mei lustrandi lustrique faciendi ergo, sicuti dixi, macte hisce suovitaurilibus lactentibus immolandis esto. Mars pater, eiusdem rei ergo, macte hisce suovitaurilibus lactentibus esto.

29I In Z. 98 schlägt Diehl (1934/35) 36r pulchr]ARVM statt propri]ARVM vor. Wie schon im Kommentar zur Textkonstitution besprochen (S. 63), ist hier propri]ARVM vorzuziehen, weil pulcher als Attribut in den Gebeten nur für die Großtieropfer für Iuno und Iuppiter gebraucht wird. Dazu kommt, dass schwarze Lämmer und Ziegen für die Moiren als der Unterwelt verbundene Göttinnen das charakteristische Opfer darstellen, ebenso wie für Terra Mater eine trächtige Sau das charakteristische Opfer ist; in ihrem Gebet (Z. I 37) ist an der entsprechenden Stelle propria erhalten. 
tes] propitiae), jedes Opfertier anzunehmen. Diese klassische Opferformel (volens propitius esse) ist in allen Gebeten bei Cato überliefert, sie gehört unverzichtbar zum Opfer dazu und drückt die Bitte um Wohlwollen der Götter aus, das mittels des Opfers erlangt werden soll. Man kann davon ausgehen, dass diese Bitte deshalb bei der immolatio eines jeden Tieres wiederholt wurde, das heißt, die Fürbitte für den populus Romanus, die Quiriten, die Quindecimviri und Augustus und seine $\mathrm{Fa}$ milie wurden insgesamt achtzehnmal ausgesprochen und einmal bei der alle Opfer zusammenfassenden Bitte (Z. 97 f.). Während diese Fürbitte noch ganz allgemein gehalten ist und alle Opfertiere zusammen nennt, wird sie in Z. $98 \mathrm{f}$. mit der Nennung jedes einzelnen Opfertieres ganz konkret (hac agna femina immolanda). Auch darin sehe ich einen Hinweis, dass es jetzt um die Opferung jedes einzelnen Tieres geht. ${ }^{292}$

Die Analyse des Opfergebets zeigt, dass die Organisatoren der augusteischen Feier formal dem Erscheinungsbild eines Gebetes Rechnung getragen haben. Das Gebet weist im Aufbau und in den charakteristischen Formeln die Elemente eines traditionellen Gebets auf. Der Inhalt wurde aber völlig neugestaltet, für die Formulierung wurde wahrscheinlich zu einem großen Teil auf bereits existierende Wendungen aus der magistralen und kultischen Sprache zurückgegriffen. Zum Teil wird es in seinen Formulierungen bewusst archaisierend gehalten, um das Gebet der Säkularfeier als alt erscheinen zu lassen. ${ }^{293}$ Sein Hauptanliegen war die Erhaltung und Stärkung des römischen Staates und seiner Bevölkerung. Dem entspricht die achtmalige Wiederholung des Wortes Quirites im Gebet, das während der immolatio jedes einzelnen Tieres noch einmal fiel - also insgesamt 26-mal ausgesprochen wurde. Daraus geht hervor, dass die Säkularfeier und die Gebete Angelegenheiten der gesamten Bürgerschaft waren und diesem Anliegen des Festes auch in den Gebeten Ausdruck verliehen wurde. In der inschriftlichen Gestaltung des commentarium findet sich eine Entsprechung davon: Das Wort Quirites ist immer voll ausgeschrieben und befindet sich oft in auffälliger Position am Anfang der Zeile. ${ }^{294}$ Ebenfalls als Neuerung kann die Einbeziehung des Augustus und seiner Familie in das Gebet gewertet werden, obwohl wir keine anderen

292 Ein Vergleich mit dem fast gleichlautenden Supplikationsgebet der Matronen stützt diese These, denn das Supplikationsgebet endet mit der allgemeinen Fürbitte, die der 7. Bitte des Opfergebets entspricht; Z. I29-I 3 I.

293 Dazu bestand ein wichtiger Grund, weil man eine Reihe von Säkularfeiern konstruiert hatte, die bis ins Jahr 456 v. Chr. zurückreichte.

294 Dies gilt in gleicher Weise für das vollständig wiedergegebene Supplikationsgebet der Matronen (Z. I 25-I 3 I), auch hier steht das Wort Quirites bei insgesamt neunmaliger Erwähnung dreimal am linken Rand. Die commentarii der Arvalbrüder enthalten dagegen das Wort Quirites stets mit Q. abgekürzt. 
Staatsgebete aus dieser Zeit überliefert haben. Dass die Möglichkeit der Erwähnung des Augustus im Gebet vollständig ausgeschöpft wurde, zeigt seine I 8-malige Wiederholung bei der immolatio jedes einzelnen Opfertieres. Hierbei handelt es sich um eine bewusste Konstruktion in der Anlage des Gebetes, die auf die Form eines privaten Opfergebets zurückgreift, wie es bei Cato überliefert ist. Auch dort betet der Opfernde immer für sich und seine Familie. Bei den Opfern auf dem Tarentum ist Augustus der Opfernde, es liegt demnach nichts Ungewöhnliches darin, dass er für sich und seine Familie betet. Aber dadurch, dass diese Form des privaten Gebets in ein Staatsgebet übertragen wurde, erhält die Fürbitte für den Opfernden eine andere Dimension. Das Gebet ist als eine Neuschöpfung zu verstehen, die sich die alten Formen auf kaum wahrnehmbare Weise zunutze macht, um neue Inhalte darin auszudrücken. ${ }^{295}$

I००-I०2 Dieser Abschnitt schildert protokollarisch die an das Opfer anschließenden rituellen Feierlichkeiten der ersten Nacht. Dazu gehören Spiele und das Gemeinschaftsmahl der I I $\circ$ Matronen, die sellisternia. ${ }^{296}$ Beide Handlungen sind als ritueller Abschluss des Opfers zu verstehen. Es handelt sich um sakrale Spiele, die anschließend an die Opferzeremonien in der Nähe des Opferplatzes an einer improvisierten Spielstätte ohne Sitzplätze durchgeführt worden sind. ${ }^{297}$ Die Opfer haben nach Zosimus in der zweiten Stunde der Nacht begonnen und mit allen dazugehörenden Zeremonien sicher einige Stunden in Anspruch genommen, auch wenn man davon ausgeht, dass Augustus sich die Aufgabe des Opferns mit den Quindecimviri geteilt hat. ${ }^{298}$ Mit den anschließenden Spielen haben die

295 Mit dieser Einschätzung des Gebets schließe ich mich Diehl (1934) $366 \mathrm{ff}$. an, der allerdings den Gesamtcharakter der Feier anders versteht. Für Diehl (S. 370) handelt es sich um ein »Freudenfest der Auferstehung und der Erneuerung, den Blick der besseren Zukunft zugewandt «.

296 Nach Piganiol (1923) I 37 ff. ist jede Art von Spielen auf einen sakralen Hintergrund zurückzuführen, das heißt, dass Spiele als religiöser Ritus zu verstehen sind. Dafür spricht die Tatsache, dass die augusteischen und severischen commentaria die Spiele nach den Opferriten erwähnen. Wenn man davon ausgeht, dass der zweite protokollarische Teil des augusteischen commentarium nur die stattgefundenen Riten in ihrer zeitlichen Abfolge aufzeichnet, müssen die Spiele ein Teil dieser Riten gewesen sein.

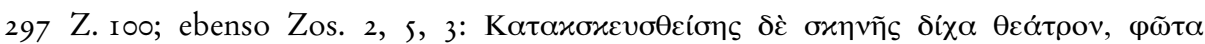

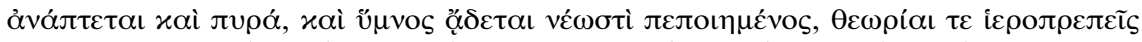

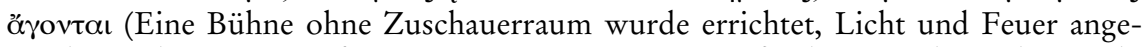
zündet und ein neu verfasster Hymnos gesungen. Außerdem wurden Schauspiele aufgeführt, die dem heiligen Ort angemessen waren). $\mathrm{Zu}$ der Einführung der ludi scaenici in Rom und ihre Bedeutung vgl. Bernstein (I998) I I9-I42.

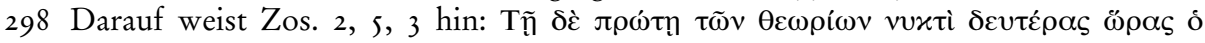

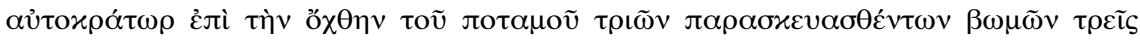

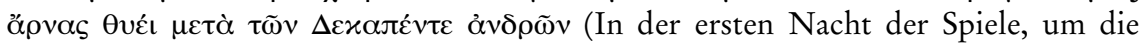


Zeremonien der ersten Nacht sehr lange gedauert, denn die Spiele des ersten Tages am sehr frühen Morgen setzen die Spiele der Nacht ohne Unterbrechung fort. ${ }^{299}$ Über den Charakter dieser Spiele weiß man bisher sehr wenig. Wissowa äußert die Vermutung, dass diese mit »allerlei Verkleidung und Mummenschanz« durchgeführten Aufführungen eine rituelle Bedeutung hatten, die uns vollständig verborgen ist. ${ }^{300}$ Diese Spiele hatten wahrscheinlich die wichtige Funktion der Sinngebung und Einbettung der Säkularfeier in einen mythologischen Zusammenhang, aus dem sich der religiöse Sinn der Feier ableitete. Sie werden im commentarium als ludi scaenici, ludi Latini oder ludi sollemnes bezeichnet. ${ }^{301}$ Dass die ganze Feier aufgrund der stattfindenden ludi als ludi saeculares überliefert ist, ist ein deutlicher Hinweis auf die wichtige Funktion dieser Spiele. Da wir von diesen rituellen Spielen der Säkularfeier nur wissen, wann und wo sie aufgeführt worden sind, aber keinerlei Angaben bei anderen Autoren über ihren Inhalt haben, sind alle Aussagen über die Gestaltung dieser ludi im Bereich der Vermutung angesiedelt. Nur Zosimus macht eine Anspielung auf die möglichen Aufführungsbedingungen der Spiele: Eine Bühne ohne Zuschauerraum wurde errichtet, man zündete Fackeln und Scheiterhaufen an und ein gerade erst verfasster Festgesang wurde gesungen, dann wurden Spiele, die dem heiligen Ort angemessen waren, aufgeführt. ${ }^{302}$ Es ist denkbar, dass die Landung des Valesius am Tiberufer zur Rettung seiner an der Pest erkrankten Kinder szenisch nachgespielt wurde. Ein Grund dafür liegt in dem Wort івролюєлєгॅ, da der Schauplatz der Spiele mit dem heiligen Ort im Mythos zusammenfällt. Es ist ein Kennzeichen sakraler Spiele im Unterschied zu rein weltlichen Spielen, dass sie im Heiligtum oder in dessen Nähe stattfinden. Wahrscheinlich wird deshalb in der Inschrift erwähnt, dass die Spiele nicht in einem Theater, sondern an einem Schauplatz ohne Bühnenwand und Zuschauerbänke stattfanden, also am heiligen Ort selbst. ${ }^{303}$ Bei dem für den Anlass der Säkularfeier verfassten Hymnos

zweite Stunde opfert der Kaiser zusammen mit den Quindecimviri an der Böschung des Flusses auf drei errichteten Altären drei Lämmer).

299 Z. Io9f.: NEQVE SVNT L[udi in]TERMISSI IEI QVI NOCTV COEPTI ERANT| FIERI.

300 Wissowa (I9I2) $449 \mathrm{f}$.

3०I Z. 83: LVDOS LATINOS SAECVLARES; Z. 85, I08: LVDOS LATINOS; Z. I 53: LVDIS SCAENICICS; Z. I 66, I60: LVDIS SOLLEMNIBVS.

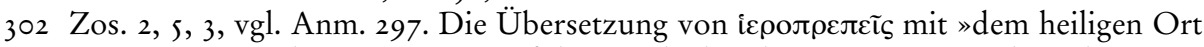
angemessen« ist hier mit Bezug auf die Geschichte des Ortes zu verstehen, der seit je als nur für Säkularspiele reservierter Kultort galt.

303 Valerius Maximus $(2,4,2)$ überliefert einen Senatsbeschluss des Jahres I 55 v. Chr., in welchem das Anschauen von Spielen sitzenderweise untersagt wird. Weitere Belege für den Widerstand gegen ausgebaute Theater bei Pighi (I94I) I26. Es scheint sich 
handelt es sich nicht um das carmen saeculare des Horaz, das erst am letzten Tag der Spiele zur Aufführung kam, sondern um einen nicht weiter bestimmbaren Festgesang, der möglicherweise auch Anspielungen auf den Mythos enthielt, aber nicht frei improvisiert wurde. ${ }^{04} \mathrm{Da}$ das commentarium die Spiele auch als ludi Latini bezeichnet, muss man bei den Theaterspielen von der Form her eher ein improvisiertes szenisches Spielen vermuten als vorformulierte Theaterstücke. ${ }^{305}$ Deswegen können von ihnen keine schriftlichen Zeugnisse vorliegen. Die Vermutung, dass in diesen Aufführungen der bisher nicht explizit erwähnte Mythos zu seinem Recht kam, drängt sich also auf. Für die Aufführung sollte man davon ausgehen, dass für die Improvisationen Vorgaben als Richtlinien galten, die in einem Bezug zu dem Anlass standen - oder wenigstens zu dem Ort des Anlasses, wie es Zosimus überliefert. Diese Forderung erfüllt der Mythos. ${ }^{306}$

Daneben oder danach feierten die Frauen sellisternia auf dem Kapitol für Iuno und Diana, wobei erwähnt wird, dass für die beiden Göttinnen zwei Sessel aufgestellt worden sind. ${ }^{307}$ Auf die sellisternia war vorher mit einem Edikt eingegangen worden, worauf der Text jetzt ausdrücklich hinweist. ${ }^{308}$ Bei den sellisternia handelt es sich ebenso wie bei den lectisternia um Kultakte, die dem griechischen Ritus entstammen und die in außerordentlichen Notsituationen übernommen worden waren, wenn die gewöhnlichen Mittel nicht auszureichen schienen. ${ }^{309}$ sellisternia stellen eine Variante dar, bei der die Teilnehmerinnen nicht mehr gemeinsam mit den

dabei um eine alte Abneigung der Römer aus einer frühen Zeit zu handeln, die sicherlich religiös-kultisch begründet war. Dazu auch Poe (1984) $64 \mathrm{f}$.

304 Scheid (1993b) I I 3 n. I 3 weist darauf hin, dass es sich bei dieser Angabe von Zosimus nicht um eine Verwechslung mit dem carmen saeculare des dritten Tages handelt, wie Pighi (1965) 54 Anm. 8 meinte, sondern dass es durchaus vorstellbar sei, dass auch an den ludi eigens produzierte Aufführungen vorgetragen wurden. Auf das carmen saeculare weist Zosimus nämlich noch bei den Angaben über den dritten Tag hin (2, 5, 5). Außerdem zeigt das Attribut iєролюєлєг̃ sehr deutlich, dass die ludi wahrscheinlich nicht, wie üblicherweise übersetzt wird, dem heiligen Charakter der Feier, sondern dass sie dem Ort, also dem Heiligtum, angemessen waren.

305 Wissowa (1912) 463 .

306 Bei den Spielen der Säkularfeier, die im Anschluss an die Opfer stattfanden, handelt es sich also nicht um Wettkampfspiele, die ebenfalls im Anschluss an Opfer ausgetragen wurden. Bei diesen Wettkampfspielen lag der religiöse Hintergrund in einer Art Zurschaustellung göttlicher Tugenden, die sich im Sieger manifestierten; vgl. Scheid (I990a) 663 f. Die Frage nach dem religiösen Hintergrund der ludi scaenici der Säkularspiele ist wahrscheinlich in der inhaltlichen Aussage dieser Spiele zu suchen, durch die die Zuschauer auf den göttlichen Willen hingewiesen wurden.

$307 \mathrm{Zu}$ sellisternia vgl. oben zu Z. I 5-I9, S. $88 \mathrm{ff}$.

308 Vgl. Z. 7if.

309 Lectisternia sind erstmals für das Jahr 399 überliefert: Liv. 5, I 3, 6; Dion. Hal. I 2, 9 f. 
männlichen Teilnehmern auf einem lectus liegen, sondern auf Sesseln sitzen. Sie wurden speziell für weibliche Gottheiten ausgerichtet. ${ }^{30}$ Das Besondere solcher Götterspeisungen war die aktive Teilnahme einer größeren Gruppe an einer rituellen Handlung und die Möglichkeit dadurch diese Gruppe vor den anderen Festteilnehmern zu ehren. Das severische commentarium belegt, dass die Matronen in Zusammenhang mit den sellisternia eigene Opfer durchführten, eine im römischen Kult sehr ungewöhnliche Ehre für Frauen. ${ }^{31}$ Im Fall der ludi saeculares kam den Matronen eine solche Ehrerweisung zu, weil sie als Mütter oder zukünftige Mütter des römischen Volkes die besondere Aufgabe der Reproduktion erfüllten und ihnen dafür an dieser Stelle eine aktive Rolle in der Kultausübung zugestanden wurde. ${ }^{312}$ Die sechsmalige besondere Ehrung der Matronen durch sellisternia fügt sich in die Gesamtaussage der ludi saeculares als ein Fest zur Bewusstmachung der Bedeutung einer zahlreichen und gesunden Nachkommenschaft.

103-109 In diesen sieben Zeilen werden die religiösen Handlungen am Tage des I. Juni wiedergegeben. Sie richten sich in ihrem Aufbau streng nach den Angaben, die das commentarium über das Moiren-Opfer der ersten Nacht macht. Es handelt sich um die Opfer zweier Ochsen, die von Augustus und Agrippa durchgeführt wurden, vor dem Tempel des Iuppiter Optimus Maximus auf dem Kapitol.

I03f. Wie in Z. 9of. werden hier Datum und Ort des Opfers, Art der Opfergabe, der berücksichtigte Gott und die Ausführenden des Opfers angegeben. Das Opfer des ersten Tages findet im Zentrum der Stadt, auf dem Kapitol, vor dem Tempel des Iuppiter Optimus Maximus statt. Es fällt auf, dass in der Einleitung zum Gebet nur steht, dass ein Ochse von Augustus dem Iuppiter geopfert wurde, daran anschließend, dass ein zweiter Ochse an demselben Ort von Agrippa geopfert wurde und nicht, dass dem Iuppiter zwei Ochsen geopfert wurden. ${ }^{313}$ Wahrscheinlich geht diese Einleitung auf den Gebetstext zurück, in dem jeder der beiden Opfernden einen Ochsen genannt hat. Diese Art der Formulierung macht klar, dass Augustus und Agrippa nicht gemeinsam zwei Opfer vollbracht

3 Io Val. Max. 2, I, 2; dabei handelt es sich nicht nur um einen römischen Brauch, wie Wissowa (I9I2) 423 annimmt, sondern wohl ebenfalls um ein griechisches Vorbild; Latte (1960) 243, Anm. 5.

3 i I Vgl. oben zu Z. i 5-i 9 , S. 89 f.

3 I 2 Zur aktiven Rolle der Matronen an den sellisternia durch eigene Opfer vgl. oben zu Z. I 5-ig, S. 89 f.

3 I 3 Darauf, dass ein Ochse das klassische Opfer für Iuppiter war, verweist das Attribut

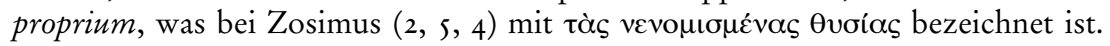


haben, sondern jeder ein Opfer nacheinander. ${ }^{314}$ Dieser Interpretation entspricht auch eine scheinbare Inkonsistenz des folgenden Textes: In Z. IO4 wird dem Gebetstext einleitend p[re]cati autem sunt ita vorangestellt, was auch bedeuten könnte, dass beide gemeinsam gebetet haben. Im Gebet selbst heißt es aber in Z. I06: quaeso precorque. Demnach hat jeder zu seinem Opfer ein Gebet gesprochen, und weil es sich in beiden Fällen um dasselbe Gebet handelte und das commentarium nicht beide überliefern wollte, steht einleitend für die Gebete: precati autem sunt ita. Daraus wird erkennbar, dass Agrippa hier nicht eine assistierende Funktion ausübte, wie die Quindecimviri während des Moiren-Opfers, sondern selbstständig als Opferer eines zweiten Ochsen nach Augustus auftrat.

rosf. Diese zwei Zeilen enthalten die Einleitung eines Gebets, an die sich bei vollständiger Wiedergabe die einzelnen von uti abhängigen Bitten anschließen. Die Anfänge der erhaltenen Gebete an Ilithyia und an Apollo weisen dieselben Angaben auf. ${ }^{315}$ Abweichend vom Gebet an die Moiren wird hier das Opfertier mit dem Attribut pulchro versehen, ein Attribut, das nur den Großtieropfern zukommt und das auch nur im Gebet selbst, also in der Rede vor dem Gott gebraucht wird und eine das Opfer preisende Funktion hat. ${ }^{316}$ In der Einleitung war das Opfer noch wie sonst üblich als proprium bezeichnet worden. ${ }^{37}$ Der ganze anschließende Gebetstext mit den Bitten ist abgekürzt mit der Formel cetera uti supra. $^{318}$ Diese Abkürzung soll darauf hinweisen, dass Iuppiter um die Erfüllung derselben Bitten gebeten wurde wie die Moiren im vorangegangenen, vollständig zitierten Gebet. Wie wir oben gesehen haben, bestanden die Bitten darin, den römischen Staat zu stärken und zu erhalten und mit ihm seinen Herrscher mit seinem Haus, seiner Familie und seinen Sklaven. Im Gebet des Agrippa werden bei gleichem Wortlaut das Haus, seine Familie und Sklaven einbezogen. Agrippas Frau, Iulia, war die

3 I 4 Im Gegensatz dazu steht die Opferung der je neun Schafe und Ziegen für die Moiren, die Augustus aufgrund der großen Zahl von Tieren wohl mithilfe der Quindecimviri auf die Schlachtung mit der immolatio und dem Gebet vorbereitete. In diesem Fall erwähnt das commentarium die Quindecimviri nicht, wir wissen nur von Zosimus (2, 5, 3), dass die Quindecimviri am Opfer beteiligt waren.

3 Is Z. I I7f.; I4 If.; ausführlich besprochen sind die entsprechenden Zeilen des Moirengebets oben zu Z. $90 \mathrm{f}$., S. i $8 \mathrm{fff}$.

3 I6 Vgl. Z. I22, wo dieses Attribut dem Färsenopfer an Iuno zukommt.

3 I7 Vgl. oben zu Z. 93, S. I 28.

3 I 8 Bereits im Moirengebet war vermieden worden, die Worte, die bei der immolatio eines jeden Tieres gesprochen wurden, aufzuzeichnen, ebenso ist hier das Gebet von Augustus und Agrippa nur einmal aufgezeichnet worden. Das commentarium hat bei der Aufzeichnung der Gebete zwar nicht Wiederholungen gescheut, aber eine gewisse Ökonomie verfolgt. Solche Abkürzungen finden sich auch in der severischen Inschrift: Act. Sev. 227. 
Tochter von Augustus, deren mit Agrippa gezeugte Kinder Caius und Lucius von Augustus im Jahre I7 v. Chr., kurz vor den Säkularspielen, adoptiert wurden. ${ }^{319}$

I07 Die Angaben des Opfers werden mit einer Anwesenheitsliste der Mitglieder des Kollegiums der Quindecimviri abgeschlossen, die an den religiösen Akten des I. Juni anwesend waren. Da die Zeremonien des Tages ohne Unterbrechung an die der Nacht anschlossen, muss man davon ausgehen, dass die hier aufgeführten Quindecimviri auch an den Riten der Nacht teilgenommen hatten. Solche Anwesenheitslisten finden sich in der Inschrift nur nach den Zeremonien des Tages. ${ }^{320}$ Dies belegt, dass die Riten der Nacht mit denen des Tages als Einheit empfunden wurden und dass die Opfer und Gebete in der Stadt als Erweiterung der eigentlichen nächtlichen Riten der Säkularfeier verstanden wurden. Es handelt sich um eine Ausweitung und ein Sichtbarmachen eines außerstädtischen Kultes in der Stadt. Die Säkularspiele erfuhren mit den Opfern am Tage in der Stadt eine beträchtliche Vergrößerung der Feier und durch die ständigen Prozessionen zwischen Stadt und Tarentum eine drei Tage währende ununterbrochene Bewegung und Aktivität der gesamten Bevölkerung, die den Bürgern den Eindruck einer aktiven Teilnahme vermittelten. Eine ähnliche Ausweitung eines Kultes zu den wichtigsten Kultstätten der Stadt Rom ist auch bei den Arvalbrüdern zu beobachten, allerdings ohne die massenhafte Beteiligung so vieler Menschen. ${ }^{321}$

Über die Auswahl der fünf Mitglieder des Kollegiums neben Augustus und Agrippa kann man keine Angaben machen, es scheint sich um eine nicht mehr nachvollziehbare oder zufällige Auswahl zu handeln.

Was genau mit atalla gemeint ist, ist nicht vollständig geklärt. Es handelt sich um ein Opfergefäß, dessen Name das Deminutivum von atana darstellt. ${ }^{322}$ In der Inschrift wird es aber nur bei den Opfern für Iuno und Iuppiter verwendet, also bei den Opfern großer Tiere. ${ }^{323}$

I०8f. Die letzten Zeilen mit Angaben des ersten Tages entsprechen ebenfalls vollständig den Abschlusszeilen der ersten Nacht (Z. I00-I02). Das Opfer wird abgeschlossen mit Spielen und sellisternia, die wieder von Frauen abgehalten werden, die in diesem Falle aber matres familiae genannt wer-

3 I9 Kienast/Eck/Heil (2017) 64. Zur Zeit der Säkularspiele waren drei der insgesamt fünf Kinder, die aus dieser Ehe hervorgingen, geboren: im Jahre $20 \mathrm{v}$. Chr. Caius, im Jahre I9 oder I 8 v. Chr. (Vipsania) Iulia und am Anfang des Jahres I7 v. Chr. Lucius.

320 Z. I32 (nach dem Iuno-Opfer und dem Supplikationsgebet der Matronen); Z. I 50I 52 (nach dem Apollo-/Diana-Opfer und dem carmen saeculare).

32 I Scheid (I990a) i $78 \mathrm{ff}$.

322 Siebert (1999) 206. Die Angabe von atalla in dieser Inschrift ist die einzige belegte Erwähnung eines solchen Gefäßes.

323 Z. 107 und 132. 
den. Es ist klar, dass eine matrona eine mater familiae sein kann und umgekehrt. Von daher stellt sich die Frage nach dem Grund der unterschiedlichen Benennung der Frauen. ${ }^{324}$ Eine Möglichkeit der Beantwortung wäre, für die verschiedenen Zeremonien unterschiedliche Gruppen von Frauen anzunehmen. Dagegen spricht, dass die severische Inschrift die Gruppe der i ı० Matronen namentlich nennt und es sich an den severischen Säkularspielen ganz eindeutig um eine einzige repräsentative Gruppe von Matronen gehandelt hat. ${ }^{325}$ Wegen des riesigen organisatorischen Aufwands der Rekrutierung von Frauen und auch wegen des folgenden, die Matronen betreffenden Edikts sollte man auch für die augusteischen Säkularspiele nur von einer einzigen Gruppe von i ı Matronen ausgehen. ${ }^{326}$ Die unterschiedlichen Bezeichnungen dieser Gruppe als matronae, matres familiae oder matres familias nuptae legt für die verschiedenen Anlässe, an denen die ı ı Matronen beteiligt waren, unterschiedliche Gewichte auf ihre Funktion innerhalb der römischen $\mathrm{Ge}$ sellschaft. Auf diese Weise konnte eine Hierarchie der Bedeutung der rituellen Anlässe etabliert werden, die in Einklang mit den kurz vorher erlassenen Ehegesetzen beziehungsweise mit der augusteischen Gesellschaftspolitik steht. ${ }^{327}$

Für die Spiele ist in Z. Io8 erwähnt, dass ein Holztheater auf dem Feld entlang des Tibers errichtet wurde. ${ }^{228}$ Offenbar handelt es sich hier nicht um das Tarentum, sondern einen anderen Ort am Tiberufer. Darauf verweist die Formulierung in campo secundum Tiberim, während das Tarentum immer als campus ad Tiberim bezeichnet wird. Es ist unwahrscheinlich, dass auf dem Tarentum zwischen den ludi der ersten Nacht und denen des ersten Tages, die ja ohne Unterbrechung ineinander übergingen,

324 Vgl. Kap. A.I 2, S. $273 \mathrm{ff}$.

325 Act. Sev. I88-205. Die Namen der Matronen werden anlässlich der supplicatio aufgeführt, es wird aber explizit darauf hingewiesen, dass es sich bei den Teilnehmerinnen der sellisternia um dieselben Frauen handelt. Vgl. Act. Sev. 206.

326 Das folgende Edikt über die Aufhebung des luctus matronarum (Z. I Io-I I4) während der Säkularspiele wurde wahrscheinlich erlassen, weil aus Gründen der privaten Trauer nicht alle i I F Frauen zu den sellisternia zusammengekommen waren. Vgl. unten zu Z. I Io-I I4, S. I4 If.

327 matres familiae Z. 80, I09; matres familiae nuptae Z. г23f., I25f., I3०f.); matronae Z. 78, Іог, I I2, I38; feminae Z. 73, I I4; mulieres Z. 7I. Am wichtigsten Anlass, der supplicatio, werden die teilnehmenden Frauen matres familias nuptae genannt (Z. I 23-I 3 I), wogegen die Teilnehmerinnen an den sechsmal abgehaltenen sellisternia matronae oder matres familiae genannt werden. Über den Unterschied zwischen diesen Bezeichnungen vgl. S. $273 \mathrm{ff}$.

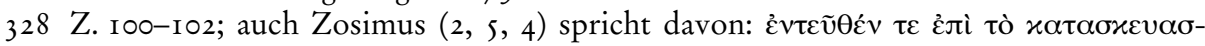

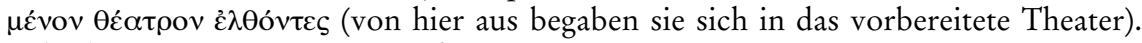
Vgl. oben zu Z. I00-102, S. I35f. 
ein Holztheater errichtet wurde, vielmehr sollte man sich vorstellen, dass in dem unbewohnten Gebiet zwischen Tarentum und Stadt ein zusätzlicher Ort für die Spiele nach den Opfern des Tages geschaffen worden war, der sich ebenfalls in unmittelbarer Nähe zum Tiberufer befand. Dazu diente wahrscheinlich der mit trigarium bezeichnete Ort, der üblicherweise als Rennbahn genutzt wurde und sich in seiner Länge entlang des Tiberufers erstreckte. ${ }^{329}$ Die Art der Spiele nach den Opfern des Tages unterschied sich nicht nur durch den unterschiedlichen Aufführungsort, sondern auch im Inhalt von denen, die an die nächtlichen Opfer anschlossen. An diesem besser eingerichteten Ort bei Tageslicht waren wohl aufwendigere Inszenierungen möglich als im Tarentum. Außerdem war dieser Aufführungsort nicht mehr mit dem Geschehen des Mythos verbunden. Allerdings wird es sich noch nicht um die beim Publikum beliebten Wettkampfspiele oder Rennen gehandelt haben. ${ }^{3{ }^{\circ}}$ Die hier (Z. 108) verwendete Bezeichnung ludi Latini gibt keinen brauchbaren Hinweis.

I Io-I I 4 Diese Zeilen enthalten ein Edikt der Quindecimviri, in welchem sie den Frauen vorschreiben, die Trauer während der Säkularspiele zu unterlassen. Zunächst einige Überlegungen über die Stellung des Edikts innerhalb des commentarium: Schon Mommsen missfiel, dass die protokollarische Schilderung des Festablaufs durch das Edikt unterbrochen wird. ${ }^{33 \mathrm{I}} \mathrm{Er}$ meinte zu Recht, dass das Edikt bezüglich der Trauer der Matronen bei den vorbereitenden Beschlüssen vergessen worden und deshalb erst erlassen worden sei, als das Fest schon in Gang war, nachdem man bei den sellisternia der Frauen der ersten Nacht und des ersten Tages darauf aufmerksam geworden war, dass wegen der Trauerriten immer einige Frauen an den Riten der Säkularfeier gefehlt hätten. Somit entspräche seine Stellung mitten im Festverlauf zwar der Chronologie der Ereignisse, ein Fehler sei aber, dass es erst zu diesem Zeitpunkt erlassen wurde. Mit diesen Überlegungen passt nicht zusammen, dass die Inschrift wahrscheinlich erst nach der Feier redigiert wurde und es somit keine Schwierigkeit dargestellt hätte, ein zu spät erlassenes Edikt nachträglich an die richtige Stelle zu rücken. Wahrscheinlich wurde die Unterlassung der Quindecimviri aber nicht als eine Unterlassung empfunden, die für die Nachwelt unkenntlich bleiben sollte. ${ }^{332}$

Der Wortlaut des Edikts schreibt den Frauen vor, während der Tage der feierlichen Opfer und Spiele die Trauerriten zu unterlassen. Diesem Edikt

329 Vgl. Kap. A.7, S. 2 I of.

330 Vgl. unten zu Z. I 53 f., S. I 57 f.

33 I Mommsen (I89I) 272 (620).

332 Die Akten der severischen Spiele belegen, dass an dieser Feier die Aufhebung der weiblichen Trauer gleich von Anfang an in der Planung berücksichtigt wurde: Act. Sev. 30 . 
ist eine auffällig ausführliche Begründung beigegeben: Einerseits berufen sich die Quindecimviri auf den mos bonus und auf zahlreiche Beispiele, wann immer ein gerechter Grund zu öffentlicher Freude bestanden habe (Z. I I I). Andererseits führen sie religiöse Gründe an, da sich die Unterlassung der Trauer auf die Ehre der Götter und auf die Erinnerung an ihre Verehrung beziehe (Z. I I3). Diese Vorschrift werde veröffentlicht und sorgfältig überwacht (Z. I 2 f.). Die Formulierung des eigentlichen Edikts nach den Begründungen ist umständlich, weil nicht wie sonst gesagt wird: Wir haben beschlossen, dass die Frauen die Trauer unterlassen sollen, sondern: Wir haben beschlossen, dass es unsere Pflicht ist, den Frauen durch ein Edikt zu verkünden, dass sie die Trauer unterlassen. ${ }^{333}$ Vielleicht spricht der Hinweis auf die den Quindecimviri zukommende Aufgabe, den Frauen dieses Edikt zu verkünden, dafür, dass sie diese Pflicht anfangs versäumt hatten oder diese Pflicht umstritten war, weil zwei religiöse Gebote miteinander in Konflikt gerieten. Die weiteren Quellen erwähnen die Unterdrückung der weiblichen Trauer während der Feiertage nicht, auch das Orakel enthält nur einen indirekten Hinweis, indem es für die Dauer der Spiele eine fröhliche Stimmung wünscht. ${ }^{334}$ Neben der Verspätung, mit der dieses Edikt erlassen worden war, sprechen all diese Tatsachen dafür, dass es sich hier um eine Vorschrift handelt, mit deren Notwendigkeit bei der Planung der Spiele nicht gerechnet wurde und deren Rechtfertigung umstritten war. Um diesen Konflikt zu verstehen, ist es nötig, die Bedeutung der weiblichen Trauer in Rom zu erfassen. Die bisherigen Untersuchungen über die ludi saeculares haben weder diese Frage behandelt noch dem Edikt große Bedeutung beigemessen.

Beim luctus matronarum handelt es sich um das bewusste Zurschaustellen des Schmerzes, den eine Matrone beim Tod eines männlichen Angehörigen empfand. Die Dauer und Intensität dieser Zurschaustellung war gesetzlich geregelt und hatte sich gewissermaßen zu einem Recht der Frauen entwickelt. ${ }^{335}$ Eine Notiz bei Festus erwähnt die Unterlassung der

333 Der Ausdruck luctum minuere scheint der gebräuchliche terminus technicus zu sein, dabei handelt es sich keinesfalls um eine Verminderung der Trauer, sondern um eine vollständige Unterdrückung der Trauerriten wie lautes Klagen auf öffentlichen Plätzen, Zerkratzen des Gesichts und der Oberarme, Unterlassen von Körperpflege und Richten der Frisur. Vgl. Fest. p. I44, 3 Lindsay.

334 Zos. 2, 6, 35 .

335 Vgl. Lorraux (1992) 48. Wenn dieser emotionale Einsatz jedoch zu stark wurde, musste er eingedämmt und in Grenzen verwiesen werden. Ein solcher Fall ist für das Wehklagen der Frauen nach der Schlacht bei Cannae überliefert, die nur zum Schweigen gebracht werden konnten, als man sie in ihre Häuser verbannte (Plut. Fab. I7, 7 f.; Liv. 22, 55, 6). Nach diesem Ereignis scheint es zu einer Trauergesetzgebung gekommen zu sein, durch welche das Recht der Frauen auf Trauer beschränkt wurde. 
öffentlich demonstrierten Trauer bei Weihung von Tempeln, beim Anbruch eines neuen lustrum und wenn ein öffentlich abgelegtes Gelübde eingehalten wird. ${ }^{336}$ Die weibliche Trauer dagegen, als besondere Ausdrucksform von privater Trauer, scheint zusätzlich eine politische Dimension gehabt zu haben. ${ }^{337}$ Die Trauer der Matronen wird nämlich in vielen Beispielen aus der Geschichte überliefert, wo die öffentlich zur Schau gestellte Trauer um die gefallenen Helden meistens ihrer Vaterlandsliebe entspricht..$^{33^{8}}$ Sie stellt ein weibliches Äquivalent zu den Heldentaten der Männer dar. Eine wichtige Rolle spielt dabei, dass es sich nicht um die Tränen irgendwelcher Frauen handelt, sondern um die von Matronen. Matrona ist zunächst ein juristischer Terminus und bezeichnet eine verheiratete Frau. Als Vertreterin dieses Status hat die Matrone Anteil an der politischen Gemeinschaft. Im Fall der Säkularfeier sollte die Trauer der Matronen vermindert werden, um der feierlichen Stimmung keinen Abbruch zu tun. Natürlich ist hier gemeint, dass privat Trauernde durch die öffentliche Zurschaustellung ihrer Trauer nicht auffallen sollten. Dass aber ein solches Edikt erst im Laufe der Feier erlassen werden musste, weist darauf hin, dass diese Ausdrucksmöglichkeit auch an einem so feierlichen Anlass wie den Säkularspielen von Matronen wahrgenommen und von offizieller Seite nicht damit gerechnet worden war. Die oben erwähnte Umständlichkeit des sprachlichen Ausdrucks und die ausführliche Begründung des Edikts weisen darauf hin, dass hier eventuell ein Widerspruch der Säkularfeier offenbar wurde: Einerseits sollten die Matronen als Teilnehmerinnen von Prozessionen und sellisternia sehr wohl eine öffentliche Rolle spielen, indem auf ihre wichtige Funktion als Gebärerinnen eingegangen wurde, andererseits wurde ihnen gerade an diesem Anlass verwehrt, eine der wenigen ihnen von alters her eigenen öffentlichen Rollen zu erfüllen. ${ }^{339}$ Außerdem wird für die Matronen selbst ein Konflikt zwischen zwei religiösen Geboten bestanden haben, den Trauerriten zu entsprechen und ihre Verpflichtungen an der Säkularfeier

Nach Seneca (Helvia I6, I) und Plutarch (Numa I, 2, 3) beträgt die Trauerzeit für Witwen neun bzw. zehn Monate, für einen Bruder, Sohn oder Vater ebenfalls. Es ist sinnvoll, in diesem Fall von einem >Recht< auf Trauer zu sprechen, wenn man bedenkt, dass dieser Anlass eine der wenigen Möglichkeiten für Frauen darstellte, die Anerkennung der Stadt zu erlangen.

336 Fest. p. I44, 3 Lindsay. Festus behandelt nicht den Sonderfall der öffentlich gezeigten Trauer der Matronen.

337 Lorraux (1992) 46-50.

338 Zum Beispiel die Trauer beim Tode Coriolans: Plut. Coriolan, 39, Io; Dion. Hal. 8, 62, 2; Liv. 2, 40, I-3.

339 Obwohl es sich beim luctus matronarum nicht um einen römischen Rechtsbegriff handelt, zeigt dieses Edikt, dass die öffentlich demonstrierte Trauer als traditionelles Recht der Frauen sehr ernst genommen wurde. 
zu erfüllen. Diesen Konflikt hob das Edikt auf, indem es der Säkularfeier Vorrang gab. Die Kontrolle der Einhaltung dieses Edikts zeigt, dass die Teilnahme von exakt i so Matronen wichtig war und die Teilnahme derjenigen Matronen, die vorher ausgewählt und durch das Edikt dazu aufgefordert waren, wohl überprüft wurde. Dieses Edikt wurde besonders im Hinblick auf die Supplikation der i io matres familiae nuptae erlassen, weil für diesen wichtigen Ritus des zweiten Tages die Anwesenheit aller I Io Matronen gesichert sein sollte.

I I -I I 8 Diese Zeilen enthalten die Angaben über die Ereignisse der zweiten Nacht. Während die Ereignisse der ersten Nacht noch I 3 Zeilen der Inschrift in Anspruch nahmen, sind diejenigen der zweiten und dritten Nacht in abgekürzter Form in nur vier Zeilen mit den nötigsten Angaben aufgezeichnet. Dazu gehört die Angabe des Datums, des Orts, der betroffenen Gottheit, der Opfergabe und des Opfernden. ${ }^{34 \circ}$ Außerdem wird der Anfang des Gebets wörtlich zitiert, der bei jedem Gebet anders lautet, weil er auf die besondere Situation des betreffenden Opfers eingeht. Die wichtigste Abkürzung besteht demnach darin, dass von den Gebeten nur die Anrede an die betreffende Gottheit, die Opfergabe und die Einleitung zu den Bitten wiedergegeben werden, die Bitten selbst aber mit der Formel cetera uti supra abgekürzt sind. Andere Kürzungen finden wir in der Angabe des Ortes, der nur mit ad Tiberim im Gegensatz zu in campo ad Tiberim genannt ist (Z.90). Die Angaben der ersten Nacht enthalten außerdem eine Erwähnung des angewandten Acbious ritus, während für die zweite Nacht diese Angabe fehlt, obwohl davon auszugehen ist, dass auch dieses Opfer nach griechischem Ritus durchgeführt wurde. ${ }^{34 \mathrm{I}}$

340 Vgl. oben zu Z. 92 f., S. I 26.

34I Dies stützt die Abbildung einer domitianischen Münze, die vermutlich das IlithyiaOpfer darstellt; siehe Anhang, Abb. I I. Eine gute Abbildung zweier Varianten dieser Münzen befindet sich bei Coarelli (I997) 89. Auf dieser Münze ist der opfernde Kaiser als togatus mit unbedecktem Kopf zu sehen, wie er rechts neben einem bekränzten Altar steht und mit einer Opferschale etwas in eine auf dem Altar brennende Flamme gießt. Die Tatsache, dass Domitian mit unverhülltem Haupt opfert, ist ein deutlicher Hinweis auf ritus Graecus. Auf der linken Seite des Altars liegt der bärtige halbnackte Gott Tiber halb aufgestützt am Boden vor dem Altar, in den Händen ein Füllhorn haltend. Hinter dem liegenden Gott sind zwei Musiker zu erkennen, die auf einer Doppelflöte und einer Lyra spielen. Manche Prägungen dieser Münze lassen im Hintergrund zwei Tempelfassaden erkennen, die mit einem Rundbogen miteinander verbunden sind. Vgl. Kap. A.7, S. 205. Die Münzabbildungen machen außerdem klar, dass das Ilithyia-Opfer vor einem Tempelgebäude stattfand, welches im Hintergrund $\mathrm{zu}$ erkennen ist. Die Formulierung in campo ad Tiberim legt nahe, dass es sich - wie Zosimus $(2,5,3)$ sagt - um die Uferböschung des Tiberufers handelte. 
Die in der zweiten Nacht verehrte Göttin ist Ilithyia, beziehungsweise sind die Ilithyien. ${ }^{342}$ Offenbar werden drei Ilithyien in der Einleitungszeile im Kollektiv genannt, während sich das Gebet an jede der Göttinnen einzeln richtet. Ihre Identifikation bereitet einige Schwierigkeiten, einzig gesichert ist, dass es sich um eine Geburtsgöttin handelt. Der Name ist derjenige der griechischen Geburtsgöttin Eileithyia. Schon Horaz bekundet im carmen saeculare Mühe, dieser Göttin einen eigenen Charakter zu geben, der Dichter scheint unentschieden, ob es sich bei der zu verehrenden geburtshelfenden Göttin um Ilithyia, Iuno Lucina oder eine Genitalis handelt. ${ }^{343}$ Dieser Umstand weist darauf hin, dass die Popularität einer Geburtsgöttin Ilithyia nicht groß war. Es bleibt daher zu untersuchen, was uns über die griechische Göttin Eileithyia bekannt ist und in welcher Weise eine Übernahme in Rom stattgefunden hat. ${ }^{344}$ Nach Burkert handelt es sich bei der griechischen Göttin Eileithyia um eine seit frühester Zeit verehrte Geburtsgöttin, die auch als Kollektiv von mehreren Eileithyiai verehrt wurde. ${ }^{345}$ Sie wird vor allem von Frauen verehrt als Helferin bei der Geburt und Heilerin von Frauen- und Kinderkrankheiten, bleibt aber ohne eigene Mythen. An einigen Kultstätten war ihr Kult mit dem des Apollo, der Artemis oder des Asklepios verbunden. Die in Rom und Italien verehrte Geburtsgöttin Mater Matuta wurde am Ende der Republik von den Mythografen mit der griechischen Geburtsgöttin Leukothea, wie Eileithyia ebenfalls bezeichnet wird, gleichgesetzt. ${ }^{34^{6}}$ Belegt ist diese Identifikation bei Ovid. ${ }^{347}$ Es besteht jedoch weiterhin die Frage, warum man an der Säkularfeier für die Verehrung einer Geburtsgöttin die wesentlich unpopulärere Göttin Ilithyia gewählt hat statt Mater Matuta, die zudem in Rom einen eigenen Tempel in der Nähe des forum boarium besaß..$^{34^{8}}$ Eine mögliche Erklärung könnte sein, dass eine Verehrung von Mater Matuta an der Säkularfeier zu Verwechslungen mit den direkt an

342 Im Orakel (Zos. 2, 6, 9) werden mehrere Eileithyiai genannt. Der Fehler des quadratarius in Z. I I s belegt wenig Vertrautheit mit einer Gottheit dieses Namens. Das severische commentarium liefert in diesem Fall keine größere Klarheit, weil die Passage mit dem Opfer der zweiten Nacht sehr fragmentarisch ist. Act. Sev. I72-177.

343 Hor. carm. saec. I $3-16$.

344 Eine ausführliche Untersuchung dieser Frage findet sich bei La Rocca (1984) 20-36, dessen Arbeit aber nicht in erster Linie davon geprägt ist, die Rekonstruktion der augusteischen Spiele zu verstehen, sondern die auf dem Tarentum angesiedelten ursprünglichen Gottheiten näher bestimmen zu können.

345 Burkert (1977) 265; der Name Eileithyia wird von Eleuthyia abgeleitet, einer Partizipialform mit der Bedeutung >die Kommendeく, wenn die vor Schmerzen schreiende Gebärende nach ihr ruft.

$346 \mathrm{Zu}$ den verschiedenen Identfikationen von Eileithyia in Rom: Wissowa (I912) I roff.

347 Ovid, Fast. 6, $473 \mathrm{ff}$. und $545 \mathrm{ff}$.

348 Wissowa (I9I2) i i i; BNP (I998) sof. 
die Säkularfeier anschließenden Feiern der Matralia Anlass gegeben haben könnte. Die am I r. Juni jeden Jahres gefeierten Matralia waren das Stiftungsfest des Tempels der Göttin und ein sehr populäres Frauenfest. ${ }^{349}$ Möglicherweise hätte an der Säkularfeier die Verehrung von Mater Matuta, die ausschließlich als Frauengöttin definiert war, Männer ausgeschlossen, am Opfer teilzunehmen und vor allem das Gebet zu sprechen, eine Aufgabe, die bei den Ilithyia-Opfern wieder Augustus übernommen hatte. Die genauen Gründe für die Wahl der Ilithyien sind nicht zu klären, sodass die Vermutung bleibt, dass es sich um eine gelehrte Konstruktion handelt, die in den Gesamtcharakter der Spiele passte. ${ }^{350}$

Die Opfergabe an die Ilithyien bestand aus drei Arten von Gebäck, über deren Beschaffenheit nichts Genaues bekannt ist. ${ }^{351}$ Am dritten Tag erhalten Apollo und Diana dieselben Opfergaben, allerdings enthält das augusteische commentarium eine unterschiedliche Aufzeichnungspraxis für die gleichen Opfer. Beim Ilithyia-Opfer sind nur die ersten beiden Zeilen des Gebets festgehalten, in dem alle drei Arten von Kuchen als Opfergabe erwähnt sind. Demgegenüber wird im Apollogebet für jede Art noch einmal um günstige Aufnahme gebetet. ${ }^{3{ }^{2}}$ Es ist davon auszugehen, dass der Ritus für die Opferung aller drei Kuchenarten beide Male gleich war, das commentarium aber eine abweichende Aufzeichnungspraxis enthält. Das Kuchenopfer wurde demnach gesondert nach Art der Kuchen folgendermaßen dargebracht: Nach der lustratio des Altars wurde eine Art von Opferkuchen auf den Altar gelegt, mit Weihrauch und Wein besprengt, das Gebet gesprochen und anschließend wurden die Kuchen mit Öl verbrannt. Man beachte die Genauigkeit der Formulierung für den Opfervorgang: Tieropfer werden mit inmolare bezeichnet, weil das Opfer vorher mit mola salsa bestreut wurde, Opferhandlungen, bei denen dies nicht geschah, mit sacrificium facere. ${ }^{353}$ Dieser Vorgang wurde mit jeder Kuchenart für jede der drei Ilithyien wiederholt.

349 Gagé (1963); Scheid (1993a) $426 \mathrm{f}$.

350 La Rocca (I 984) $30 \mathrm{ff}$. versucht durch den überlieferten Ausdruck Nixas für einen Teil des Marsfeldes in der Nähe des trigarium eine ältere Beziehung dieses Ortes zu den Ilithyien herzustellen. Die überlieferte Bezeichnung stammt aus späterer Zeit und wird in Zusammenhang mit dem Oktoberross erwähnt: equus ad Nixas fit. Siehe Degrassi (1963) $52 \mathrm{I}$.

35 I Scheid (1998b) I 5 behilft sich bei der Übersetzung mit "galettes, gâteaux, pâtisseries«. Auch die Münzen der domitianischen Säkularspiele bestätigen, dass kein Fleischopfer dargebracht wurde, weil auf der Münze ein Tier fehlt (siehe Anhang, Abb. I I).

352 Z. I 4 I ff.; allerdings enthält das commentarium nur für zwei Arten von Opferkuchen die Gebete, für die dritte Art von Opferkuchen wird abgekürzt; vgl. unten zu Z. I4I-I 44, S. I 53 .

353 Z. I I5; I39. Das severische commentarium verwendet für die Opferung von Kuchen im Apollo-/Diana-Opfer sacrificavit: Act. Sev. 23 I. 
Am Ende der zweiten Nacht sind keinerlei Angaben über Spiele und sellisternia gemacht. Auch dies entspricht der nicht einheitlichen Aufzeichnungspraxis des augusteischen commentarium. ${ }^{354}$ Es ist in jedem Fall davon auszugehen, dass anschließend wieder wie in der ersten Nacht nach dem Moiren-Opfer sellisternia der Matronen auf dem Kapitol und ludi im Tarentum stattgefunden haben. Für den Redaktor des commentarium muss darin eine so große Selbstverständlichkeit bestanden haben, dass er diese Riten nicht mehr erwähnt hat. Wahrscheinlich hielten die Matronen auch an diesem Tag eigene Tieropfer ab, deren Fleisch sie anschließend verzehrt haben. Das severische commentarium erwähnt solche eigenen Opfer der Matronen nach dem Opfer für Apollo und Diana am dritten Tag, an dem ebenfalls Opferkuchen verbrannt worden waren. ${ }^{355}$ Die ludi werden den gleichen Charakter und dieselben Aufführungsbedingungen wie in der Nacht zuvor gehabt haben. ${ }^{356}$

I I9-I33 Hier handelt es sich um die ausgeführten Rituale des zweiten Tages. Sie nehmen einen breiten Raum ein, weil in diesen Zeilen neben dem abgekürzten Opfergebet das Supplikationsgebet an Iuno vollständig wiedergegeben ist.

I I f. Der Einleitungssatz zu dem Gebet enthält die üblichen Angaben: Datum, Ort, Gottheit, Opfergabe und Ausführende des Opfers. Hinsichtlich des Opfers weicht mein neu konstituierter Text vom alten Text ab und spricht nur noch von einem Opfer, welches von Agrippa allein durchgeführt wurde. ${ }^{357}$ Neben den textkritischen Überlegungen liegt in der Opfergabe ein stützendes Argument dafür, dass Agrippa dieses Opfer allein vollbracht hat. Im Orakel ist nämlich ebenfalls nur von einem weiblichen Rind für Iuno die Rede, während es für Iuppiter von mehreren männlichen Rindern spricht. ${ }^{358}$ Unter diesen Voraussetzungen muss man davon ausgehen, dass das Iuno-Opfer des zweiten Tages von Agrippa allein vollbracht wurde, der eine Färse opferte, die wahrscheinlich weiß war, wie es das severische commentarium festhält. Der Opferritus für Iuno wurde Graeco Achivo ritu durchgeführt, wie ebenfalls im commentarium

354 Vgl. die Tabelle S. 91 und S. 99, Anm. is I.

355 Act. Sev. 259-260: E]adem die Iulia Aug. m[ater] castrorum et matro[nae ce]ntum nove[m habuerunt] | [sellistern]ia sua sicut praec[eden]ti bidua, porcilias immolaverunt [et] eisdem cena[verunt et antr]uav[erunt. Vgl. oben zu Z. I 5-19, S. $88 \mathrm{ff}$.

356 Vgl. oben zu Z. 100-102, S. I35.

357 Vgl. Kommentar zur Textkonstitution zu Z. i i 9 ff., S. 64 .

358 Zos. 2, 6, is (Iuno-Opfer); Zos. 2, 6, I 2 f. (Iuppiter-Opfer). Das Iuppiter-Opfer wurde mit Sicherheit von Augustus und Agrippa gemeinsam durchgeführt, das heißt, jeder opferte einen Ochsen. Die Angaben, welche Zosimus (2, 5, 4) für den zweiten Tag zum Festverlauf macht, sind sehr ungenau und erwähnen das Opfer überhaupt nicht, sondern nur die supplicatio der Matronen. 
der severischen ludi saeculares zu lesen ist. ${ }^{359}$ Wesentlich ist, dass mit der Ausschließung von Augustus von dem Opfer des zweiten Tages, das Problem seiner plötzlichen Abwesenheit in Z. I 32 gelöst ist und die Regelmäßigkeit der Verteilung der Opfer nicht gestört wird: Augustus scheint ganz eindeutig für die Opfer der Nächte die alleinige Ausführung übernommen zu haben. Das Opfer für Iuppiter, dem höchsten aller Götter, haben Augustus und Agrippa zusammen vollbracht, ebenso die Opfer für Apollo und Diana. ${ }^{360}$ Es liegt kein Grund vor anzunehmen, dass deswegen alle drei Tagesopfer von Augustus und Agrippa gemeinsam durchgeführt wurden. Im Gegenteil ist es gut möglich, dass Agrippa zugestanden wurde, an einem Tag allein die Hauptrolle zu spielen, um aus dem Schatten von Augustus herauszutreten. Mit der Geburt der beiden Enkel des Augustus im Jahre 20 und I7 v. Chr. gehörte Agrippa endgültig in den nächsten, sogar familiären Kreis des Augustus, und seine Beteiligung an der Machtausübung scheint auf diese Weise demonstriert worden zu sein. Außerdem ist vorstellbar, dass eine Teilnahme an allen Riten der Säkularfeier für Augustus auch aus physischen Gründen gar nicht möglich war, zumal die Riten der Nächte direkt an die der Tage anschlossen und dem Hauptbeteiligten keine Ruhepause erlaubten. Nach den Abbildungen der domitianischen Münzen hat der Opfernde das Iuno- und das Iuppiter-Opfer in der tunica fimbriata durchgeführt. ${ }^{361}$

I 2 I f. Die Zeilen enthalten den Anfang des Opfergebets, das wieder mit cetera uti supra abgekürzt wurde. Das Gebet entspricht außer in Anrede und Opfergabe vollständig dem Iuppitergebet in Z. Ios $\mathrm{f}$.

I23f. Es handelt sich um die Einleitungszeilen zum Supplikationsgebet an Iuno, welches von Agrippa den Matronen vorgesprochen wurde. Die Supplikation hat direkt anschließend an das Opfer stattgefunden, denn die das Opfer abschließende Aufzählung der dabei Anwesenden folgt erst im Anschluss an das Supplikationsgebet (Z. I32). Die supplicatio der I Io Matronen dürfte als einer der Höhepunkte der Riten, die am Tage durchgeführt wurden, betrachtet werden. Wahrscheinlich war auch deswegen kurz zuvor das Edikt zur Aufhebung des luctus matronarum ergangen, um sicher sein zu können, dass die Zahl von i ı Matronen gewährleistet ist. Auffällig ist, dass die beteiligten Frauen nicht als Matronen wie in

359 Act. Sev. I8I: immol[avit I]unoni Reginae vaccam alb(am) Graeco Achivo Rit[u.

360 Vor dem Apollo-/Diana-Opfer in Z. I40 ist preca]tique sunt ita belegt, was für die Beteiligung der beiden spricht.

36r Vgl. Anhang, Abb. I3. Scheid (I998b) 24 weist darauf hin, dass die Abbildungen dieser Münzen nicht eindeutig anzeigen, ob das Opfer Iuppiter oder Iuno gilt, da das Geschlecht des Opfertiers nicht erkennbar ist. Diese Doppeldeutigkeit hält Scheid für beabsichtigt im Sinne einer Verdichtung der Aussage durch die Münzabbildungen. 
Z. Io I für die sellisternia bezeichnet sind, sondern als i Io matres familias nuptae, die naürlich auch Matronen waren, aber schon geboren hatten. ${ }^{362}$ Alle verwitweten und ledigen Mütter waren somit von diesem Ritus ausgeschlossen. Damit scheint ein Bezug zu der Aussage der Säkularfeier als Fest der Reproduktion des römischen Volkes geschaffen worden zu sein, aber auch zu den kürzlich erlassenen Ehegesetzen. ${ }^{363}$ Der Hinweis auf QVIBVS DENVN/tiatum erat bezieht sich auf das vorbereitende Edikt der Zeilen 64-89, in welchem in Z. 8of. ebenfalls von den matres familiae der supplicatio die Rede ist. Das Verb praeire in verba ist für das Vorsprechen von Gebeten oder Gelübden überliefert, Agrippa wird bei der supplicatio den knienden Matronen stehend das Gebet vorgesprochen haben. ${ }^{364}$

Der Akt der supplicatio war immer eine außerordentliche Maßnahme der Götterbitte in Fällen von besonderen Bedrohungen oder nach der Rettung aus solchen Bedrohungen. ${ }^{365}$ Sie wurde von staatlicher Seite angeordnet und ihre Durchführung oblag nach Befragung der sibyllinischen Bücher dem Kollegium der Quindecimviri, weshalb man davon ausgeht, dass sie nach ritus Graecus durchgeführt wurde. Sie gehörte zu den Riten der römischen Religion, die durch die Beteiligung vieler Menschen und durch ihre Außerordentlichkeit eine große Wirkung auf die Bevölkerung ausübte. Auch die supplicatio der augusteischen Säkularfeier mit ihrer Stellung in der Mitte der Feier und dem Auftreten der i Io knienden Frauen vor dem Tempel der Iuno auf dem Kapitol wird diese Wirkung gehabt haben.

I25-I3 I Diese Zeilen enthalten das Supplikationsgebet an Iuno. Obwohl der Text nur am linken Rand in einer Breite von etwa 20 Buchstaben erhalten ist, ist er fast vollständig ergänzbar. Grund dafür ist die fast völlige Übereinstimmung mit den Opfergebeten und der relativ gut erhaltene Zustand des Supplikationsgebets des severischen commentarium. ${ }^{366}$ Das Suppli-

362 Z. I7 erwähnt das Alter der Matronen, die für eine Beteiligung an den Riten der Säkularspiele älter als 25 sein sollen, ein Alter in dem die meisten römischen Frauen Mütter waren. Das bedeutet, dass Iulia, die Tochter von Augustus und Ehefrau von Agrippa, nicht beteiligt war, weil sie zum Zeitpunkt der Säkularspiele erst 22 oder 23 Jahre alt war.

363 Vgl. Kap. A.r 2, S. 272 f.

364 Wissowa (I9r2) 394, Anm. 7; eine domitianische Münze (siehe Anhang, Abb. I4) zeigt die supplicatio in dem Moment, als Domitian vor drei knienden und verschleierten matres familias nuptae steht, die die Hände zum Gebet erhoben haben. Domitian, in einer Toga mit unverhülltem Haupt, hält in der linken Hand eine Schriftrolle mit dem Gebetstext, die rechte Hand streckt er den Frauen entgegen.

365 Wissowa (1912) $423 \mathrm{ff}$.

366 Act. Sev. I 83-205, mit der namentlichen Aufzählung der i Io Matronen und ihrer Ehemänner. 
kationsgebet wird von Agrippa vorgesprochen und sicher von den i Io knienden matres familias nachgesprochen worden sein, denn es richtet sich in der I. Person Plural an die Göttin. Es beginnt mit der Anrede an Iuno Regina, gefolgt von einer Gebetsformel, die auch in den Opfergebeten am Anfang steht (qu[o]d meli[us siet p. R., Quiritibus), hier aber anders an die Anrede angeschlossen ist. ${ }^{367}$ Es fehlt der Hinweis auf die Bücher, aus denen der Gebetstext abgelesen wird, und auf eine Opfergabe. Dagegen erwähnen die betenden Frauen sich selbst und ihre kniende Haltung während des Gebets, wodurch bereits am Anfang dessen Charakter erkennbar wird, so wie ein Opfergebet durch die Angabe der Opfergabe am Beginn als solches definiert ist. Obsecramus als zusätzlich einleitendes Verb neben precamur und oramus kennzeichnet den Charakter eines Supplikationsgebetes, das dieselben Bitten wie das Opfergebet noch emphatischer vorträgt. ${ }^{368}$ Die Bitten aller Opfergebete sind demgegenüber mit quaeso precorque eingeleitet. Nach dem besser erhaltenen Text des severischen commentarium wurde die beschwörende Formel precamur, oramus obsecramusque am Anfang des Gebets im Konjunktiv als Absicht vorgetragen, am Ende des Gebets wird sie im Indikativ formuliert. ${ }^{369}$

In Z. I26-I3 I folgen sechs Bitten, die die matres familias durch ihre Supplikation an Iuno erfüllt haben möchten. Sie sind identisch mit den ersten sechs des Opfergebets an die Moiren. ${ }^{370}$ Es geht also auch hier um die Erhaltung und Vergrößerung der römischen Macht, nur am Ende ist wie in den Opfergebeten eine Bitte um das Wohlergehen der eigenen Familien angeschlossen. Dieser politische Gehalt der Bitten der Frauen entspricht der konzeptuellen Einbeziehung der Frauen in die rituelle Gestaltung der Feier. An der Säkularfeier wurde mit den Riten, die die Frauen betrafen, vor allem ihre Wichtigkeit als matres familias nuptae für das Wohlergehen des gesamten Staates verdeutlicht. Mit der Bitte an eine weibliche Göttin bleiben die Frauen zwar in einem weiblichen Bezugsrahmen, Iuno Regina aber war neben ihrer Rolle als Geburtsgöttin auch eine Göttin mit politischer Bedeutung. ${ }^{371}$ Diese Verbindung gestattete ihre Aufnahme in die kapitolinische Trias. Das Verständnis von Iuno bot sich

367 Bei dem Wort ast handelt es sich um eine archaische Form für at, die auch in den Arvalakten geläufig ist; es hat bei Wünschen und Gebeten einleitende Funktion. Die Belegstellen bei Pighi (I94I) i $27 \mathrm{f}$.

368 Gelegentlich tritt anstelle von supplicatio der Begriff obsecratio auf. Der Gebrauch von obsecrare weist eindeutig auf den bittenden Charakter des Gebets hin. Vgl. Fest. p. 207 Lindsay: Obsecrare est opem a sacris petere.

369 Act. Sev. I 85, i 86 (Konjunktiv) und I 88 (Indikativ).

370 Vgl. oben zu Z. 93-99, S. I $28 \mathrm{ff}$.

37 I Graf, BNP s.v. Juno. 
also an, um gerade von ihr das Gedeihen der Stärke und Macht des römischen Volkes zu erbitten. Die matres familias nuptae als Bittflehende stellen die Bitten des Supplikationsgebets in einen Interpretationsrahmen, der einerseits die biologische Reproduktionskraft des römischen Volkes betrifft, andererseits einen Bezug zu den gerade erst erlassenen Ehegesetzen herstellt. Denn es sind nicht irgendwelche Frauen, die diese Bitten aussprechen, sondern verheiratete Mütter, ein Status, den die Ehegesetze als Idealstatus der römischen Frau vorsahen. Als einzige Bitte fehlt die siebente des Opfergebets, welche die Götter um Annahme des Opfers bat. Ein Vergleich des Supplikationsgebets mit den Opfergebeten zeigt als besonderes Element die Erwähnung der bittflehenden Frauen am Anfang und am Ende des Gebets (Z. I25f. und I3०f.). Dem entspricht die Erwähnung der Opfergabe in dem vollständig wiedergegebenen Opfergebet an die Moiren (Z. 92 f. und 97 f.). Außerdem ist die einleitende Formel der Bitten gegenüber dem sonst verwendeten quaesumus precamur durch ein precamur, oramus, obsecramus gesteigert, was für ein Supplikationsgebet durchaus sinnvoll erscheint. Die wichtigste Erkenntnis des Vergleichs ist aber, dass die Gebete sonst völlig identisch sind, dass der Gehalt der Bitten genau gleich ist wie der der Opfergebete. Dies spricht für eine große Einheitlichkeit des Gehalts der Säkularfeier, deren wichtigste Aufgabe war, das Wohlergehen und den Erhalt des römischen Staates durch die Götter sicherzustellen.

I32 Ausgehend von dieser Zeile ist die Anwesenheit des Augustus zum ersten Mal infrage gestellt worden..$^{372}$ Mit dieser Angabe wird die Darstellung der rituellen Handlungen auf dem Kapitol abgeschlossen, sie erwähnt die anwesenden Mitglieder der Priesterschaft der Quindecimviri, wie dies in Z. I07 nach dem Iuppiter-Opfer der Fall war. Die Angabe dort war vollständig erhalten, es waren als Anwesende sieben Mitglieder der Priesterschaft genannt. Man wird auch in diesem Fall von einer ähnlichen Anzahl anwesender Priester ausgehen müssen. Festzuhalten bleibt aber, dass eine solche Anwesenheitsliste nur anschließend an die Riten des Tages in der Stadt verzeichnet ist, weil Riten der Nacht und des Tages als Einheit verstanden wurden. ${ }^{373}$ Das mit atalla benannte Gerät bezeichnet eine besondere Art von Opferschale. ${ }^{374}$

I33 Die Feierlichkeiten des zweiten Tages werden wie die des ersten Tages mit ludi Latini abgeschlossen worden sein, die sich in dem zweiten Theater am Tiberufer abspielten. ${ }^{375}$ Die Zeile bricht hier ab, aber mit Sicherheit

372 Wissowa in CIL VI 32323.

373 Vgl. oben zu Z. 107, S. I 39.

374 Vgl. oben zu Z. 107., S. I39.

375 Vgl. oben zu Z. I08, S. I 39 ff. 
wurden ebenfalls sellisternia für die matres familias auf dem Kapitol angeschlossen..$^{37}$

I34-I38 Diese Zeilen beschreiben die ausgeführten Riten der dritten und letzten Nacht, die Terra Mater gewidmet waren und wieder im Tarentum am Tiberufer stattfanden.

I34f. Die Angaben entsprechen denen der zweiten Nacht und enthalten in den ersten beiden Zeilen Angaben über Zeitpunkt, Ort, Opfergabe, Ritus und den Ausführenden des Opfers. Die fehlenden Angaben lassen sich zum Teil aus dem folgenden Gebetsanfang rekonstruieren. Das von Pighi aus den severischen Akten übernommene Attribut prodigivam für das Opfertier der Terra Mater weist auf den chthonischen Charakter dieser Gottheit hin und gibt an, dass es vollständig verbrannt und nicht verzehrt wurde. Ebenso entspricht die dunkle Farbe des Tieres einer chthonischen Gottheit. Das Opfer für Terra Mater wurde in derselben Weise vollzogen wie das für die Moiren, das heißt nach Achivo ritu. ${ }^{377}$ Wie in allen anderen Nächten wird das Opfer von Augustus allein dargebracht. Die an der Säkularfeier verehrte Terra Mater ist eine spätere Bezeichnung für die Erdgöttin Tellus; die Verbindung wird noch im carmen saeculare des Horaz sichtbar, welches statt der im Ritus Terra Mater genannten Göttin die Göttinnen Tellus und Ceres nennt. ${ }^{378}$ Die in der dritten Nacht verehrte Gottheit hatte wahrscheinlich ebenso wie Ilithyia der zweiten Nacht keinen ausgeprägten Charakter und war in dieser Bezeichnung einem breiten Publikum unbekannt, wobei der Name Terra Mater selbsterklärend wirkte. Nach dem carmen saeculare war ihr Aufgabenbereich die Sicherung der Fruchtbarkeit auf Äckern und in Ställen. ${ }^{379}$ Damit passt die Verehrung der Terra Mater in das Programm der Säkularspiele, denn zum Wohlergehen des römischen Volkes gehört nicht nur die eigene Reproduktion, sondern auch die Sicherung der Ernährung der Bevölkerung. Die Opfergabe einer trächtigen Sau weist auf Tellus hin, deren charakteristisches Opfer an den feriae sementivae im Januar ebenfalls eine sus plena oder gravida war. ${ }^{380}$

376 Vgl. die Tabelle S. 9i und S. 99, Anm. is I.

377 Vgl. oben zu Z. 90 f., S. i 2 if.

378 Hor. carm. saec. 29f.; Weinstock (1934) 79I ff. hält die ursprünglich römische Erdgöttin Tellus zuständig für das Wachstum der Pflanzen, die durch Überlagerung mit Ceres erst in augusteischer Zeit als Terra Mater bezeichnet wird und durch griechische Einwirkung den chthonischen und mütterlichen Charakter erhält.

379 Hor. carm saec. 29 ff.; Gesztelyi (I98I) 442. Das Auftreten einer Fruchtbarkeitsgottheit und die Inkonsequenz im Gebrauch des Namens bei Horaz hat immer wieder dazu geführt, dass die Säkularspiele mit dem Tellusrelief der ara pacis in Verbindung gebracht wurden als eine Verherrlichung künftiger paradiesischer Zustände.

380 Wissowa (1912) i93; Ov. fast. I, $657 \mathrm{ff}$. 
I36f. Der folgende Gebetsanfang ist wie alle anderen Gebetsanfänge formuliert und enthält die Berufung auf die sibyllinischen Bücher, die Angabe des Opfers und die Quiriten als Nutznießer dieses Opfers. Die folgenden Bitten sind wie üblich abgekürzt mit cetera uti supra.

I38 Anschließend an das Terra-Mater-Opfer folgten wie nach allen Opfern ludi und sellisternia für die Matronen. Das augusteische commentarium verzeichnet an dieser Stelle nur die sellisternia. Für die Aufzeichnung von ludi und sellisternia liegt keine Einheitlichkeit des augusteischen commentarium vor. So werden nach den Riten des zweiten Tages nur die ludi erwähnt, hier nur die sellisternia..$^{31}$

I39-I58 Diese Zeilen schildern die Apollo und Diana gewidmeten Riten und Ereignisse des letzten Tages. Sie finden auf dem Palatin vor dem von Augustus neben seinem Wohnhaus errichteten Apollotempel statt. ${ }^{32}$

139-I46 Das Opfer dreier verschiedener Arten von Opferkuchen wird von Augustus und Agrippa gemeinsam dargebracht, die auch die anschließenden Gebete sprechen. Dabei wurde das vollständige Opfergebet mit seinen sieben Bitten zuerst für alle drei Arten von Opferkuchen gemeinsam gesprochen (Z. I4If.). Dann wurde jede Art für sich verbrannt, wobei noch einmal um günstige Annahme gebetet wurde (Z. I43-I45). ${ }^{3{ }^{8}}$ Daran anschließend wurden dieselben Handlungen für Diana vollbracht. Auch für sie wurde ein vollständiges Opfergebet gesprochen mit den Zusätzen für die beiden anderen Arten von Opferkuchen.

Zosimus erwähnt in seiner Schilderung des Festablaufs auch Latona unter den verehrten Göttern des dritten Tages. ${ }^{34}$ Das commentarium erwähnt Latona jedoch an keiner Stelle. Im Orakel wird Apollo zusätzlich mit seinem Matronym als Letoides bezeichnet. Das Orakel verlangt für Apollo dieselben Opfer wie für Hera/Iuno, somit hätte für Apollo bei strikter Einhaltung des Orakels ebenfalls eine Färse geopfert werden müssen. ${ }^{385}$ Diana dagegen wird im Orakel als Göttin nicht berücksichtigt. Die Abweichung zum commentarium ist wahrscheinlich aufgrund eines Kompilationsfehlers bei der Zusammenstellung des Orakeltextes entstanden. ${ }^{366}$ Aus diesem Grunde ist den Angaben des commentarium zu folgen

38 I Z. I 33 .

382 BNP (I998) I98f.; Kolb (I995) 334f.; Kienast (2014) 230ff. und 4IIf.

383 Gagé (I955) 632 macht darauf aufmerksam, dass an dieser Stelle wahrscheinlich das erste fleischlose Opfer für Apollo in Rom begegnet, was möglicherweise auf Apollo als Schützer der Fruchtbarkeit hinweist; eine solche die Fruchtbarkeit der Felder fördernde Funktion hat Apollo bei Tibull 2, 5 .

384 Zos. 2, 5, 2.

385 Zos. 2, 6, I6ff.

386 Vgl. Kap. A.ro, S. 242. 
und von einem fleischlosen Opfer auszugehen. Nach den Angaben bei Zosimus sieht es aber so aus, als ob die Götter Apollo, Diana und Latona eine Einheit bildeten, sodass bei der Ehrung Apollos auch seine Mutter und Schwester einbezogen wurden, auch wenn in diesem Fall Latona nicht eigens bedacht wurde. Dafür spricht auch ein Properz-Zitat, welches die Verehrung des palatinischen Apollo zwischen Mutter und Schwester belegt. ${ }^{387}$ Es muss aber betont werden, dass die Stellung Dianas am dritten Tag mit der Apollos nicht zu vergleichen ist, wie auch der ihr gewährte Raum in der Inschrift zeigt. ${ }^{88}$ Die Berücksichtigung von Apollo an der Säkularfeier stellte eine religiöse Neuerung dar, die mit den älteren Feiern nichts gemeinsam hatte. Apollo wird als dritter Gott der Tagesopfer der Säkularspiele in eine Reihe mit Iuppiter und Iuno gestellt. Damit erfährt er eine Bestätigung der Aufwertung, die sein Kult unter Augustus schon vom Anfang der augusteischen Herrschaft erhalten hatte. Die Säkularspiele sind deshalb nicht als Ausdruck des Beginns eines apollinischen Zeitalters zu verstehen, wie Gagé meinte, sondern Apollo erscheint an diesen Spielen als einer der Staatsgötter. Darin mag eine Neuerung liegen, sie hatte aber schon vor Jahren eingesetzt und fand hier nichts anderes als eine Umsetzung in der Ausübung eines öffentlichen Kultes. Das carmen saeculare macht deutlich, dass Apollos Rolle auch dort nicht aufgrund einer neuen apollinischen Zeit gepriesen wird, sondern dass er als Schutzherr der Dichtkunst und der jugendlichen Sänger gesehen wird.

I47-I 49 Diese drei Zeilen sind wegen der Erwähnung des Dichters Quintus Horatius Flaccus wohl die berühmtesten der Inschrift. In ihnen wird als abschließender Akt des dritten Tages die Aufführung eines Kinderchores erwähnt, der das von Horaz verfasste carmen saeculare aufführte. Der Gesang schloss sich an die ludi scaenici an. ${ }^{38}$ Eine erste Aufführung fand auf dem Palatin statt, anschließend eine zweite auf die gleiche Weise auf dem Kapitol. Sowohl die Zahl der Kinder - je 27 Knaben und Mäd-

387 Properz 2, 3 I, I f.: deinde inter matrem deus ipse interque sororem/Pythius in longa carmina veste sonat.

388 Mommsen (I 89I) 259f. (604 f.) bemerkte das Ungleichgewicht zwischen Apollo und Diana ebenfalls. Er stellt außerdem die Frage, ob die Einbeziehung Dianas, die ja im Orakel nicht erwähnt wird, auf Ateius Capito zurückgehe. Diese Frage ist nicht mehr zu beantworten. Es bleibt nur die Vermutung, dass Diana als beteiligte Göttin der sellisternia von einem Opfer im palatinischen Tempel, wo sie als Kultstatue neben ihrem Bruder auch ihren Platz hatte, nicht ausgeschlossen werden sollte.

389 Das augusteische commentarium erwähnt den Abbruch der an die Opfer stattfindenden ludi scaenici vor der Aufführung des carmen saeculare (Z. I 53: ludis scaenicis dimissis). Zusätzlich wurden an diesem Tag Wagenrennen und Kunstreiter vorgeführt, weswegen die ludi scaenici wohl abgekürzt wurden. Das severische commentarium zeichnet auf, dass vor dem carmen saeculare direkt nach dem Opfer Spiele abgehalten wurden (Act. Sev. 233f.). 
chen $^{390}$ - wie auch das Auswahlkriterium, dass sie patrimi et matrimi sein mussten, weist auf alte rituelle Zusammenhänge hin. ${ }^{391}$ Die Zahl >drei< hat schon bei dem Moiren-Opfer von neun schwarzen Ziegen und Schafen, bei der Zahl der drei Moiren, bei dem Opfer an drei Ilithyien von 3 mal 9 Opferkuchen und auch bei dem gleichen Opfer an Apollo und Diana eine Rolle gespielt. Auch die dreitägige Dauer der Säkularfeier weist auf die Bedeutung dieser Zahl hin. ${ }^{392}$

Unter dem Begriff patrimi et matrimi wird das römische Gegenstück zu

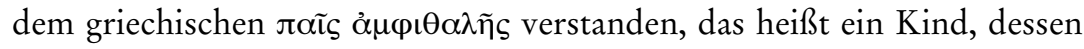
Vater und Mutter noch am Leben sind. ${ }^{393}$ In der Kultausübung spielt der Einsatz solcher Kinder an besonders feierlichen Anlässen eine Rolle, oft handelt es sich nur um Knaben. Wie hier an der Säkularfeier treten solche Kinder als Sänger von Kultliedern und Reigentänzen auf. Es handelte sich um Kinder vornehmer Familien. ${ }^{394}$ Horaz spricht in carm. 4, 6 explizit über die vornehme Herkunft der Kinder und über den Stolz, der diese Kinder später anlässlich der Erinnerung an die Aufführung ergreifen wird. ${ }^{395}$ In der Inschrift haben wir keinen Hinweis darauf, um welche Kinder es sich handelt, der Ausdruck quibus denuntiatum erat (Z. I47) weist auf das vorher ergangene Edikt von Z. 73 hin.

390 Diese Zahl lässt sich aufgrund Zos. 2, 5, 5 ergänzen.

39I Z. 20 und das Orakel (Zos. 2, 6, 22) erwähnen diese kultische Qualifikation.

392 Val. Max. 2, 4, 5 setzt diese Bedeutung der Zahl drei in Beziehung zur Zahl der Kinder des Valesius im Mythos: Hoc postquam Valesius nuntiante servo accepit, omisso emendae arae proposito hostias nigras, quae antiquitus furvae dicebantur, Tarenti immolavit ludosque et lectisternia continuis tribus noctibus, quia totidem filii periculo liberati erant, fecit. Koch (1949) Sp. 2252 glaubt, dass die Zahl von 27 auf einen alten sibyllinischen Ritus zurückgehe. Fowler (I902) 2II-2I 2 widerspricht Diels, der ebenfalls schon die Zahl 3 und ihre Quadrate in einen Zusammenhang mit dem sibyllinischen Orakel gestellt hatte. Fowler geht davon aus, dass die Zahlen 3, 9 und 27 viel älter und in allen alten Kulten und Ritualen anzutreffen sind. Sie gehen wahrscheinlich auf alte Tanzschritte zurück, wie sie in den Volksmusiken aller Völker anzutreffen sind, so auch bei den Römern in den Liedern der Arvalbrüder und Salier, wie in den Wörtern: tripodare, triumphus.

393 Diese Übersetzung mit einer entsprechenden Erklärung findet sich im Orakel, Zos. 2, 6, 2 If.

394 Vgl. oben zu Z. 2of., S. 9i f. Koch (1949) Sp. 2250 ff.; dort finden sich auch Angaben über die überlieferten Anlässe, an denen solche Kindergruppen auftraten. Allerdings kann auch Koch keine Gründe dafür angeben, warum Kinder, deren Eltern noch leben, eine bevorzugte Stellung im Kult einnehmen. Er schließt sich der Interpretation Nilssons an, der von der Vorstellung ausgeht, dass Kinder, die noch nicht mit dem Tod in Berührung gekommen sind, für den Umgang mit den Göttern in ihrer Reinheit und Arglosigkeit besonders geeignet sind, für die Menschen aber eine segensreiche Vision darstellen.

395 Hor. carm. 4, 6, 3 I f. und 4I ff.; im carm. saec. 6 erwähnt Horaz virgines lectas, was auf einen Auswahlprozess schließen lässt. 
Hinsichtlich der Aufführungspraktiken des carmen saeculare gehen die Meinungen auseinander. Die verschiedenen Positionen sind im Kapitel über das carmen saeculare besprochen, da sie zum Teil in Zusammenhang mit dem Text des Liedes stehen. Die Inschrift selbst lässt keinerlei Schlüsse darüber zu, ob das Lied prozessionsartig gesungen wurde oder einmal auf dem Palatin und einmal auf dem Kapitol. Gemäß dem Orakel und seiner Erwähnung im Text des commentarium, der den Inhalt des Orakels wiedergibt, wird es sich aber nicht um einen gemischten Chor gehandelt haben, sondern um je einen Knaben- und einen Mädchenchor. ${ }^{396}$ Einige Hinweise über die Aufführung geben die entsprechenden Angaben des severischen commentarium: Dort wird beschrieben, dass Knaben in der toga praetexta mit einem Kranz auf dem Kopf und Mädchen mit verhülltem Haupt einander an den Händen haltend ein Lied gesungen haben. ${ }^{397} \mathrm{Da}$ der Vortrag eines solchen von Kindern gesungenen Liedes sehr alte Vorbilder hat, kann davon ausgegangen werden, dass sowohl der severische wie der augusteische Reigen auf alte Vorbilder zurückgriffen, wobei es sich vielleicht sogar um ein Element alter Säkularfeiern handelt. ${ }^{398}$ Das Singen solcher Hymnen durch Kinder ist bei Livius mehrmals bestätigt. ${ }^{399}$

Zosimus geht davon aus, dass die Knaben und Mädchen der Säkularfeier griechische und lateinische Hymnen und Päane gesungen haben. ${ }^{400}$ Dass es sich hier um einen Irrtum von Zosimus handeln muss, belegt nicht nur das carmen saeculare selbst, sondern auch das Orakel, in dem ausdrücklich auf die lateinisch gesungenen Päane der Chöre hingewiesen wird. ${ }^{401}$

I 50-I 52 In diesen Zeilen werden die Quindecimviri aufgezählt, die am Opfer für Apollo und Diana und am Vortrag des carmen saeculare anwesend waren. Die Liste enthält neunzehn Namen, also fast die Gesamtheit des Kollegiums der Quindecimviri. Durch einen Vergleich mit den anderen Listen von Mitgliedern der Priesterschaft weiß man von zwei weiteren Mitglie-

396 Zos. 2, 6, 8-22.

397 Act. Sev. $234 \mathrm{f}$.

398 BNP (I998) 7 Iff.; demnach sind die Reigen von Mädchen, Matronen und Kindern eines der Erneuerungselemente der römischen Religion, die seit dem Beginn des dritten vorchristlichen Jahrhunderts in Rom Einzug hielten.

399 Livius (37, 27; 27, I I, I-6; 3 I, I 2) beschreibt mehrere solcher Zeremonien, die in Zusammenhang mit der Geburt oder Entdeckung eines Hermaphroditen stehen. Bei diesen Zeremonien findet eine Art Prozession vom Tempel des Apollo am Circus Flaminius bis zum Tempel von Iuno Regina auf dem Aventin statt. Die Zahl der teilnehmenden virgines beträgt ebenfalls immer 27.

400 Zosimus 2, 5, 5 .

40 I Auch Mommsen (I89I) 256 (602) und Pighi (I94I) 55, Anm. I gehen von einem Irrtum bei Zosimus aus. Siehe den Text des Orakels S. 24I, Vers I $8 \mathrm{ff}$. 
dern, die in dieser Aufzählung fehlen.402 Zwischen M. Agrippa und Q. Lepidus müsste bei Vollständigkeit des Kollegiums als weiteres Mitglied L. Censorinus angeführt sein, der in Z. 45 der Inschrift direkt nach Agrippa genannt ist. Der zweite nicht aufgeführte Quindecimvir ist Cn. Pompeius, der in Z. 167 vor C. Stolo platziert ist. An den Riten des letzten Tages waren also bedeutend mehr Quindecimviri als an den anderen Tagen anwesend. Nach dem Iuppiter-Opfer sind nur sieben Mitglieder erwähnt, nach dem Iuno-Opfer etwa ebenso viele. ${ }^{003}$ Damit erhalten die Riten des letzten Tages eine besondere Aufmerksamkeit seitens des Kollegiums der Quindecimviri.

I53f. Die ludi scaenici, die mit den sellisternia der Matronen alle Opfer des Tages abschlossen, fanden wie an den vorangegangenen Tagen auf dem Feld entlang des Tiberufers statt, wo ein Holztheater dafür errichtet war. ${ }^{404}$ Die nächtlichen ludi scaenici hatten im Kultort des Tarentum stattgefunden, an einem Ort, der nur aus einer Bühne bestand, ohne Einrichtungen für die Zuschauer. ${ }^{405}$ Die ludi der Tage, die auch als ludi Latini bezeichnet sind, wurden an einem Ort ebenfalls am Tiber aufgeführt, die genaue Bestimmung dieses Ortes war aber aufgrund der Angaben im commentarium bisher nicht möglich. ${ }^{406} \mathrm{Mit}$ den Angaben in diesen beiden Zeilen können wir nun genauere Bestimmungen über diesen Ort vornehmen. Er liegt IVXTA EVM LOCVM, VBI SACRIFICIVM ERAT FACTVM SVPERIORIBVS NOCTIBVS - also neben dem Ort, an welchem in den vorangegangenen Nächten die Opfer stattgefunden hatten. $\mathrm{Zu}$ diesem Zweck war ein Zuschauerraum hergerichtet worden, wovon schon vorher die Rede war. ${ }^{407}$ Außerdem wurden auf dem vorher als Bühne genutzten Raum nun Umfahrungssäulen für Pferderennen aufgestellt. Dies ist ein weiterer Hinweis darauf, dass als Ort der Spiele, welche am Tage ausgerichtet wurden, einzig das trigarium infrage kommt, denn außer diesem ist keine andere am Tiber gelegene, als Pferderennbahn

402 Listen von Mitgliedern der Quindecimviri finden sich in der Inschrift an folgenden Stellen: C 5-8 (fragmentarisch, enthielt wahrscheinlich alle Mitglieder mit vollständiger Namensnennung); 44f.; I07; I66-I68 (fragmentarisch, enthielt ebenfalls alle Mitglieder mit unvollständiger Namensnennung).

403 Z. I07; I 32.

404 Z. ı०8; vgl. oben zu Z. ı०8, S. I $4 \circ$ f.

405 Z. roof.

406 Z. го8 (ludi Latini); I33 (ludi ut pridie facti sunt). Vgl. oben zu Z. ı०8, S. I $4 \circ$ f.

407 Z. 108: Deinde ludi Latini in th[ea]tro ligneo quod erat constitutum in campo s[ecu]ndum Tiberim sunt commissi. Auch das severische commentarium (Act. Sev. 254) spricht von einem speziell für die Säkularspiele errichteten circus temporalis. Offenbar enthielt das trigarium eine Art provisorisches Theater und auch für größerer Zuschauermengen ein Gelände, das einem circus gleichkam, aber ebenfalls nur für diesen Anlass hergerichtet wurde. 
nutzbare Stätte möglich, die gleichzeitig neben dem Tarentum liegt und Raum für Pferderennen bietet. ${ }^{408}$ Neben dem Rennen vierspänniger Wagen sind Kunstreiter vorgeführt worden. Potitus Messalla kam die Ehre zu, das Startsignal zu geben. Es handelt sich möglicherweise nicht zufällig um ein Mitglied der gens Valeria, die mit dem Ursprungsmythos der ludi saeculares eng verbunden ist. Am letzten Tag wurden also neben den ludi scaenici Wettrennen und Reiterspiele aufgeführt, die als ludicircenses galten. Im Gegensatz zu den ludi scaenici wurden die ludi circenses nicht aus dem lucar der Priesterschaft finanziert. ${ }^{409}$ Dass aber dennoch ein Bezug zum Mythos bestehen blieb, zeigt sich darin, dass Potitus Messala ausgewählt war, das Startzeichen zu geben, der auch dem Kollegium der Quindecimviri angehörte. Eine zusätzliche Ehrung stellt die Erwähnung dieser Tatsache in der Inschrift dar. ${ }^{1 \mathrm{IO}}$ Außerdem wird mit dem Austragen von Wagenrennen an frühere Säkularspiele erinnert, die ebenfalls schon Wettkampfspiele ausgetragen haben sollen. ${ }^{41}$ In jedem Fall gehören auch die Wagenrennen und Aufführungen von Kunstreitern zu den rituellen Spielen, wie aus Z. I 6 hervorgeht, wo sie als ludi sollemnes von den anschließenden ludi honorarii abgegrenzt werden. Über die sellisternia der Matronen existieren keine Angaben des commentarium für den dritten Tag, sie haben aber mit Sicherheit stattgefunden..$^{42}$

Über die nicht mehr vorhandene Stundenangabe des Endes der Spiele können keine sicheren Ergänzungen oder Aussagen gemacht werden.

I 55-I 58 In diesen Zeilen liegt ein Edikt vor, das zusätzliche Spiele (ludi honorarii) $\mathrm{zu}$ den feierlichen rituellen Spielen (ludi sollemnes) ansagt. Dabei handelt es sich um drei verschiedene Arten von Spielen an drei verschiedenen Aufführungsorten. Dieses Edikt ist ebenso wie das Edikt über die Unterlassung der Trauer in die protokollarische Schilderung der Feier eingeschoben und scheint am Ende des dritten Tages (3. Juni) erlassen worden

408 Vgl. Plan S. 203.

409 Wissowa (I9I2) $462 \mathrm{f}$.

4IO Dem Kollegium der Quindecimviri gehört neben Potitus Messalla als zweiter Valerier Messalla Messallinus an, der aber noch zu jung war, um eine solche Ehre ausfüllen zu können. Potitus Messalla ist in Z. i 50 und I66 erwähnt.

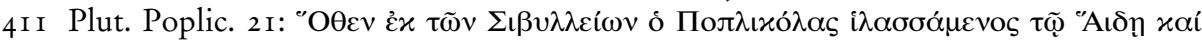

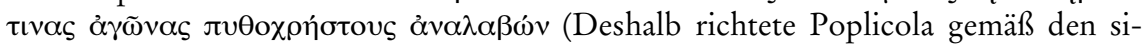
byllinischen Büchern dem Hades Opfer aus und führte nach den Weisungen des Orakels Wettkämpfe auf). Bernstein (I998) I 29-I 32 dagegen geht davon aus, dass die Integration von Spielen in eine alte bestehende Kulteinrichtung erst im Jahre 249 v. Chr. für die ludi Tarentini erfolgte.

4 I 2 Act. Sev. 259 f. erwähnt sellisternia für den dritten Tag. Ebenso schreibt Zosimus (2, 5, 5), dass neben dem carmen saeculare auch andere Zeremonien durchgeführt wurden, wie sie von der Gottheit vorgeschrieben sind, womit er wahrscheinlich die sellisternia meint. 
zu sein, also nicht zu den vorbereitenden Edikten der Spiele zu gehören. ${ }^{43}$ Das bedeutet, dass die Säkularfeier auf drei Tage und drei Nächte angelegt war und die anschließenden Spiele vielleicht schon vorgesehen waren, aber erst jetzt öffentlich angesagt wurden. Eine solche Verlängerung ist keine ungewöhnliche Erscheinung und als besonderes Entgegenkommen an die Wünsche des Volkes zu verstehen.

Die Unterscheidung zwischen ludi honorarii und ludi sollemnes bezieht sich nicht in erster Linie auf die Art der Spiele, sondern betrifft eher ihre Einbettung in den Festablauf und ihre Finanzierung. Mommsen geht davon aus, dass die ludi sollemnes einen Teil des Opferritus darstellten und einer religiösen Motivation entsprangen, die ludi honorarii dagegen nicht mehr als Teil der Riten nötig waren und von der Priesterschaft freiwillig als zusätzliche Vergnügung für das Volk organisiert wurden. ${ }^{414}$ Obwohl an dieser Stelle nicht explizit auf einen bestimmten Finanzierungsmodus hingewiesen wird, ist Mommsens Annahme, dass diese ludi honorarii selbstverständlich auf Kosten der Quindecimviri gehen, nicht so klar. Cavallaro hat gezeigt, dass die Überweisung einer bestimmten Summe aus dem aerarium in das lucar, das der Finanzierung der Spiele diente, der in den res gestae $(22,2)$ üblichen Formulierung von ludos feci entspricht. ${ }^{45}$ Somit verrät Augustus selbst durch diese Formulierung, dass eine klare Trennung von aerarium und seinem Privatvermögen nicht mehr möglich war. ${ }^{416}$

Das Edikt erwähnt drei verschiedene Arten von ludi an drei unterschiedlichen Orten:

I. Ludi Latini fanden in dem bereits erwähnten provisorischen Holztheater am Tiber statt, womit das Theater im trigarium gemeint ist, das als Spielort nach den Opfern des Tages diente. Diese Spiele sollten zur zweiten Stunde stattfinden, für Anfang Juni bedeutet das zu einer Zeit zwischen $5.40 \mathrm{Uhr}$ und $7.00 \mathrm{Uhr}$. Wie schon erwähnt handelt es sich dabei um einfache Volkspossen, die mit den besser ausgestatteten ludi Graeci nicht konkurrieren konnten, möglicherweise aber in einem Zusammenhang zum Mythos der Säkularfeier oder dem Ort standen. Beide Gattun-

4 I 3 Z. I IO-I I4; das severische commentarium (Act. Sev. 209-222) erwähnt ein entsprechendes Edikt schon am Ende des zweiten Tages. Die dort angesagten Spiele beginnen aber einen Tag früher, also direkt nach dem dritten Feiertag, ohne dass ein Ruhetag eingeschoben wurde. Das deutet darauf hin, dass ein Tag zur Vorbereitung der Spiele nötig war.

4I4 Mommsen (I89I) 269f. (6I6f.) stützt sich mit dieser Interpretation auf Fest. p. IO2 Lindsay und Suet. Aug. 32, 2, die ebenfalls ludi honorarii im Sinne von zusätzlichen Volksvergnügungen erwähnen.

4is Cavallaro (1984) i s9f.

4I6 Kienast (20I4) 38 I ff. 
gen wurden als ludi scaenici bezeichnet. Sie unterschieden sich wahrscheinlich nicht nur durch ihren unterschiedlichen Aufführungsort voneinander, sondern auch in ihrer inhaltlichen Aussage. Mit diesen ersten im Morgengrauen aufgeführten ludi Latini wird wahrscheinlich bewusst auf den zugrunde liegenden Anlass der Spiele hingewiesen. Es erstaunt, dass diese Spiele so früh am Tag stattfanden, ein Hinweis zur Erklärung durch die Tageszeit anderer Spiele lässt sich aber nicht heranziehen.

2. Ludi Graeci thymelici wurden im Theater des Pompeius zur dritten Stunde aufgeführt, das heißt zwischen 7.00 Uhr und 8.20 Uhr. Die ludi Graeci gehen ebenso wie die einfacheren ludi Latini auf eine alte Tradition zurück und wurden im Rom in der zweiten Hälfte des dritten Jahrhunderts eingeführt. ${ }^{47}$ Es gab innerhalb der Gattung ludi Graeci einerseits die ludi thymelici, andererseits die ludi astici. Unter ludi thymelici versteht man verschiedenste Darbietungen künstlerischer Art wie Tanz, Akrobatik und Ähnliches mit Musikbegleitung. ${ }^{418}$ Es scheint sich dabei nicht um die Vorführung einer dramatischen Handlung zu handeln. Als Ort für diese Aufführungen ist das Theater des Pompeius angegeben, welches sich vom Aufführungsort der vorangegangenen Spiele auf dem Weg in Richtung Stadtzentrum befand. Es ist vorstellbar, dass die Zuschauermenge sich von einer Aufführung zur nächsten bewegte, da die drei Aufführungsorte vom trigarium aus in einer Linie stadteinwärts liegen. Das würde aber gleichzeitig bedeuten, dass die Dauer der einzelnen Vorführungen nicht sehr lang sein konnte, weil zwischen den einzelnen Vorführungen nur 80 Minuten liegen. Wahrscheinlicher ist, dass an jedem der drei Orte Spiele von der üblichen Dauer einiger Stunden stattfanden, dass die Prozessionsgruppe mit Augustus, den Quindecimviri und eventuell noch anderen Würdenträgern nur zur Eröffnung der jeweiligen Spiele anwesend waren und lediglich die dritten Spiele im Marcellustheater bis zum Ende angeschaut haben. ${ }^{419}$

Das Theater des Pompeius war im Jahre 55 v. Chr. als erstes Steintheater Roms von Pompeius errichtet worden. Es war in einen größeren Gebäudekomplex eingebunden und wurde als Treffpunkt und Versammlungsort

4I7 Wissowa (I9I2) $462 \mathrm{f}$.

$4 \mathrm{I} 8$ Vitruv. 5, 7, 2: tragici et comici actores in scaena peragunt, reliqui autem artifices suas per orchestram praestant actiones: itaque ex eo scaenici et thymelici Graece separatim nominantur. Dazu Mommsen (I89I) 270f. (6I7); Wissowa (I9I2) 464; Piganiol (i 923 ) i $3 \mathrm{f}$.

4I9 Diese Vermutung stammt von Abaecherli Boyce (I94I) 36-43. Gestützt wird ihre Annahme durch die Formulierung des severischen commentarium, das für die dritten Spiele zusätzlich angibt, dass sich die Gruppe um Severus erst dort gesetzt habe und die Spiele bis zum Ende geschaut habe (perspectaverunt), eine Angabe, die für die vorangehenden Spiele fehlt (Act. Sev. $266 \mathrm{ff}$.). 
gern benutzt. Augustus hat dieses Theater aufwendig restaurieren lassen. ${ }^{420}$ Durch die Verlegung der ludi Graeci vom eigentlichen Kultplatz der ludi saeculares weg hat sich wahrscheinlich auch der Charakter der Spiele verändert. Die ludi Graeci thymelici haben wohl nicht mehr auf den zugrunde liegenden Mythos angespielt, sondern dienten in erster Linie der Unterhaltung des Publikums. Allerdings sind unsere Informationen über diese Art von Spielen sehr beschränkt.. ${ }^{21}$ Ein weiteres Indiz für eine Abwendung von den religiösen Bezügen der Spiele besteht in der Tatsache, dass bei diesen Vorführungen den Zuschauern Sitzplätze zur Verfügung standen, eine Tatsache, die für rein religiöse Spiele nicht vorgesehen war. ${ }^{422}$

3. Als letzte fanden ludi Graeci astici in dem Theater, das sich im Circus Flaminius befindet, zur vierten Stunde statt, das heißt zwischen 8.20 Uhr und 9.30 Uhr. Der Aufführungsort wird allgemein als das Marcellustheater identifiziert, das im Jahre I 7 v. Chr. schon benutzbar, aber noch nicht eingeweiht war. ${ }^{423}$ Dieses Theater war zum Zeitpunkt der Säkularfeier noch nicht nach dem verstorbenen Neffen und Schwiegersohn des Augustus Marcellus benannt. Das Theater bot etwa is 000 Zuschauern Platz. Für diese letzte Aufführung ist ebenfalls zu sagen, dass sich die Veranstaltungen nun von dem religiösen Gehalt der Säkularfeier abwendeten und zur Freude des Publikums ausgerichtet wurden.

In dem vorliegenden Edikt werden diese drei Arten von Spielen für die folgenden sieben Tage angesagt, das heißt vom 5. bis i I. Juni (Z. I 56). Unklar bleibt, ob es sich dabei um Wiederholungen handelt, sodass siebenmal für jeweils etwa I 5000 Menschen Vorführungen gegeben wurde, sodass am Ende des siebentägigen Zyklus gegen ro0000 Zuschauerinnen und Zuschauer diese Vorführungen gesehen haben können, oder ob an jedem Tag neue Vorstellungen gegeben wurden.

I59 Diese Zeile nimmt die Fortsetzung der protokollarischen Schilderung wieder auf und berichtet von dem Ruhetag am 4. Juni nach dem Abschluss des rituellen Teils der ludi saeculares. Es ist unklar, ob Z. I 59 weitere Informationen enthielt. Da Z. I60 mit vorgezogenem linkem Rand beginnt, ist es möglich, dass Z. I 59 nicht bis zum rechten Rand ausgeschrieben war und nur den Vermerk des Ruhetags lieferte.

420 Kolb (1995) $256 \mathrm{ff}$. und 343.

42 I Wissowa (I9I 2) 464 führt weitere Zeugnisse über ludi astici und thymelici an, die alle bestätigen, dass die ursprünglich im griechischen Drama vereinigten Elemente der Aufführung einer szenischen Handlung und begleitenden choristischen Einlagen mit Tanz und Pantomine jetzt getrennt aufgeführt werden als ludi astici und ludi thymelici.

422 Val. Max. 2, 4, 2; Wissowa (I9I2) 464 Anm. I.

423 Kloft (1996) 64; Kolb (1995) 343. 
I60f. Diese beiden Zeilen bezeugen die Durchführung der im vorangegangenen Edikt (Z. I56-I58) angesagten ludi honorarii. Dabei ist nur die Durchführung der Spiele vom 5. Juni erwähnt, während alle anderen Tage, an denen dieselben Spiele stattgefunden haben, nicht aufgeführt sind. ${ }^{424} \mathrm{Da}$ für wird der nur noch kleine verbleibende Freiraum auf dem Stein verantwortlich gewesen sein, der noch für die wichtigsten Ereignisse und vor allem für eine vollständige Aufzählung des Kollegiums der Quindecimviri ausreichen musste.

I62f. Diese zwei Zeilen enthalten ein Edikt, das während der siebentägigen ludi bonorarii am 7. Juni erlassen wurde. Es sagt eine zusätzliche venatio für den 8. Juni an, wie aus Z. 163 hervorgeht. Danach bricht die Zeile ab, es ist jedoch klar, dass in dem Edikt noch etwas anderes angesagt wurde. Pighi hat deswegen zusätzlich et ludos circenses committemus ergänzt. ${ }^{25}$ Bereits Mommsen hatte sich bezüglich dieser letzten Zeilen sehr unentschieden geäußert. ${ }^{426}$ Auch ihm war nicht klar, ob der hier angekündigte Abschluss der Säkularfeier ordnungsgemäß wiedergegeben ist, das heißt, er konnte in der Überlieferung keine Beispiele für einen vergleichbaren Anlass finden. In der Tat machen diese letzten Zeilen den seltsamen Eindruck, als ob die sonst streng beachtete Übereinstimmung von Festakten, die in einem Edikt angesagt wurden, mit den im Protokoll genannten Aktivitäten nicht mehr gegeben ist. Das hier vorliegende Edikt enthielt in dem nicht erhaltenen Teil der Zeile sicher weitere Hinweise auf die folgenden Aktionen, wozu mit Sicherheit eine pompa und ein von Agrippa veranstaltetes Wagenrennen gehörten. ${ }^{47}$ Dies geht aus den protokollarischen Schilderungen der Zeilen I64 und I65 hervor. Danach müssten nach den verschiedenen ludi scaenici in den drei verschiedenen Theatern (Z. I56-I 58) noch andere Spiele stattgefunden haben, wozu auch ein Wagenrennen gehörte. An welcher Stelle die pompa anzusiedeln ist, geht aus dem severischen commentarium hervor, das umfassendere Angaben enthält, wie der Abschluss der severischen ludi saeculares aus-

$424 \mathrm{Da}$ das commentarium, das streng chronologisch angelegt ist, in Z. I62 f. von einem Edikt spricht, welches zur Zeit dieser Spiele erlassen wurde, ist davon auszugehen, dass die Durchführung der ludi honorarii des 5 . Juni beispielhaft erwähnt wird, damit chronologisch >richtig< anschließend das nächste Ereignis mit dem Datum des 7. Juni genannt werden kann. Wie wichtig die Datumsangabe war, zeigt ihre Position am linken Rand der Inschrift, die immer gewahrt wird.

425 Pighi (I94I) I 29f. stützt sich dabei auf Suet. Caes. 39, 2; Aug. 43, 2; Tib. 6, 4. Diese Stellen belegen, dass Circusspiele mit lusus Troiae stattgefunden haben. Da Pighi davon ausgeht, dass in Z. I64 auch ein lusus Troiae stattgefunden hat, glaubt er, dass die dem lusus Troiae vorangehenden Circusspiele im Edikt erwähnt gewesen sein mussten.

426 Mommsen (189i) 217f. (619).

427 Gagé (1933) I99. 
gesehen hat. ${ }^{428}$ Die dort geschilderte pompa fand im Holztheater und in dem zur Zeit der Säkularspiele errichteten circus auf dem Gebiet des trigarium statt. An diesem Ort hatten bei der augusteischen Säkularfeier schon alle ludi nach den Opfern des Tages stattgefunden, und auch ein Teil der ludi honorarii war an diesem Ort vorgesehen. ${ }^{229}$ Die pompa hatte wie an den severischen Spielen die Aufgabe, den rituellen Teil der ludi saeculares abzuschließen und danach die spektakuläreren ludi circenses beginnen zu lassen, die beliebt waren, aber keine rituelle Funktion mehr hatten. Dazu fand die pompa der severischen Spiele ihren Abschluss im theatrum ligneum am Tiber, welches sich im Gelände des trigarium befand. Dieses trigarium wird auch der Austragungsort der auf die pompa folgenden ludi circenses und des Wagenrennens gewesen sein. Eine genaue Kenntnis über den Abschluss der augusteischen Spiele und die Gestaltung der pompa ist nicht möglich, da das augusteische commentarium darüber schweigt und eine Analogie zwischen severischen und augusteischen Spielen nicht grundsätzlich für alles vorausgesetzt werden kann..$^{40^{\circ}}$

$\mathrm{Da}$ der Stein nicht mehr viel Raum bot, wurde das Edikt vielleicht in verkürzter Weise wiedergegeben, zumal eine die Inschrift abschließende Erwähnung aller beteiligten Quindecimviri noch Platz haben musste. Es ist aber erstaunlich, dass die übliche Form des Edikts mit der auffälligen Einleitungszeile dennoch in der gewohnten Form ausgeführt wurde, während das Edikt selbst nur eine Zeile umfasst. Das bestätigt die Vermutung, dass die Edikte der Quindecimviri einen großen Stellenwert hatten, zumindest was ihre Bedeutung für die Überlieferung betrifft. Aufgrund solcher Unregelmäßigkeiten, die ihren Grund sicher nur in der Begrenztheit des Raumes auf dem Stein haben, sollten in diesem Edikt keine Ergänzungen vorgenommen werden, obwohl wir heute aufgrund der I93 I gefundenen Fragmente $\mathrm{zu}$ der severischen Inschrift einen etwas besseren Wissensstand über die abschließenden Festakte besitzen als Mommsen.

Der Ort der im Edikt angekündigten venatio bleibt ebenso ungewiss, da Augustus selbst als Orte für von ihm veranstaltete venationes mehrere Möglichkeiten nennt. ${ }^{4{ }^{1}}$

428 Act. Sev. 252-254; siehe den Sachkommentar zur Stelle S. $390 \mathrm{ff}$.

429 Z. I08; I $56 \mathrm{f}$.

430 So nennt zum Beispiel das severische commentarium (Act. Sev. 267) andere Aufführungsorte für die ludi honorarii als das augusteische commentarium, weil das Marcellustheater zur Zeit der Severer in schlechtem Zustand war. Vgl. Abaecherli Boyce (I94I) 48 .

43 I Aug. RG 22: [Ven]ation[es] best[ia]rum Africanarum meo nomine aut filio[ru]m meorum et nepotum in ci[r]co aut in foro aut in amphitheatris populo dedi sexiens et viciens. 
I64f. Diese Zeilen enthalten die protokollarische Aufzeichnung der im Edikt von Z. I62 und I63 angesagten Veranstaltungen. Dazu gehörte mit Sicherheit die für den 8. Juni vorgesehene venatio, die an dieser Stelle aber fehlt. Für denselben Tag ist in Z. I64 eine pompa verzeichnet. Das Datum ist ohne Monatsangabe aufgezeichnet, was den Eindruck der Gedrängtheit dieser letzten Zeilen verstärkt. Die hier verwendete Ausdrucksweise von pompa praelata hatte bereits Mommsen Verständnisschwierigkeiten bereitet. ${ }^{432}$ Gagé gewinnt durch Einbeziehung der I93 I gefundenen Fragmente der severischen Inschrift einige zusätzliche Kenntnisse. ${ }^{433}$ Dabei wurden in der abschließenden pompa im circus des trigarium Gegenstände mitgeführt, die auf Kissen getragen wurden. Die Analogie des Festablaufs beider Säkularfeiern legt nahe, dass an beiden Feiern die pompa auf diese Weise durchgeführt wurde. Dabei handelt es sich um einen dem Triumphzug nachempfundenen Festzug, der bei Circusspielen oft dazugehörte. ${ }^{434}$ Die dabei von Knaben mitgeführten Gegenstände erinnern an einen Triumphzug, wie im Falle der severischen pompa die exuviae. Einen weiteren Hinweis liefert die Liste von Knaben am Ende der severischen Inschrift, die zum Teil mit denen einiger Choristen des severischen carmen saeculare identisch sind. ${ }^{435}$ Die augusteische Inschrift scheint ein analoges Ereignis in kürzerer Form zu überliefern. ${ }^{43^{6}}$ Es bleibt aber bei diesen Erkenntnissen durch die Gegenüberstellung der beiden Fragmente. Wie die pompa circensis genau aussah und vor allem welche Absicht sie verfolgte, wird aus dieser Stelle allein nicht klar. Abaecherli Boyce vermutete als Funktion der pompa die Trennung der rituellen Handlungen von den nicht rituellen ludi circenses.437 Gagé und nach ihm Pighi gingen davon aus, dass diese pompa schließlich in eine Art lusus Troiae mündete, den Augustus nachweislich hat aufführen lassen..$^{43^{8}}$ Der Grund für diese

432 Mommsen (I89i) 27if. (6I9).

433 Gagé (1933) I $98 \mathrm{ff}$. Da die severischen Akten (Act. Sev. 304) von exuvias in pulvinari la[tas sprechen, glaubt er, dass es sich bei dieser nur sehr fragmentarisch am der Ende der Inschrift überlieferten Handlung um eine pompa handelt, wobei das Wort pompa selbst an dieser Stelle nicht erhalten ist. Die dabei von Knaben mitgeführten Gegenstände erinnern aber an einen Triumphzug oder eine pompa, wie die exuviae des Fragments.

434 Wissowa (1912) I 27 und 452. Die Beschreibung einer pompa findet sich bei Dion. Hal. 7,72 .

435 Act. Sev. 306-317.

436 Das augusteische commentarium verzichtet grundsätzlich auf die namentliche Erwähnung der verschiedenen Matronen und Choristen im Gegensatz zum severischen.

437 Abaecherli Boyce (I94I) $39 \mathrm{f}$.

438 Suet. Aug. 43, 2. Gagé (I933) 20I f.; Pighi (194I) 287ff. Der lusus Troiae war nach Verg. Aen. 5. $588 \mathrm{ff}$. und Sen. Tro. $777 \mathrm{f}$. ein Labyrinth-Spiel, welches von berittenen jungen Männern vornehmer Herkunft durchgeführt wurde. 
Vermutung lag darin, dass bei den hier überlieferten pompae Knaben als Ausführende beteiligt sind, die zwar ähnlich zusammengesetzt sind wie die Choristen des carmen saeculare, aber eine andere Funktion erfüllten. $\mathrm{Da}$ unsere Informationen über beide Arten von Aufführungen sehr beschränkt sind und wir an anderer Stelle keine Verbindung von pompa mit lusus Troiae überliefert haben, müssen die Überlegungen von Gagé und Pighi weiterhin offenbleiben.

I66-I68 Die letzten drei Zeilen der Inschrift enthalten ein Verzeichnis des gesamten Kollegiums der Quindecimviri. ${ }^{439}$ Diese Zeilen lassen sich mithilfe der Ergebnisse Hoffman Lewis' aus den anderen Listen von Quindecimviri des commentarium leicht ergänzen. ${ }^{44^{\circ}}$ Bei dieser Liste handelt es sich um eine abschließende Fixierung aller Mitglieder des Kollegiums. Am Anfang von Z. 168 ist der Name von C. Asinius Gallus getilgt, der in Zusammenhang mit der Verschwörung des Seianus unter Tiberius in Missgunst fiel.

Dabei ist als epigrafische Kuriosität zu vermerken, dass sein Name nur an dieser exponierten Stelle getilgt wurde, während er in Z. I07 und I I I erhalten blieb. Diese Tatsache liefert uns einen zusätzlichen Beweis, dass bei der Betrachtung von Monumentalinschriften nicht nur der Gesamttext als Informationsträger vorgesehen war, sondern dass auch die Gestaltung der Inschrift mit ihren auffälligen Elementen wie Rand, Leerstellen etc. wichtig war und ihre Wirkung mit Sicherheit berechnet wurde. Im vorliegenden Fall scheinen nicht einmal die einen Namen tilgenden Steinmetze den gesamten Text der Inschrift gelesen zu haben, sondern sie haben nur den Namen, der durch seine auffällige Position in der letzten Zeile des linken Rands ins Auge stach, unleserlich gemacht.

439 Zur Funktion dieser Liste vgl. Kap. A.8, S. $232 \mathrm{f}$.

440 Hoffman Lewis (1952) $290 \mathrm{ff}$. Dabei ergibt sich im Vergleich mit Pighis Ergänzungen nur eine Abweichung in Z. I66, wo L. Censorinus, Q. Lepidus und Potitus Messalla in anderer Reihenfolge erscheinen, was Hoffman Lewis mit ihrem unterschiedlichen Zeitpunkt des Eintritts in das Kollegium begründet. Weitere Listen von Quindecimviri: C 5-8; 44 f.; I07; I 50-I 52; I 54 . 